\title{
High Efficiency Room Air Conditioner
}

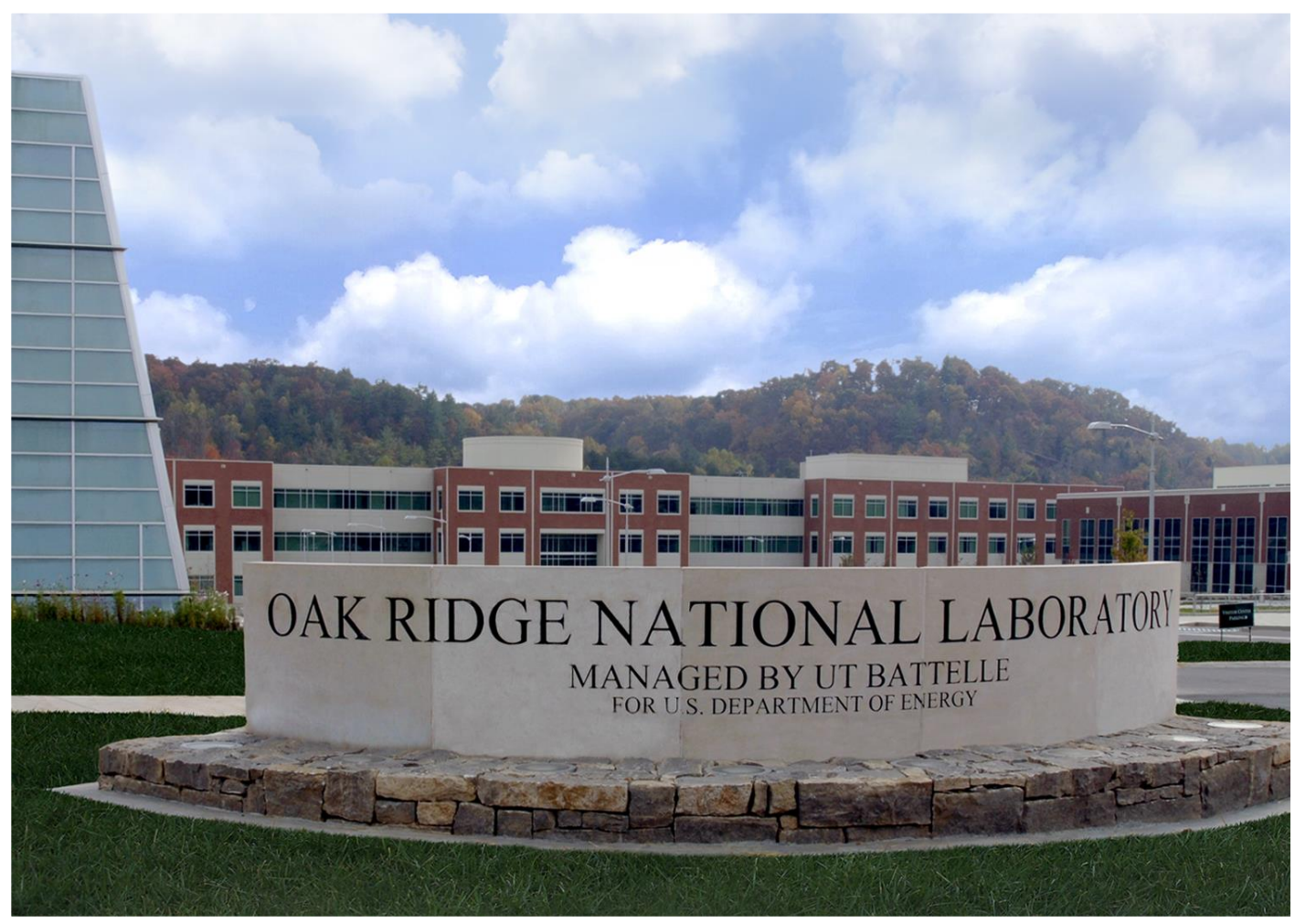

Approved for public release; distribution is unlimited.

Pradeep Bansal, $\mathrm{PhD}$

$1 / 31 / 2015$ 


\section{DOCUMENT AVAILABILITY}

Reports produced after January 1, 1996, are generally available free via US Department of Energy (DOE) SciTech Connect.

Website http://www.osti.gov/scitech/

Reports produced before January 1, 1996, may be purchased by members of the public from the following source:

National Technical Information Service

5285 Port Royal Road

Springfield, VA 22161

Telephone 703-605-6000 (1-800-553-6847)

TDD 703-487-4639

Fax 703-605-6900

E-mail info@ntis.gov

Website http://www.ntis.gov/help/ordermethods.aspx

Reports are available to DOE employees, DOE contractors, Energy Technology Data Exchange representatives, and International Nuclear Information System representatives from the following source:

Office of Scientific and Technical Information

PO Box 62

Oak Ridge, TN 37831

Telephone 865-576-8401

Fax 865-576-5728

E-mail reports@osti.gov

Website http://www.osti.gov/contact.html

This report was prepared as an account of work sponsored by an agency of the United States Government. Neither the United States Government nor any agency thereof, nor any of their employees, makes any warranty, express or implied, or assumes any legal liability or responsibility for the accuracy, completeness, or usefulness of any information, apparatus, product, or process disclosed, or represents that its use would not infringe privately owned rights. Reference herein to any specific commercial product, process, or service by trade name, trademark, manufacturer, or otherwise, does not necessarily constitute or imply its endorsement, recommendation, or favoring by the United States Government or any agency thereof. The views and opinions of authors expressed herein do not necessarily state or reflect those of the United States Government or any agency thereof. 
Energy Transportation and Science Division

\title{
High Efficiency Room Air Conditioner
}

Pradeep Bansal, PhD

Date Published: 1/31/2015

\author{
Prepared by \\ OAK RIDGE NATIONAL LABORATORY \\ Oak Ridge, Tennessee 37831-6283 \\ managed by \\ UT-BATTELLE, LLC \\ for the \\ US DEPARTMENT OF ENERGY \\ under contract DE-AC05-00OR22725
}




\section{TABLE OF CONTENTS}

Page Nos.

1. Executive Summary 4-5

2. Statement of Objectives 6

3. Benefits to the Funding DOE Office's Mission 6

$\begin{array}{ll}\text { 4. Introduction } & \text { 7-8 }\end{array}$

5. Preliminary modelling of baseline unit: description of modelling tools 9-13

6. Testing of laboratory breadboard unit $\quad$ 14-27

7. Validation of HPDM with test data of base window air conditioner 28-35

8. Efficiency enhancement options and testing of the prototype 36-42

9. Assessment of alternative refrigerant options using HPDM-Flex-7.9.1 43-47

10. Design of production ready high efficiency window prototype 48-53

11. Commercialization plans $\quad 54$

12. Plans for future collaboration

13. Conclusions $\quad 54$

14. Acknowledgements $\quad 55$

15. References $55-56$

16. Appendices (A and $B) \quad$ 57-77 


\section{EXECUTIVE SUMMARY}

This report documents the design and development of the next generation high efficiency window air-conditioner (WAC). There are currently nearly 47 million WACs operating in the United States which account for approximately $1.5 \%$ of the total US residential energy use or about 0.21 quads per year. Assuming a $20 \%$ penetration rate, higher efficiency models could result in energy savings of 0.985 quads over next 20 years.

A state-of-the-art WAC unit having an EER of 10.8 with 10,000 BTU/hr capacity was chosen for the development and experimentation. The project involved both simulation and the experimental analysis of the new prototype. The CRADA partner, GE supplied two of their standard 10,000 BTU/hr capacity models (AEM10AP) for evaluation and testing. This unit was fully instrumented for the following measurements-

(1) refrigerant mass flow rate

(2) 3 in-line refrigerant temperatures (at suction, discharge and liquid line)

(3) 4 refrigerant side pressures

(4) 11 refrigerant side, tube wall temperatures to aid modeling of heat exchangers

(5) 24 air-side temperatures

(6) 4 air side \%RH measurements

(7) fan, compressor, and total power

(8) barometric pressure for ideal gas calculations

A dedicated measurement/data acquisition (DAS) system was developed using the Campbell Scientific CR3000 data logger. The system included integrated refrigerant lookup tables as well as a graphical user interface (GUI) to provide real-time feedback during testing. In addition, a MathCAD based analysis tool was developed to perform a zero order uncertainty analysis in both the base measurements and the corresponding calculated quantities. The program tracks the propagation of uncertainties in the base measurements through to the final calculated quantities. (Capacity, COP, EER etc.)

The WAC was tested in the environmental chambers at ORNL as per the design rating conditions of AHAM/ASHRAE (Outdoor- 95F and 40\%RH, Indoor- 80F, 51.5\%RH). In general, the experimental results were found to correlate well with the published numbers, with differences of $-3 \%$ and $+2.6 \%$ for the experimental values of EER and capacity respectively.

In order to achieve higher EER, one of the major modifications was made by downgrading the unit capacity from 10,000 $\mathrm{BTU} / \mathrm{hr}$ to $8,000 \mathrm{BTU} / \mathrm{hr}$ by replacing the original compressor with a lower capacity $(8,000 \mathrm{BTU} / \mathrm{hr})$ but more efficient compressor. However, all heat exchangers from the original unit were retained to provide higher EER. The other subsequent major modifications included- (i) the AC fan motor was replaced by a brushless high efficiency ECM motor along with its fan housing, (ii) the capillary tube was replaced with a needle valve to better control the refrigerant flow and refrigerant set points, and (iii) the unit was tested with a 'drop-in' environmentally friendly binary mixture of R32 (90\% molar concentration)/R125 (10\% molar concentration).

The use of the blended mixture of R32/R125 lowers the Global Warming Potential (GWP) of the refrigerant by about $40 \%$ since the refrigerant mixture has a GWP of 1,251 while the original R-410A refrigerant has a 2,079 GWP. In addition, these modifications resulted in a number of added advantages including the reduction in its operating cost, electrical demand, and the environmental impact. 
The modelling of the new WAC prototype suggest an EER of 13.0; several tuning and testing were conducted to verify and validate the model.

The WAC prototype (with 8,000 BTU/HR capacity) was shipped to Intertek for independent testing at the DOE test condition in early October 2014. Due to the heavy usage of the climatic chambers at Intertek, there was a long waiting time for any unit to be tested at Intertek, and hence our WAC could only be tested in late January 2015. By that time, our WAC unit unfortunately lost charge of the R32/R125 (90\%/10\%) blend and could not perform at the expected level. Intertek were not willing to charge the unit with the refrigerant blend of R32/R125 (90\%/10\%) due to slightly higher flammability of R32 and hence this testing had to be abandoned. The WAC unit was, however, evacuated, recharged with R410A and tested at DOE conditions. Although the WAC prototype was optimized for R32/R125 blend and not for R410A, an EER of 12.1 was achieved for the unoptimized WAC prototype.

In the meantime, GE had advised that they have already designed a high efficiency WAC unit (with 8,000 BTU/HR capacity) using R410A refrigerant with an EER of 12.1. GE will be commercializing this new unit during 2015. This new unit, however, neither uses ECM fan motor nor the refrigerant blend. This suggests that our WAC should yield much higher EER than the GE's new WAC due to these two important parameters. Although the final EER of the unit could not be verified through an independent testing, both the modelling and the experimental evaluations suggest that this WAC offers $12-20 \%$ energy savings in comparison to the state-of-the-art basine unit. 


\section{STATEMENT OF OBJECTIVES}

The purpose of this Cooperative Research and Development Agreement (CRADA) between UT-Battelle, LLC (the "Contractor") and General Electric (herein "Participant"), is to conduct research and development to evaluate the technical and commercial viability of a high efficiency room air conditioner with an energy efficiency ratio (EER) of 13.0. The Participant has commercialized a series of Energy Star rated room air conditioners. In order to further improve the performance of such units and facilitate larger annual energy savings, the proposed project will evaluate multiple technical solutions, such as high efficiency compressors, improved heat exchangers (micro-channel condensers), and brushless dc fan motors, from the perspectives of energy efficiency and manufacturing cost. The Participant is a leading U.S. manufacturer of room window air conditioners.

\section{BENEFITS TO THE FUNDING DOE OFFICE'S MISSION}

The Department of Energy's (DOE) Building Technologies Program (DOE-BT) has as its long term goal to create marketable technologies and design approaches that address energy consumption in existing and new buildings. The current vision that DOE-BT has for achieving this goal involves reducing the energy and carbon emissions used by the energy service equipment (equipment providing space heating and cooling, water heating, etc.) by $50 \%$ compared to today's best common practice BY 2030. The installed base of window air conditioners in the U.S is approximately 46.7 million. Existing window air conditioners consume approximately $1.5 \%$ of total U.S annual residential energy consumption or 0.33 Quads. Window units are popular because they are inexpensive, provide zonal control, and are easy to install. The most popular product classes are cooling-only units equipped with louvered sides and ranging in capacity from 5,000 to $16,000 \mathrm{Btu} / \mathrm{hr}$. Prices range from $\$ 100$ to $\$ 500$, making it challenging to cost effectively reduce

energy consumption. However, improving the efficiency of window units is essential to enhancing overall residential building energy performance. The new design offers the technical potential of 0.1 quads of energy savings per year. 


\subsection{INTRODUCTION}

Window air conditioners (WAC) are inexpensive and sold in large numbers internationally as alternatives to central airconditioning systems for space cooling, supplemental cooling and for retrofitting air conditioning homes to improve comfort. They are particularly attractive in older buildings that lack ducted systems and in cases where a central system upgrade is first-cost prohibitive [Shen and Bansal (2014), Nogueira (2013), Winkler et al. (2013)]. According to the US Energy Information Administration (EIA) there were nearly 46.7 million WACs operating within the United States in 2009 [EIA (2009)], accounting for approximately $1.5 \%$ of the total US residential energy use or about 0.33 quads (0.35 EJ).

WACs are available in sizes typically between 5,000 and16,000 Btu/h (0.4-1.3 tons, or 1460-4700 W of cooling). A WAC is generally installed either in a window or in a framed wall opening depending on the design of the condenser side vents. When the project was initiated in 2011, the minimum efficiency levels for window air conditioners were set at 9.7 (for capacity less than 10,000 BTU/h) to 9.8 (for 10,000 BTU/h or higher capacity) for most product classes. These levels have since been subsequently raised to 10.7 and 10.8 respectively in 2014 [e-CFR (2014)]. The average lifetime of window air conditioners, which is 10 to 13 years, coupled with the potential for rapid replacement of older, less efficient units, some of which have EERs of 5, makes them a primary target for reduction in annual U.S. energy consumption. Such an initiative would not only bring energy savings to the end user but would also assist in protecting the environment as a result of reduced greenhouse gas emissions. In addition, it will assist in meeting the DOE/BTO goals across all HVAC technologies to reduce energy use by $50 \%$ by 2030 compared to a 2010 baseline that requires the development and implementation of advanced equipment options.

The technology will be used in residential buildings, both single family and small, low-rise multifamily types, and certain types of small commercial buildings. With over 8 million units shipped each year, high efficiency units could make a significant impact on sector energy use in a short amount of time based on the replacement rate. Based on business case analyses conducted by ORNL, the new design offers the technical potential of 0.1 quads of energy savings per year.

Although vapor compression refrigeration is a highly researched topic, surprisingly very little research has been devoted to the energy efficiency improvement of WACs in the open literature [Goswami et al (1993), Hajidavalloo (2007), Naphon (2010), Sawant et al (2011)], while a few studies were devoted to investigating alternative refrigerants for WACs [Bansal and Shen (2014), Bolaji (2011), Devotta et al. (2005), Jabaraj et al. (2006). One of the efficiency enhancement option used in the literature [Goswami et al (1993), Hajidavalloo (2007)] included evaporative wet cooling media pads on the condenser of window-air-conditioner that resulted in the reduction of power consumption of the WAC by about up to $20 \%$. However, this system had practical limitations of clogging up of media pads and issues of keeping them wet. Sawant et al (2011) applied slightly different approach by spraying dehumidified water on to the media pads placed on both sides of the air conditioner that led to $13 \%$ energy savings of the WAC. They also studied an alternative approach of using wicks of porous cloth where one end of the wick was immersed in the dehumidified water tank and the other end was wrapped on the air flow enter side of the condenser. Naphon (2010) found that the use of a 3-rows heat pipe with refrigerant R134a as the working fluid to cool the air entering the condenser of a window air conditioner improved the EER of the WAC by $17.5 \%$.

One of the challenges to improve energy efficiency is that traditional design improvement features that are generally used to improve the energy efficiency of central HVAC systems, such as variable-speed compressors and advanced control systems, somehow do not result in the EER improvement of window air conditioners due to performance testing limited to single test point. It should, however, be noted here that the novelty of the 'single point' test is that it captures the energy consumption of the unit during peak load, which is a major consideration when conserving energy for the US. Thus, improvements are limited to efficiency gains in the heat exchangers, compressor, and fan motors. In addition, 
because of the low first cost of window air conditioners, typically in the $\$ 100$ to $\$ 500$ range, added costs for design improvements are limited. However, one important point to note here is that the modern WACs use a 'slinger' (explained later) to provide evaporative cooling of condenser that leads to significant efficiency improvement of a WAC.

This report, therefore, discusses the novel elements that have been applied to improve the energy efficiency of a stateof-the-art WAC with base capacity of 10,000 BTU/h, including a ECM fan motor, a reduced capacity but high efficiency compressor (with reduced refrigeration capacity of 8,000 BTU/h) and a new 'drop-in' refrigerant mixture of R32/R125 (with 90\%/10\% molar concentration). The novel use of this blended mixture of R32/R125 lowers the Global Warming Potential (GWP) of the refrigerant by about 40\% since the refrigerant mixture has a GWP of 1,251 while the original R410A refrigerant has a 2,079 GWP. This results in a number of advantages including the reduction in its operating cost, electrical demand, and the environmental impact.These features led to the development of a high efficiency WAC (with capacity of $8,000 \mathrm{BTU} / \mathrm{h}$ ) that resulted in $12-20 \%$ annual energy savings as compared with the-state-of-the-art baseline unit. 


\subsection{PRELIMINARY MODELLING OF BASELINE UNIT: DESCRIPTION OF MODELING TOOLS}

Two different versions of ORNL's Heat Pump Design Model (HPDM) were used to simulate the window units being analyzed for this study. The first of these is a version modified by the consulting firm "Navigant" for the 2011 DOE rulemaking for room air conditioners [DOE (2011)], and is based on the Mark III version of HPDM and is specified as "Mark N". This modified HPDM included additional features specific to window units such as condensate sub cooler, condensate spray slinger, as well as heat transfer between the indoor and outdoor sections of the unit. Other features of the Navigant code "MarkN" included adjustment factors to account for enhanced tubes, short circuiting of indoor air, and compressor power and refrigerant mass flow rate.

The second modeling tool used for this study was a modified Beta version of HPDM Mark 7 [Rice et al. (1981)]. This version featured a MS Excel interface for generation of the input files which greatly expedited the parameter input process. Also included in this version was a discretized heat exchanger model. This feature allowed the heat exchanger refrigerant flow paths to be represented in the simulation exactly as they were on the actual unit. Additionally, the discretization of the coils allowed for the various stages of 2 phase flow in the evaporation/condensation processes to be modeled more accurately. This simulation tool lacked some of the window-unit-specific features of the Mark $\mathrm{N}$ code.

\section{PARAMETRIC STUDY}

As a starting point, both models were calibrated to match the design specs of the GE window units being used as the baseline. Compressor data was received from GE and this was then converted into the standard 10 coefficient maps for power, mass flow, and capacity as functions of the discharge and suction saturation temperatures. The heat exchangers were measured and the refrigerant flow paths determined. Fan power for the baseline unit was estimated to be the motor rated power and is specified as 95W. The published specifications for the baseline unit are shown in Table 1.

Table 1: GE AEM10AP Window Air-Conditioner Unit Specifications

\begin{tabular}{|l|l|}
\hline GE AEM10AP & \\
\hline EER & $10.8 \mathrm{BTU} / \mathrm{W}-\mathrm{hr}$ \\
\hline Capacity & $10,000 \mathrm{BTU} / \mathrm{hr}$ \\
\hline Dehumidification & $2.3 \mathrm{pint} / \mathrm{hr}$ \\
\hline SHR & .767 \\
\hline Indoor Airflow & $290 \mathrm{cfm}$ \\
\hline Outdoor Airflow & $500 \mathrm{cfm}$ \\
\hline Fan Rated Power & $95 \mathrm{~W}$ \\
\hline Evaporator Length & $12.75 \mathrm{in}$ \\
\hline Evaporator Height & $9.75 \mathrm{in}$ \\
\hline Evaporator Thickness & $2 \mathrm{in}$ \\
\hline Evaporator Number of Rows & 4 \\
\hline Evaporator Tubes per Row & 13 \\
\hline Evaporator Fin Pitch & $20 /$ in \\
\hline Condenser Length & $16.25 \mathrm{in}$ \\
\hline Condenser Height & $13 \mathrm{in}$ \\
\hline Condenser Thickness & $1.3125 \mathrm{in}$ \\
\hline
\end{tabular}




\begin{tabular}{|l|l|}
\hline Condenser Number of Rows & 3 \\
\hline Condenser Tubes per Row & 17 \\
\hline Condenser Fin Pitch & $24 /$ in \\
\hline
\end{tabular}

Due to the different capabilities of the two models, the following separate procedures were used for the parametric studies using each tool.

\section{Mark 7 Beta Analysis}

To establish the baseline model using the Mark 7 Beta code, the following procedure was used.

(1) The known inputs were fed into the model. These included HX geometry and circuitry, fan power, compressor map, indoor and outdoor airflow rate. Additionally, an evaporator superheat degree of $10 \mathrm{~F}$ was specified. For the Beta Mark 7, there was currently not a model for the expansion device, so a condenser sub-cooling value was also specified. For this simulation the condenser sub-cooling degree was held constant at $12 \mathrm{~F}$.

(2) The compressor shell loss was assumed to be $20 \%$.

(3) The window units being used for the baseline incorporate both a condensate sling fan as well as a condensate condenser sub-cooler to enhance the performance of the unit. Since this version of Beta Mark 7 does not currently have modules for these two components, for modeling purposes these two effects were combined and were treated as a refrigerant line heat loss. The magnitude of this line loss was used as a calibration factor.

(4) An air side heat transfer multiplier was used to quantify the misdistributions in the condenser air flow. This value was used as a second calibration factor.

(5) The model was run and the calibration factors adjusted until good correlation is achieved for the predicted values of EER, capacity, and SHR and the values specified by the manufacturer. Values of line loss=7.65 BTU/lb, and air_side_mult $=0.4008$ were found to give good correlation between the model and the published performance data.

With the baseline established, a preliminary parametric study was conducted to explore possible options for upgrading the units to EER 13.0. Based upon the 2011 DOE study [2011], this initial parametric analysis was limited to changes to the components which were found to have the greatest impact on the unit efficiency. Additional consideration was given to limit changes to those which would not require major changes in the chassis, fan geometry, or airflow routing of the stock unit. The selected parameters were as follows;

(1) Compressor efficiency

(2) Fan motor efficiency

(3) Additional condenser tube row

(4) Condenser Airflow

The level of change to the compressor and fan were selected based upon the estimates of the technology currently available. For the compressor, this limit was estimated to be $E E R=10.8$ at the standard ASHRAE conditions of $T_{e}=45 F$, $T_{c}=130 F$. Since maps for the commercially available high efficiency rotaries were not currently available, the power consumption for the stock unit was scaled to deliver an EER of 10.8 at the standard conditions. This correlated to a reduction of the stock input power by $5.6 \%$ over the entire operating range.

Heat exchanger geometry changes were limited to the addition of one additional tube row to the condenser. This constraint was selected for the preliminary study because, unlike changes to the frontal surface area of the heat 
exchangers, the addition of a tube row would require minimal alteration to the existing chassis and fan. Condenser airflow was varied between the stock value and stock $+20 \%$. This analysis assumed that it was possible to vary the condenser airflow without changing the flow through the evaporator. In the actual units, both fans were driven by a single motor so unless the two were decoupled, actual implementation of this would require some changes to the evaporator fan geometry to maintain the airflow at the stock level.

A full factorial set (16 runs) of simulations was conducted using the Mark 7 Beta model. The results are shown in Tables 2 and 3.

Table 2: Predicted AEM10AP Performance at Stock Condenser Airflow (ORNL Mark 7 Beta Model)

\begin{tabular}{|l|l|l|l|l|l|l|l|l|}
\hline Parameter & $\begin{array}{l}\text { Run \#1 } \\
\text { Settings } \\
\text { (stock) }\end{array}$ & $\begin{array}{l}\text { Run \#2 } \\
\text { Settings }\end{array}$ & $\begin{array}{l}\text { Run \#3 } \\
\text { Settings }\end{array}$ & $\begin{array}{l}\text { Run \#4 } \\
\text { Settings }\end{array}$ & $\begin{array}{l}\text { Run \#5 } \\
\text { Settings }\end{array}$ & $\begin{array}{l}\text { Run \#6 } \\
\text { Settings }\end{array}$ & $\begin{array}{l}\text { Run \#7 } \\
\text { Settings }\end{array}$ & $\begin{array}{l}\text { Run \#8 } \\
\text { Settings }\end{array}$ \\
\hline $\begin{array}{l}\text { Compressor } \\
\text { EER }\end{array}$ & 9.9 & 10.8 & 9.9 & 10.8 & 9.9 & 10.8 & 9.9 & 10.8 \\
\hline Fan Efficiency & low & low & hi & hi & low & low & hi & hi \\
\hline $\begin{array}{l}\text { Condenser } \\
\text { Rows }\end{array}$ & 3 & 3 & 3 & 3 & 4 & 4 & 4 & 4 \\
\hline $\begin{array}{l}\text { Mark 7 Beta } \\
\text { Results }\end{array}$ & $\begin{array}{l}\text { EER=10.80 } \\
\text { Cap=1003 } \\
\text { SHR=.771 }\end{array}$ & $\begin{array}{l}\text { EER=11.40 } \\
\text { Cap=10012 } \\
\text { SHR=.770 }\end{array}$ & $\begin{array}{l}\text { EER=11.35 } \\
\text { Cap=10003 } \\
\text { SHR=.771 }\end{array}$ & $\begin{array}{l}\text { EER=12.01 } \\
\text { Cap=10012 } \\
\text { SHR=.770 }\end{array}$ & $\begin{array}{l}\text { EER=11.55 } \\
\text { Cap=10247 } \\
\text { SHR=.761 }\end{array}$ & $\begin{array}{l}\text { EER=12.18 } \\
\text { Cap=10253 } \\
\text { SHR=.761 }\end{array}$ & $\begin{array}{l}\text { EER=12.16 } \\
\text { Cap=10247 } \\
\text { SHR=.761 }\end{array}$ & $\begin{array}{l}\text { EER=12.86 } \\
\text { Cap=10252 } \\
\text { SHR }=761\end{array}$ \\
\hline
\end{tabular}

Table 3: Predicted AEM10AP Performance at $+20 \%$ Condenser Airflow (ORNL Mark 7 Beta Model)

\begin{tabular}{|c|c|c|c|c|c|c|c|c|}
\hline Parameter & $\begin{array}{l}\text { Run \#9 } \\
\text { Settings } \\
\text { (stock) }\end{array}$ & $\begin{array}{l}\text { Run \#10 } \\
\text { Settings }\end{array}$ & $\begin{array}{l}\text { Run \#11 } \\
\text { Settings }\end{array}$ & $\begin{array}{l}\text { Run \#12 } \\
\text { Settings }\end{array}$ & $\begin{array}{l}\text { Run \#13 } \\
\text { Settings }\end{array}$ & $\begin{array}{l}\text { Run \#14 } \\
\text { Settings }\end{array}$ & $\begin{array}{l}\text { Run \#15 } \\
\text { Settings }\end{array}$ & $\begin{array}{l}\text { Run \#16 } \\
\text { Settings }\end{array}$ \\
\hline $\begin{array}{l}\text { Compressor } \\
\text { EER }\end{array}$ & 9.9 & 10.8 & 9.9 & 10.8 & 9.9 & 10.8 & 9.9 & 10.8 \\
\hline Fan Efficiency & low & low & hi & hi & low & low & hi & hi \\
\hline $\begin{array}{l}\text { Condenser } \\
\text { Rows }\end{array}$ & 3 & 3 & 3 & 3 & 4 & 4 & 4 & 4 \\
\hline $\begin{array}{l}\text { Mark } 7 \text { Beta } \\
\text { Results }\end{array}$ & $\begin{array}{l}\mathrm{EER}=11.40 \\
\mathrm{Cap}=10259 \\
\mathrm{SHR}=.761\end{array}$ & $\begin{array}{l}\mathrm{EER}=12.00 \\
\mathrm{Cap}=10266 \\
\mathrm{SHR}=.760\end{array}$ & $\begin{array}{l}\text { EER }=12.08 \\
\text { Cap }=10259 \\
S H R=.761\end{array}$ & $\begin{array}{l}\mathrm{EER}=12.77 \\
\mathrm{Cap}=10266 \\
\mathrm{SHR}=.760\end{array}$ & $\begin{array}{l}\mathrm{EER}=12.19 \\
\mathrm{Cap}=10511 \\
\mathrm{SHR}=.752\end{array}$ & $\begin{array}{l}E E R=12.84 \\
C a p=10516 \\
S H R=.751\end{array}$ & $\begin{array}{l}E E R=12.96 \\
C a p=10511 \\
S H R=.752\end{array}$ & $\begin{array}{l}\text { EER }=13.70 \\
\text { Cap }=10516 \\
\text { SHR }=.751\end{array}$ \\
\hline
\end{tabular}

The results suggested that the combination of the high efficiency compressor, ECM fan motor, increased condenser airflow, and wider condenser (Run \#16) would achieve the stated goal of EER=13.0 or greater. The predicted incremental increase in EER for each change is shown in Figure 2. 


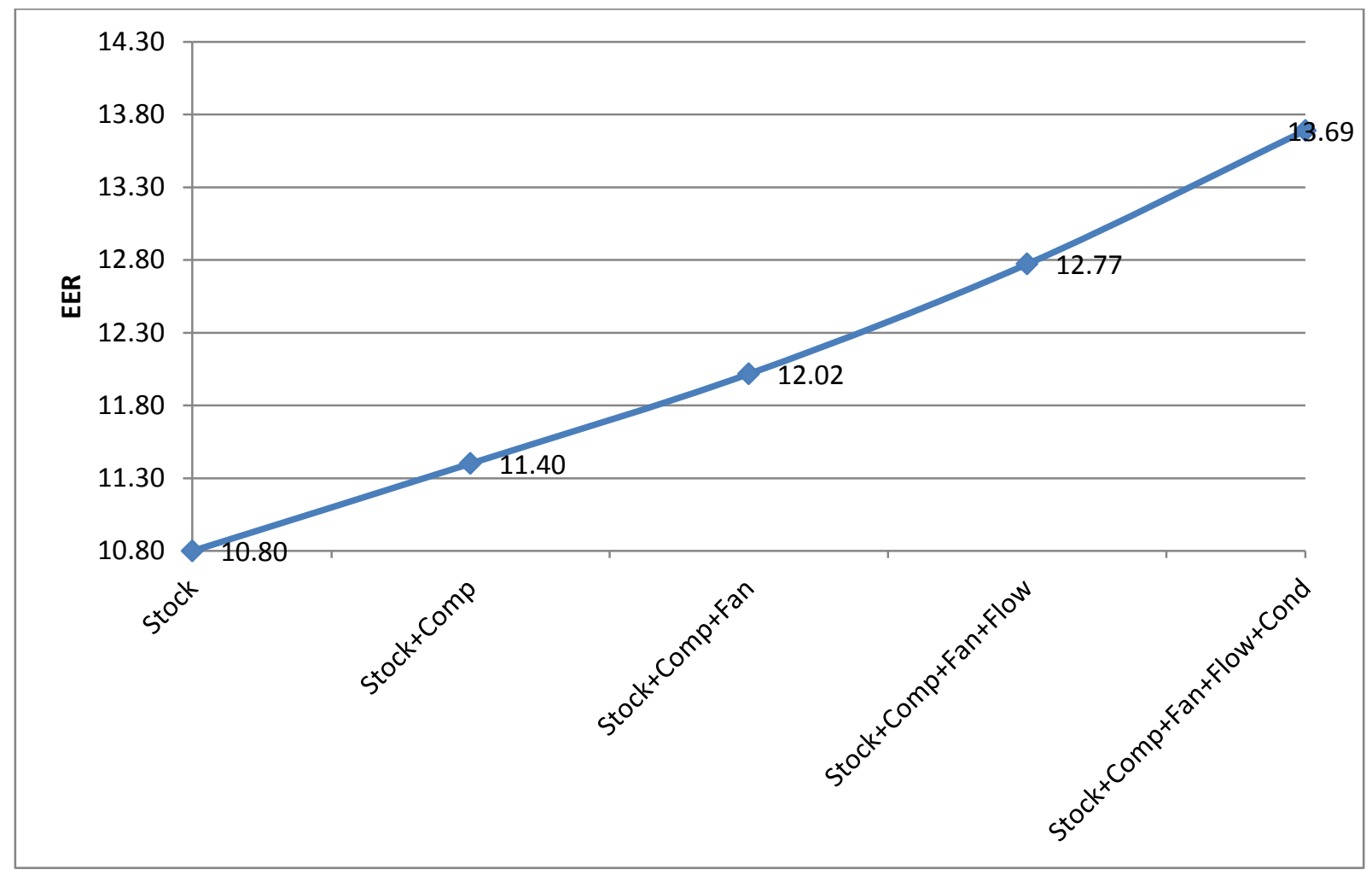

Figure 2: Predicted Incremental EER Variation for GE AEM10AP (ORNL Mark 7 Beta Model)

\section{Mark N Analysis}

A similar analysis was performed using the Mark $\mathrm{N}$ code for the baseline GE AEM10AP. As was done for the Mark 7 Beta analysis, an input file was created using the measured heat exchanger geometry and the compressor map for the GE unit. The model seemed to over predict the air-side condenser heat transfer coefficients and unit capacity. The model was calibrated to the published design point performance by adjusting the capillary tube diameter, mass flow correction factor as well as the multiplier for the condenser air-side heat transfer. The parameters which were studied are as follows.

(1) Compressor efficiency

(2) Fan motor efficiency

(3) Heat Transfer Between Indoor and Outdoor Sides

(4) Heat Exchanger Frontal Area

As in the Mark 7 Beta analysis, the higher efficiency compressor was simulated by reducing the input power by the same factor as before to yield an EER of 10.8. Fan power was varied from $95 \mathrm{~W}$ to $50 \mathrm{~W}$ and heat transfer between the indoor and outdoor sides of the unit were given high and low values of $100 \mathrm{BTU} / \mathrm{hr}$ and $10 \mathrm{BTU} / \mathrm{hr}$ respectively. Heat exchanger frontal area was allowed to vary between the stock values to $10 \%$ larger for both evaporator and condenser. The volumetric airflow rate and subsequent fan power were scaled up for cases using the larger heat exchangers to maintain air velocity across the coil at the stock level. The capacity was fixed at $10000 \mathrm{BTU} / \mathrm{hr}$. The results of the Mark $\mathrm{N}$ parametric study are shown in Table 4. 
Table 4: Predicted AEM10AP Performance (Mark N Model)

\begin{tabular}{|c|c|c|c|c|c|}
\hline Parameter & $\begin{array}{l}\text { Baseline Settings } \\
\text { (stock) }\end{array}$ & $\begin{array}{l}\text { Case I: High EER } \\
\text { Compressor }\end{array}$ & $\begin{array}{l}\text { Case II: Divider } \\
\text { Wall Heat Loss }\end{array}$ & $\begin{array}{l}\text { Case III: High } \\
\text { efficiency fan } \\
\text { motor }\end{array}$ & $\begin{array}{l}\text { Case IV: } 10 \% \\
\text { Large Condenser } \\
\text { Frontal Area }\end{array}$ \\
\hline Compressor EER & 9.9 & 10.8 & 10.8 & 10.8 & 10.8 \\
\hline $\begin{array}{l}\text { Divider Wall Heat } \\
\text { Loss (BTU/H) }\end{array}$ & 100 & 100 & 10 & 10 & 10 \\
\hline Fan Power (W) & 95 & 95 & 95 & 50 & 55 \\
\hline $\begin{array}{l}\text { Heat Exchanger } \\
\text { Areas (ft2) }\end{array}$ & $\begin{array}{l}0.8633 \text { (Evap) } \\
1.467 \text { (Cond) }\end{array}$ & $\begin{array}{l}0.8633 \text { (Evap) } \\
1.467 \text { (Cond) }\end{array}$ & $\begin{array}{l}0.8633 \text { (Evap) } \\
1.467 \text { (Cond) }\end{array}$ & $\begin{array}{l}0.8633 \text { (Evap) } \\
1.467 \text { (Cond) }\end{array}$ & $\begin{array}{l}0.9496 \text { (Evap) } \\
1.614 \text { (Cond) }\end{array}$ \\
\hline $\begin{array}{l}\text { MarkN } \\
\text { Results }\end{array}$ & $\begin{array}{l}\mathrm{EER}=10.80 \\
\mathrm{Cap}=10006 \\
\mathrm{SHR}=0.7\end{array}$ & $\begin{array}{l}\mathrm{EER}=11.7 \\
\mathrm{Cap}=10011 \\
\mathrm{SHR}=0.7\end{array}$ & $\begin{array}{l}\mathrm{EER}=11.8 \\
\mathrm{Cap}=10101 \\
\mathrm{SHR}=0.7\end{array}$ & $\begin{array}{l}\mathrm{EER}=12.5 \\
\mathrm{Cap}=10112 \\
\mathrm{SHR}=0.7\end{array}$ & $\begin{array}{l}\text { EER }=13.04 \\
\text { Cap }=9999 \\
\text { SHR }=0.72\end{array}$ \\
\hline
\end{tabular}

The results suggested that the combination of the high efficiency compressor, fan motor, and $10 \%$ larger heat exchangers would achieve the stated goal of EER=13.0 or greater. The predicted incremental increase in EER for each change is shown in Figure 3.

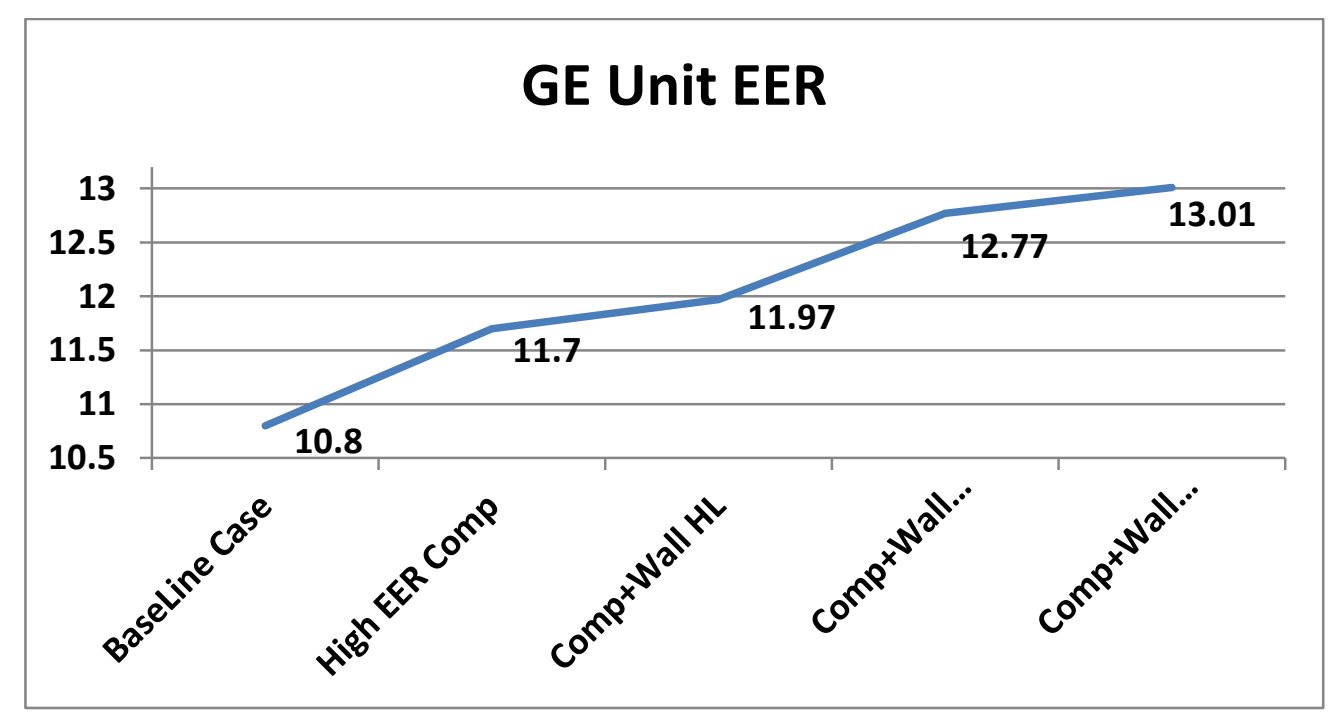

Figure 3: Predicted Incremental EER Variation for GE AEM10AP (Mark N Model) 


\subsection{TESTING OF LABORATORY BREADBOARD UNIT}

The CRADA partner, GE, supplied two Window Units (Model AEM10AP). The research started with the instrumentation of the units, development of the data acquisition system and its programming, and finally the baseline testing of the units. Figure 4 shows the partially disassembled AEM10AP window air conditioner prior to sensor installation.

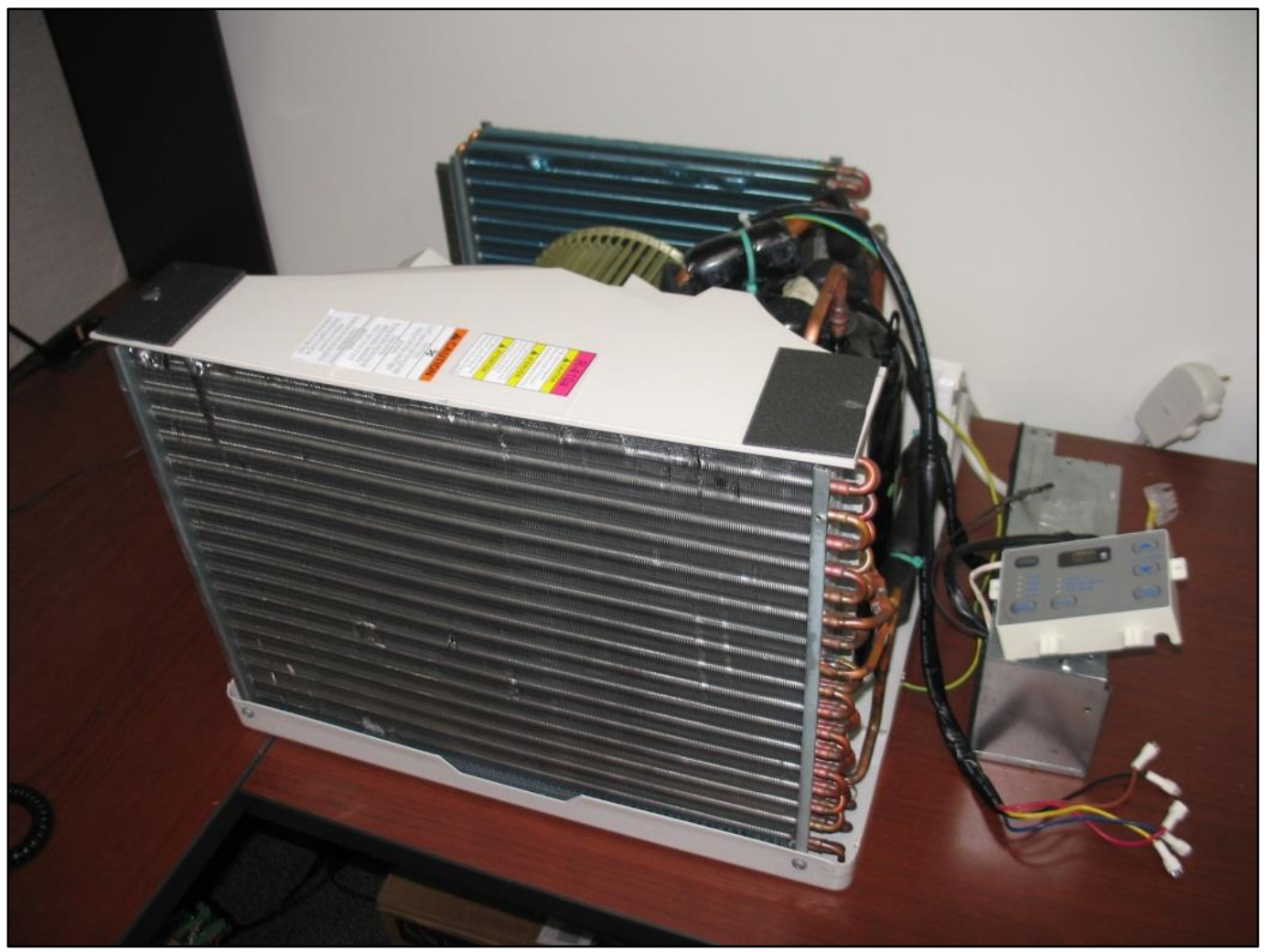

Figure 4 Disassembled AEM10AP window air conditioner prior to instrumentation

The WAC has a single-speed rotary compressor, a fin- $\&$-tube evaporator and condenser, a capillary tube and a motor mounted on a single axis shaft to drive both the evaporator blower and the condenser fan. In addition to these basic components, the WAC has a fin-\&-tube sub-cooler, submerged in a water collection pan, which gathers water condensate from the evaporator. The submerged sub-cooler is downstream of the air-to-refrigerant condenser to further subcool the liquid refrigerant. The schematic diagram of the WAC and its P-h diagram are shown in Figures 5 and 6 respectively. The condenser fan blade is specially configured to pick up water from the water collection pan and to spray it in the air stream flowing over the condenser coil surface. The water droplets evaporate and enhance the condenser heat transfer. This feature is called the "sling" effect [LBNL (1997)]. Figures 6, 7 and 8 respectively show the single axis fan, the "slinger" and instrumented WAC. 


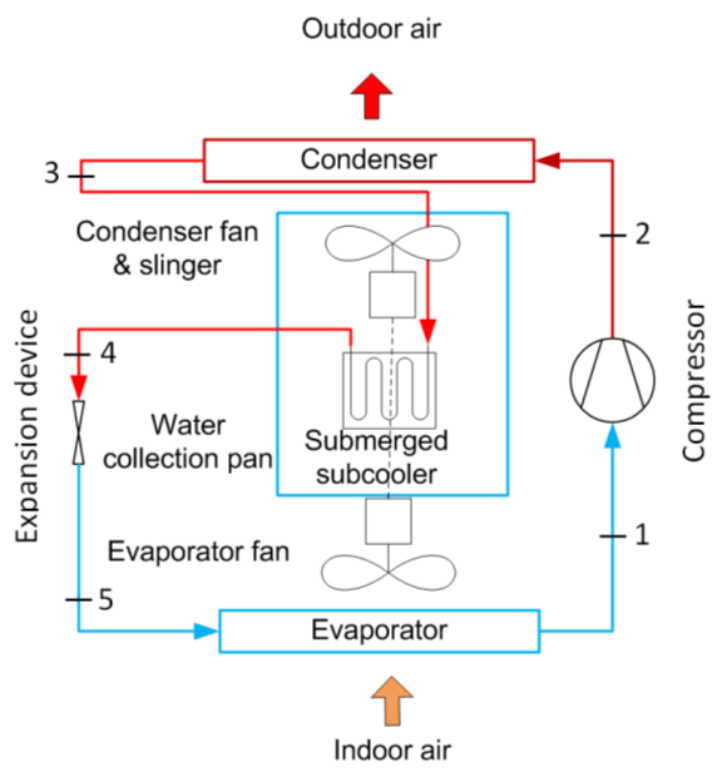

Figure 5: Schematics of Window Air Conditioner

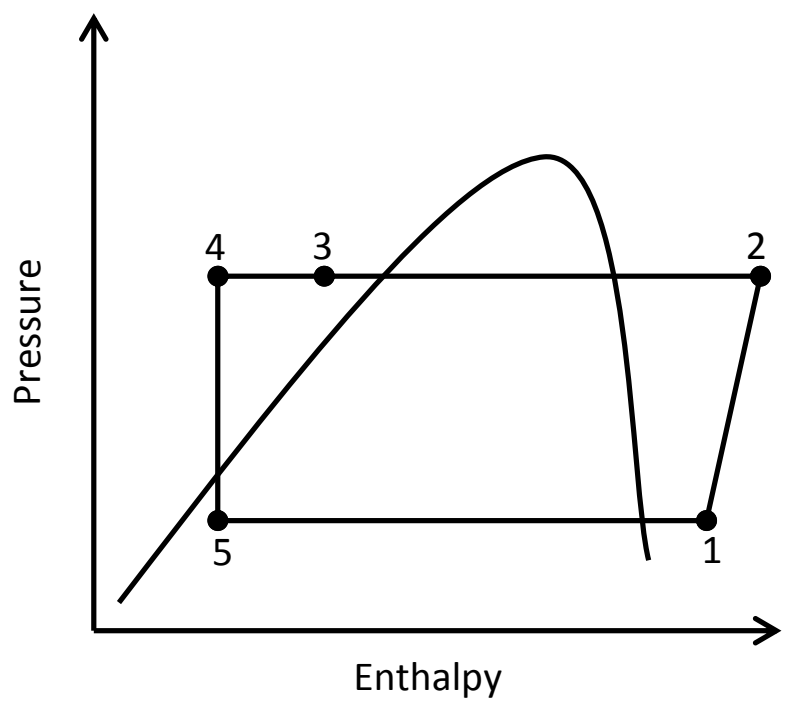

Figure 6: P-h diagram of Window Air Conditioner

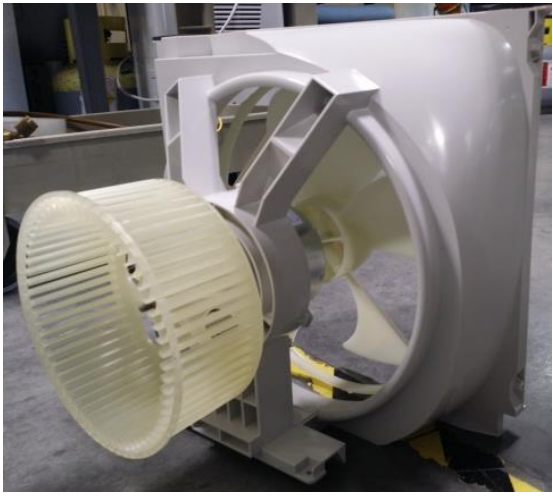

Figure 7: Single axis blower/fan

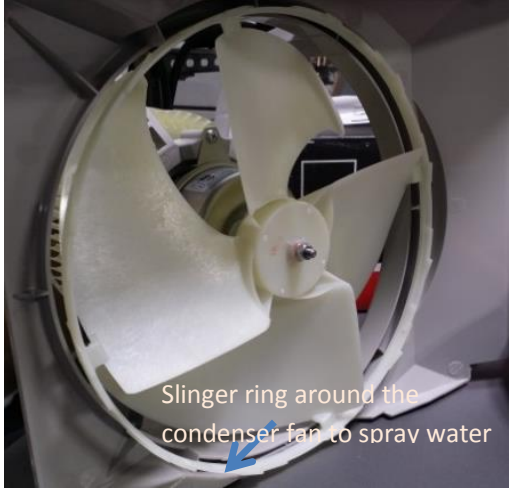

Figure 8: Slinger on condenser fan

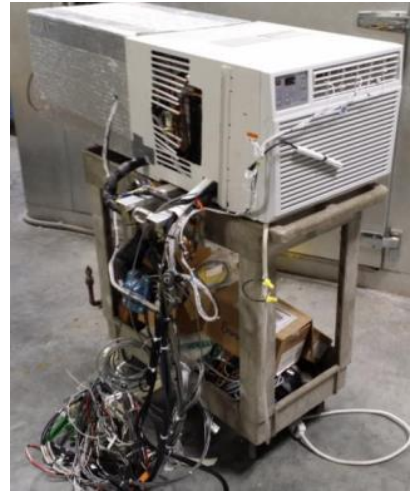

Figure 9: Instrumented WAC

\section{INSTRUMENTATION AND DATA ACQUISITION}

\section{Instrumentation}

In order to quantify the performance of the unit, a measurement/DAS system was developed based upon the Campbell Scientific, CR3000 data logger. The setup consisted of the logger, as well as an AM16/32B multiplexer and PS100 power supply mounted in a Campbell Scientific enclosure. The selection of the measurement points as well as the instrumentation was based upon the requirement that everything needed to fit into the existing chassis with as little modification to the unit as possible. Additionally, because the values of air flow, refrigerant mass flow, and unit capacity were smaller for window air conditioners than they would be for larger units, the management of measurement uncertainty became more critical.

Figure 10 shows a schematic of the basic vapor compression refrigeration cycle along with the locations of the various measurement points. 


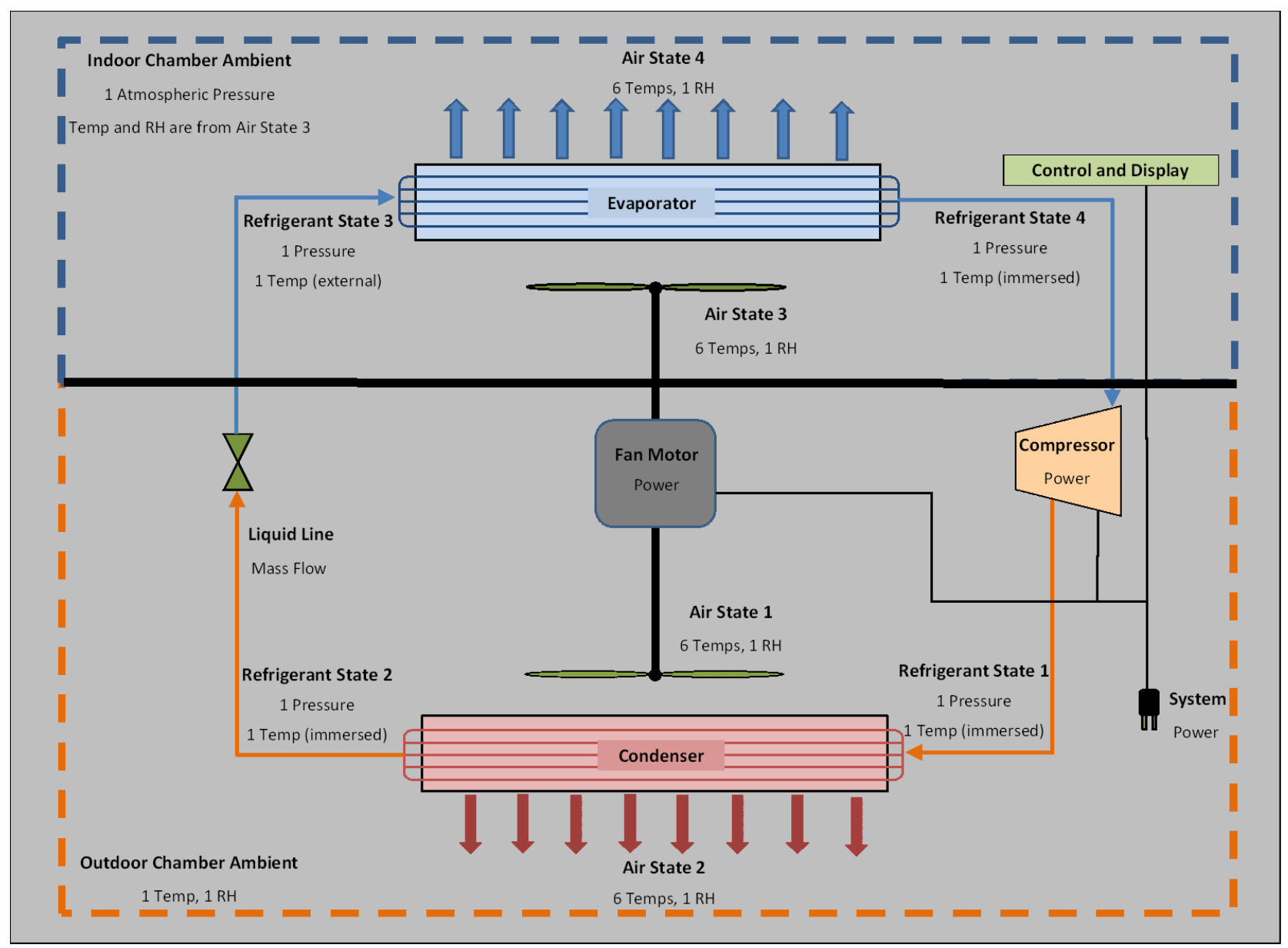

Figure 10 Measurement types, locations, and quantities

As shown, temperature and pressure measurements were made at the four refrigerant state points. The temperature measurements at states 1,2 and 4 are all made by pipe-plug type, thermistor immersion probes. Due to space limitations, the refrigerant temperature at state 3 was measured with a sensor mounted outside of the line rather than the immersion probes used at the other 3 states. Since state 3 was a two-phase flow, the pressure measurement alone was sufficient for the efficiency calculations. Although they are not shown in the diagram, nine additional external line temperatures were added as an aid to future modeling work.

Electrical power usage was measured for both the compressor and fan, as well as for the entire unit, with the difference between the measured total and the sum of the fan and compressor providing an estimate of the controller/display usage. The measurements were made using split-core, current transformers coupled to a pulse-output, power transducer which was mounted inside the data acquisition box. The AC power to the DAS box provided both the charging power to the logger as well as the measurement of the AC voltage used for the power calculations. For this reason, all tests were conducted with the DAS box and the air-conditioner plugged into the same electrical outlet to minimize any local differences in the measured and actual line voltages. The power transducer mounted in the completed DAS enclosure is shown in Figure 11. 


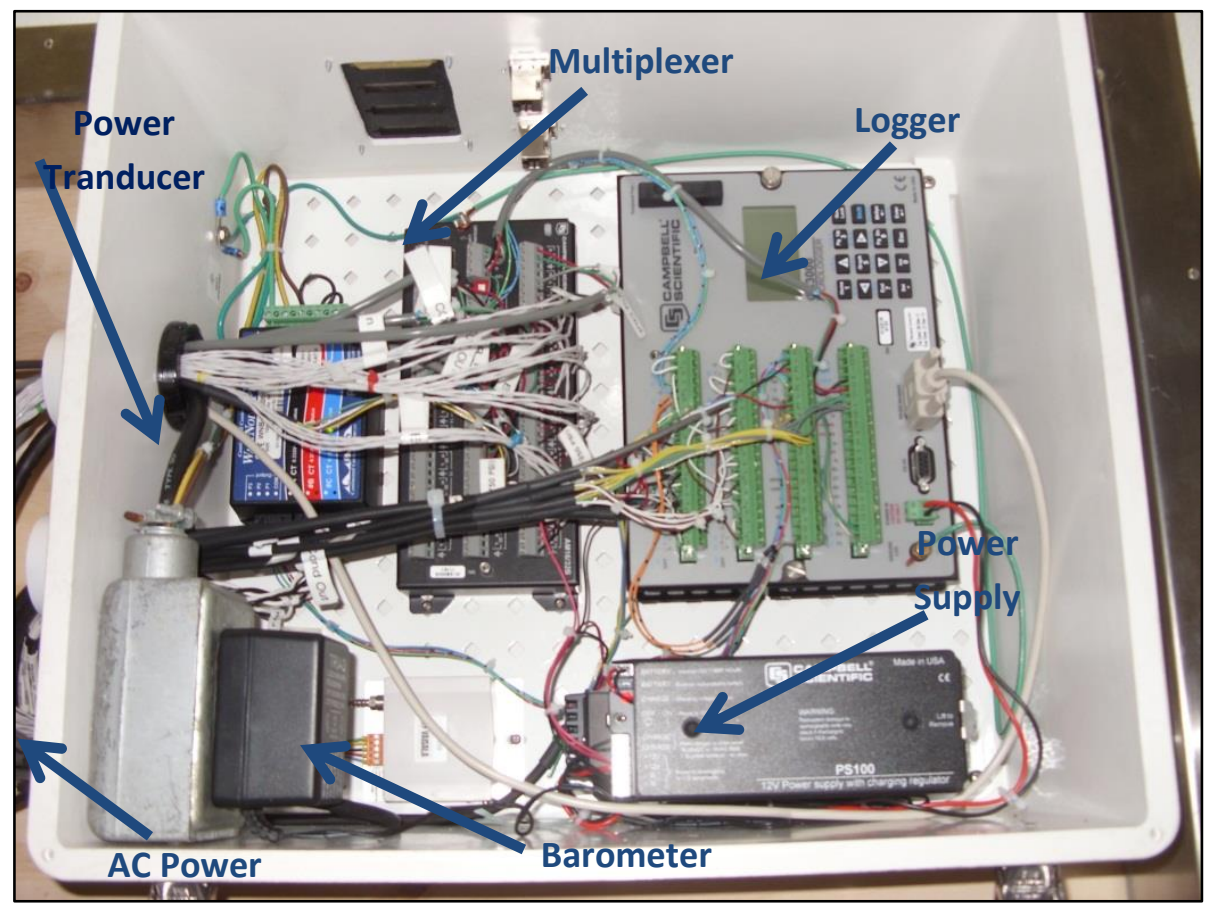

Figure 11: Completed DAS Cabinet

Refrigerant mass flow rate was measured using a Coriolis mass flow sensor, coupled to a pulse output transmitter. Due to the size of these units (even the smaller ones), it was impractical to try to fit the device inside of the air conditioner chassis. Instead, the refrigeration piping was modified such that the unit would hang on the outside of the chassis, suspended from a unistrut bracket. To allow the sensor to vibrate freely, the connections to the unit were made using rubber isolators. The installed mass flow sensor is shown in Figure 12.

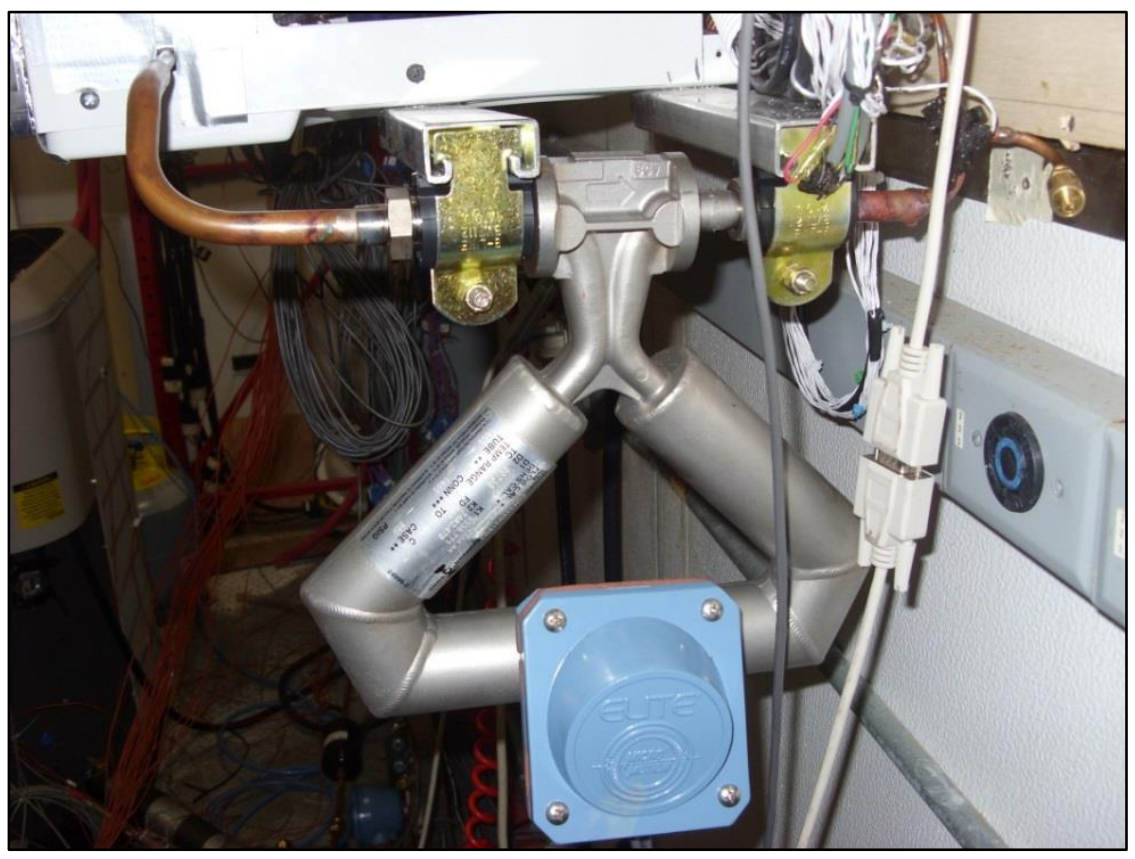

Figure 12: MicroMotion CMF025 Coriolis mass flow sensor 
As also shown in Figure 10, air side temperature and \%RH measurements were made at the inlets and outlets of both the compressor and evaporator. Each of the calculated average temperatures at each of the four air-side measurement points was an average of 6 individual measurements spaced evenly over the face of the heat exchanger. The measurements at each point were made by 5 thermistors (of the same temperature/resistance curves as those used on the refrigerant side) and one additional, platinum RTD measurement which was integrated in the capacitance type \% RH probes. One additional temp/RH probe was used to control the ambient conditions of the outdoor side test chamber. The air side measurement points are shown in Figures 13 and 14.

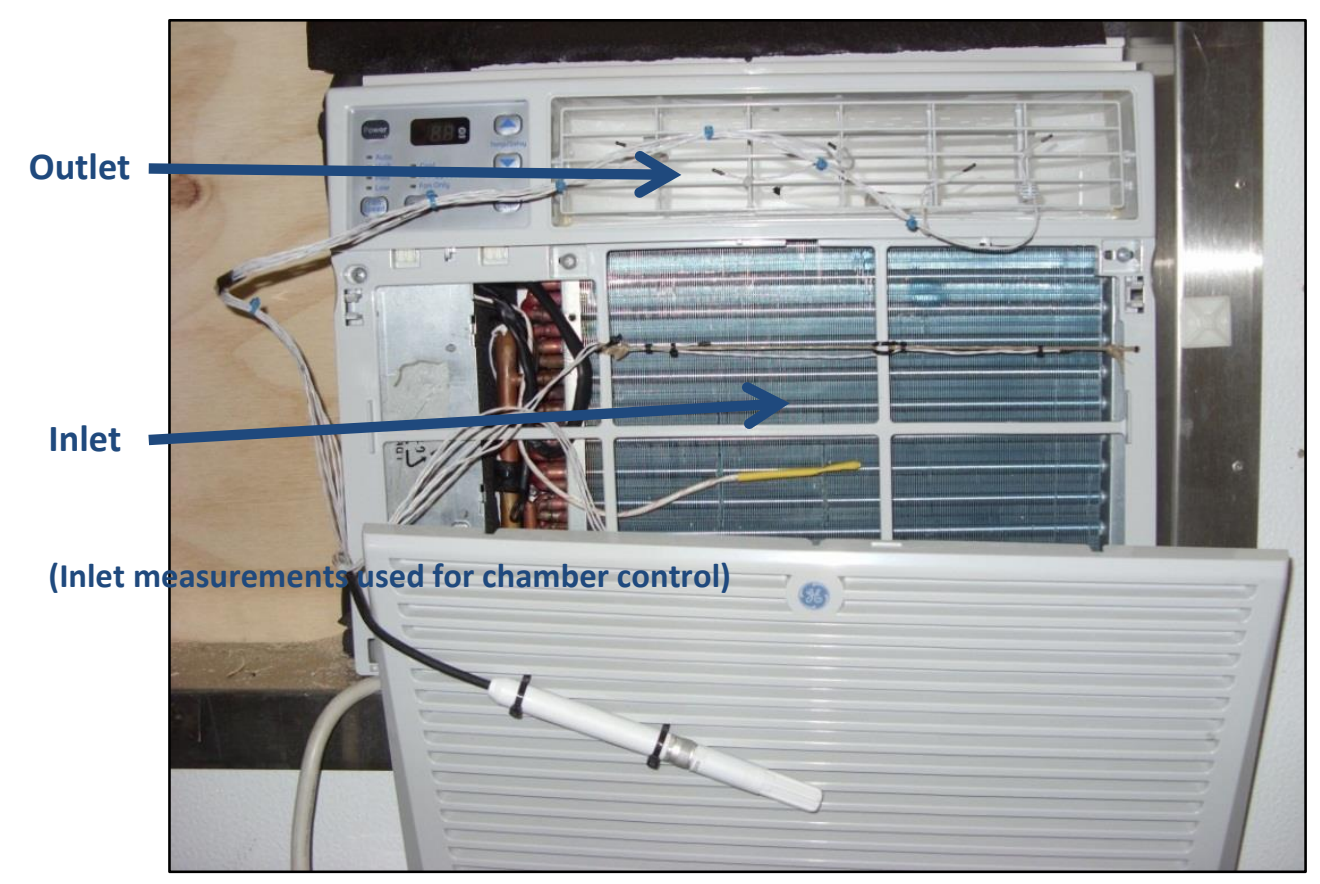

Figure 13: Evaporator air side measurements

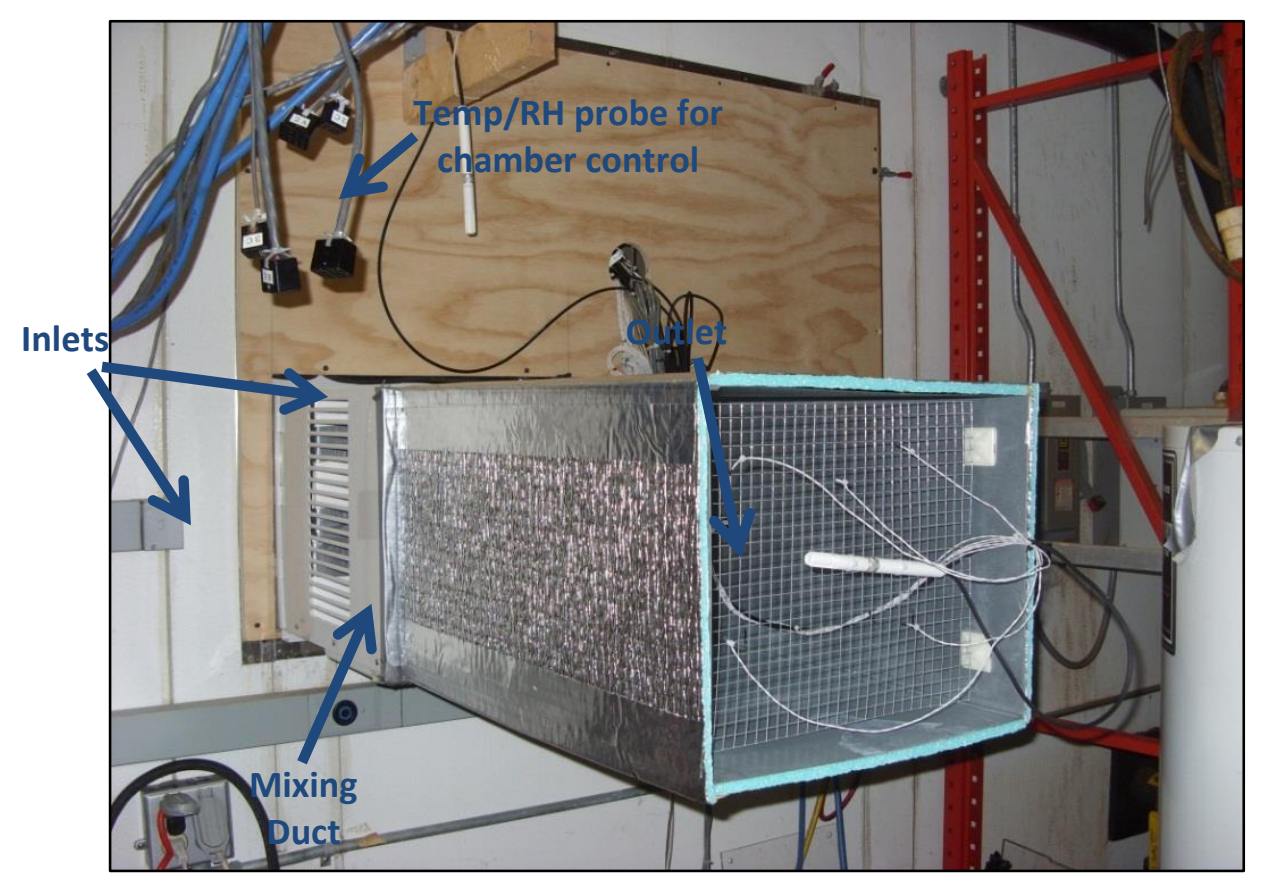

Figure 14: Condenser outlet air side measurements (Inlet measurements are on fan shroud inside of the unit) 


\section{DAS Programming and User Interface}

To perform the measurement sequence as well as post-measurement calculations, a CRBasic program was developed. The routine was designed to generate high resolution data (10s scan interval) while minimizing the measurement uncertainties as well amount of data post-processing required. To achieve this, refrigerant and water saturation tables were generated using REFPROP and these tables imported directly to the CR3000's memory. Three linear-interpolation subroutines were called from the main program to calculate thermodynamic properties of the refrigerant (either general or saturated) as well for saturated water vapor, based upon the measured temperatures and pressures. The step sizes for the pressure and temperature interpolation were $1 \mathrm{psi}$ and $1 \mathrm{~F}$ respectively. The linear fit of the data over this small step, in general, was found to be quite good and any uncertainties introduced into the calculated values due to the interpolation are assumed to be negligible in the subsequent analysis.

In addition to the measurement program, a graphical user interface was created to provide real-time feedback during testing. The GUI was created using the Campbell Scientific "Real Time Monitoring and Control" (RTMC) software and provides a display of pertinent measured and calculated quantities updated every 10s. Figure 15 shows the interface developed for this project.

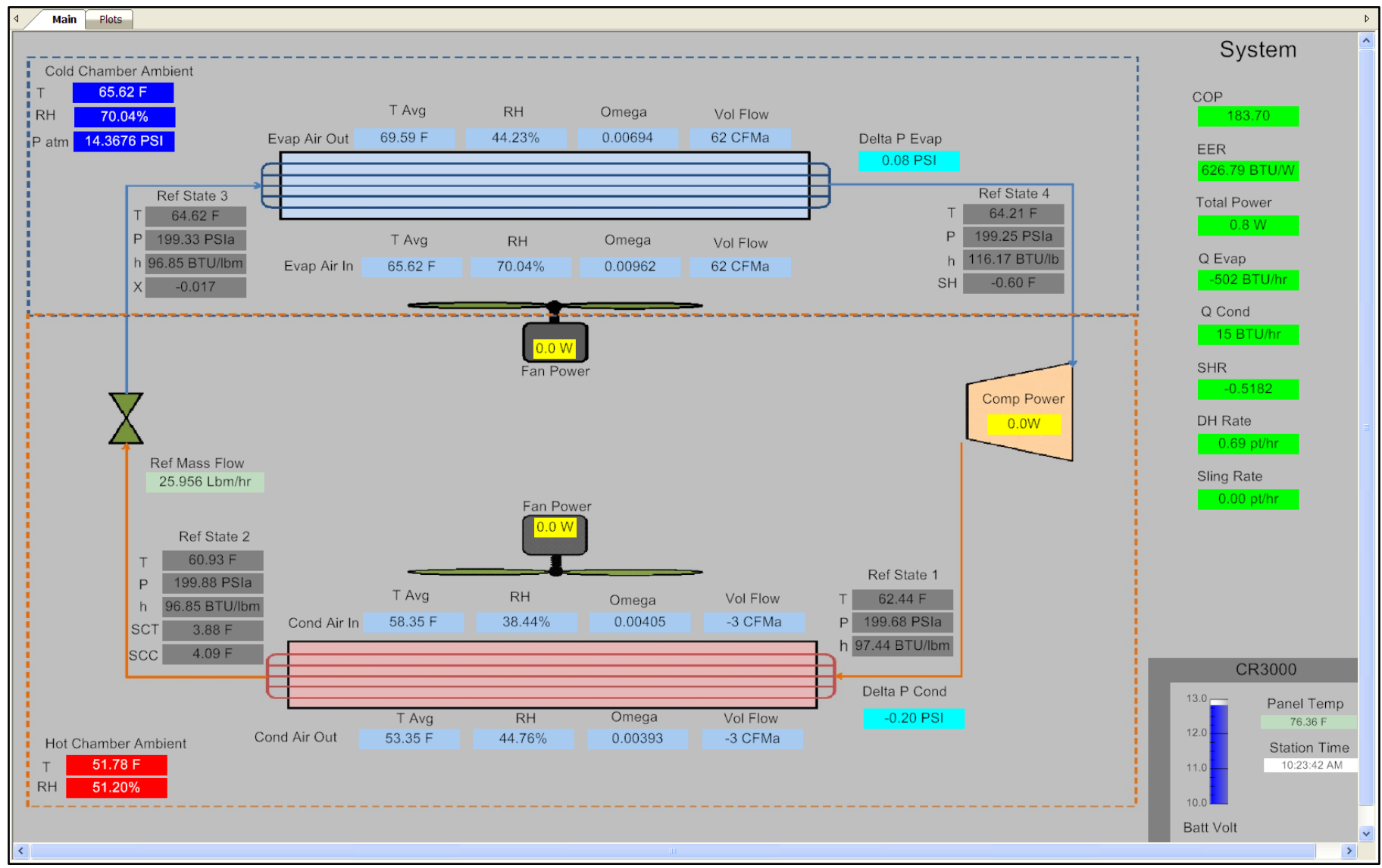

Figure 15: Screenshot of graphical interface

\section{Refrigerant Side Calculated Values}

Some of the pertinent values calculated by the program are presented here; 
Evaporator and condenser heat transfer rates are given by;

$$
\begin{aligned}
& q_{c}=\dot{m}\left[h\left(T_{1}, P_{1}\right)-h\left(T_{2}, P_{2}\right)\right] \\
& q_{e}=\dot{m}\left[h\left(P_{3}, X_{3}\right)-h_{4}\left(T_{4}, P_{4}\right)\right]
\end{aligned}
$$

where $\mathrm{T}$ and $\mathrm{P}$ are the measured temperature and pressure at the various refrigerant state points, $\mathrm{h}$ is the interpolated specific enthalpy for R410A and $\dot{m}$ is the measured refrigerant mass flow rate. It is worthwhile to note here that the expansion from state 2 to 3 is assumed isenthalpic, or;

$$
h_{3}=h_{2}\left(T_{2}, P_{2}\right)
$$

With the quality at state 3 calculated as;

$$
X_{3}=\frac{h_{f}\left(P_{3}\right)-h_{3}}{h_{f}\left(P_{3}\right)-h_{g}\left(P_{3}\right)}
$$

where $h_{f}$ and $h_{g}$ are the interpolated specific enthalpies for the fluid and gas phases respectively.

The evaporator superheat and condenser subcooling are given by

$$
\begin{aligned}
& T_{S H}=T_{4}-T_{\text {sat }}\left(P_{4}\right) \\
& T_{S C}=T_{\text {sat }}\left(P_{2}\right)-T_{2}
\end{aligned}
$$

where $T_{\text {sat }}$ is the interpolated saturation temperature at pressure $P$.

The overall efficiency of the unit is given by

$$
E E R=\frac{-q_{e}}{E_{t}}
$$

Where $\mathrm{q}_{\mathrm{e}}$ is the system capacity in BTU/hr and $\mathrm{E}_{\mathrm{t}}$ is the total electrical power usage in watts.

\section{Air Side Calculated Values}

Although the initial baseline efficiency tests require only refrigerant side measurements, the eventual modification of the fan motors, and heat exchangers will require the ability to reliably measure and adjust the air side flow rates as design parameters. Due to the relatively low air velocities, (especially on the condenser side) airflow measurements using the traditional pitot arrays were not practical without significant alterations to the flow geometry. For this reason, it was decided to explore the feasibility of using airflows calculated from the refrigerant side measurements and the heat exchanger energy balances. The air side mass flow rates for the evaporator and condenser can be expressed as;

$$
\begin{aligned}
& \dot{m}_{e}=\frac{-q_{e}}{C_{p}\left(T_{3}-T_{4}\right)+\left[\omega\left(T_{3}, R H_{3}\right)-\omega\left(T_{4}, R H_{4}\right)\right]\left[h_{g}\left(T_{3}\right)-h_{f}\left(T_{4}\right)\right]+\omega_{4}\left[h_{g}\left(T_{3}\right)-h_{g}\left(T_{4}\right)\right]} \\
& \dot{m}_{c}=\frac{q_{c}}{C_{p}\left(T_{2}-T_{1}\right)+\left[\omega\left(T_{2}, R H_{2}\right)-\omega\left(T_{1}, R H_{1}\right)\right]\left[h_{g}\left(T_{2}\right)-h_{f}\left(T_{1}\right)\right]+\omega_{1}\left[h_{g}\left(T_{2}\right)-h_{g}\left(T_{1}\right)\right]}
\end{aligned}
$$

where, $\mathrm{q}$ is (as before) the refrigerant side heat transfer rates, $\omega$ is the humidity ratio calculated at the measured bulk air temp and \%RH for air states $1-4, C_{p}$ is the constant pressure specific heat for dry air, and $h_{f}$ and $h_{g}$ are the specific enthalpies of the saturated water (fluid and gas respectively) interpolated at the bulk temperature of the mix for air 
states 1-4. It is worthwhile to mention here that, while the inclusion of the water vapor terms in the evaporator energy balance is relatively standard, these terms are generally omitted for the condenser analysis. In this case however, the condenser fan is fitted with a condensate slinger ring which mixes evaporator condensate into the condenser inlet airstream where some of it is evaporated. Due to this, both the latent and sensible change in the water vapor are included in the energy balance.

The validity of equations 8 and 9 is dependent upon the validity of two basic assumptions about the energy transfer.

(1) All of the energy lost or gained by the refrigerant, enters or leaves via the air stream. Losses from natural convection and radiation from the sides of the evaporator or condenser are negligible.

(2) The air entering and leaving the heat exchanger is well mixed.

Overall, assumption 1 is believed to be reasonable for both the evaporator and condenser, as the areas of the sides are small compared to the total fin surface areas. Due to the construction of the unit, however, assumption 2 is more valid at the evaporator than at the condenser.

The inlet air for the evaporator was pulled directly from the indoor test chamber which was typically well mixed. The air is not required to pass over any components which could induce temperature/ $\mathrm{RH}$ gradients before the measurement was made. Additionally, since the fan was not an axial type, there was no dead spot at the hub, and the Styrofoam fan shroud helped to insulate the flow from the hot side of the unit. After passing over the evaporator coils, the air went through the blower and was then turned 180 degrees where it exited through a much smaller area at the front of the unit at much higher velocity than the inlet. The turbulence induced by the blower, coupled with the velocity and direction change ensured that the exit air was also well mixed. For these reasons, the measured average air temperature and $\mathrm{RH}$ were believed to be a good representation of the bulk properties at both the inlet and outlet of the evaporator.

The condenser airflow by comparison was less suited to the simplifying assumptions. The inlet air entered from louvers in the top and side of the unit before passing through the fan shroud inlet where the temperature and $\mathrm{RH}$ measurements were made. Inside the unit, some of the inlet air passeed over the internal components of the unit (compressor, fan motor, etc.) potentially causing flow, temperature, and \%RH gradients. At the condenser outlet, there was noticeable temperature stratification in the flow from top to bottom as well as an area of low flow around the fan hub. To promote mixing at the condenser outlet, a 24" section of insulated duct (shown in Figure 9) was added upstream of the measurement point. This improved the results to a certain extent but the condenser airflow rate was still found to be sensitive to the somewhat arbitrary location of the sensors.

The calculated numbers for the evaporator side were found to correlate quite well with the published numbers for the unit and were found to relatively independent of the sensor placement. Condenser airflow rates were not typically published for window units but with some adjustment of the sensor placement, reasonable numbers were produced.

\section{UNCERTAINTY ANALYSIS}

To quantify the level of uncertainty in both the base measurements as well as the calculated quantities, a zero order analysis was performed - detailed are given in Appendix A. The study establishes overall uncertainties for the various sensors when used in combination with the CR3000 data logger at the standard test conditions. The analysis then tracks how these base uncertainties propagate through to the final calculated quantities (EER, COP, SHR etc.). The analysis used the following assumptions. 
(1) Uncertainties due to transient conditions were not considered. Since the tests focus on steady state analysis, this was considered a valid assumption.

(2) Uncertainties introduced from linear interpolation of the refrigerant and saturated water vapor tables were considered negligible. As was mentioned previously, analysis of the data shows the linear approximation to be quite good over the small temperature/pressure increments used for the interpolation subroutines.

(3) The analysis did not take into account deviations in the actual physics from the simplifying assumptions made. This is to say that the accuracy of any calculated value will be a function of both the ability to accurately measure the parameters used to calculate it as well as how accurately the equation models the actual physics of the process. The values presented in this study did not account for the latter.

(4) The results of the analysis presented here are for a single instantaneous measurement. Since many of the final results are based upon the average of $\mathrm{N}$ multiple measurements, the uncertainty in the average will decrease approximately by the factor of $\mathrm{N}^{-1 / 2}$, assuming that the sensor error is random in nature. Because of this, even in cases where the uncertainty for a single measurement is high (as is the case for the calculated condenser airflow) the average of 30 minutes of data is still a fair estimate.

The results of the uncertainty analysis are presented in Table 5.

Table 5 Results of design point uncertainty analysis

\begin{tabular}{|l|c|}
\hline \multicolumn{2}{|c|}{ Base Measurements } \\
\hline Measurement & Estimated Combined Logger and Sensor Uncertainty \\
\hline Temperature & $\pm .25 \mathrm{~F}$ \\
\hline Refrigerant Pressure (low) & $\pm .2 \mathrm{psi}$ \\
\hline Refrigerant Pressure (high) & $\pm .6 \mathrm{psi}$ \\
\hline Mass Flow Rate & $\pm .7 \mathrm{lbm} / \mathrm{hr}$ \\
\hline Electrical Power (fan) & $\pm 2 \mathrm{~W}$ \\
\hline Electrical Power (compressor and system total) & $\pm 10 \mathrm{~W}$ \\
\hline Atmospheric Pressure & $\pm .009 \mathrm{psi}$ \\
\hline Relative Humidity & $\pm 1.4 \% \mathrm{RH}$ \\
\hline & \\
\hline Calculated Values & Estimated Uncertainty \\
\hline Parameter & $\pm .12 \mathrm{BTU} / \mathrm{Whr}$ \\
\hline EER & $\pm 57 \mathrm{BTU} / \mathrm{hr}$ \\
\hline System Capacity & $\pm 62 \mathrm{BTU} / \mathrm{hr}$ \\
\hline Condenser Heat Transfer Rate & \pm .002 \\
\hline State 3 Quality & $\pm .3 \mathrm{~F}$ \\
\hline State 4 Superheat & $\pm .3 \mathrm{~F}$ \\
\hline State 2 Subcool & $\pm .3 \mathrm{psi}$ \\
\hline Refrigerant Evaporator Pressure Drop & $\pm .8 \mathrm{psi}$ \\
\hline Refrigerant Condenser Pressure Drop & $\pm .1 \mathrm{~F}$ \\
\hline Average Air Temperatures & $\pm 15 \mathrm{CFM}$ \\
\hline Evaporator Volumetric Flow Rate & $\pm 98 \mathrm{CFM}$ \\
\hline Condenser Volumetric Flow Rate & $\pm .5 \mathrm{pint} / \mathrm{hr}$ \\
\hline Dehumidification Rate & \pm .05 \\
\hline SHR & \\
\hline
\end{tabular}




\section{BASELINE TESTING}

\section{Test Procedure}

Before efficiency modifications could be made to the test unit, it was first necessary to establish the baseline performance. To facilitate this, the instrumented unit was first mounted in a plywood partition between the indoor and outdoor test chambers. Care was taken to ensure that none of the intake louvers on the sides and top were obstructed. The temperature and relative humidity of the indoor chamber were adjusted based upon the measurements at the evaporator air inlet (air state 3). The outdoor chamber was adjusted based upon a single temperature/RH probe mounted a few feet from the intake louvers on the top of the unit. This is shown in Figure 14.

Before actual testing could begin, the refrigerant charge in the unit first needed to be adjusted to compensate for the additional volume of the system due to the installed sensors. To do this, the unit was first charged to 24 oz., which is slightly more than the amount which was recovered from the unit prior to the instrumentation. The test chambers were brought up to the standard rating conditions and the level of evaporator superheat observed. Per instructions from ORNL's contacts with GE, charge was added in $1 / 3 \mathrm{oz}$. increments to achieve a superheat of around $10 \mathrm{~F}$, at the standard rating conditions. The final charge used for the test was $25.13 \mathrm{oz}$ of R410A. This produced a superheat of between, 11 and $12 \mathrm{~F}$. While this was considered a good initial estimate, it was felt that some additional performance could be coaxed from the unit if this level was brought down to 9-10 F.

With the unit installed in the chamber and charged, a test procedure was developed. The procedure used to generate the data presented here is as follows;

(1) With the unit running, bring both chambers to near the desired setpoints.

(2) Fine tune the chamber setpoints to achieve the desired inlet conditions as measured at the evaporator inlet sensors for the indoor chamber and the single temp/RH probe near the intake louvers on the outdoor chamber.

(3) When steady temp/ $\mathrm{RH}$ readings are achieved, allow at least $1 / 2$ hour for the window unit to achieve equilibrium. This allows time for the condensate level in the pan to reach a steady value. Per instructions from GE, the capacity and total electrical power measurements should be steady within $\pm 2 \%$ of the mean value before testing begins. Allowing $1 / 2$ hour after any changes was found to achieve this condition.

(4) Once steady state is achieved, data is collected for an additional $1 / 2$ hour period.

Although the rated EER is calculated at a single test condition, for modeling purposes, a series of 9 tests were run for the three sets of outdoor conditions specified by AHAM at three different fan speeds. The test matrix is shown in Table 6 .

Table 6: Test matrix

\begin{tabular}{|c|c|c|c|}
\hline Outdoor & \multicolumn{3}{|c|}{ Fan Speed } \\
\hline $90 \mathrm{~F}, 45 \% \mathrm{RH}$ & High & Med & Low \\
\hline $95 \mathrm{~F}, 40.1 \% \mathrm{RH}$ & High & Med & Low \\
\hline $110 \mathrm{~F}, 24.4 \% \mathrm{RH}$ & High & Med & Low \\
\hline
\end{tabular}

\section{Results}

Figures 16-21 show the results of the tests at the rated indoor/outdoor test conditions (outdoor=95F, 40.1\%RH indoor $=80 \mathrm{~F}, 51.5 \% \mathrm{RH}$ ) for the three fan speeds. 


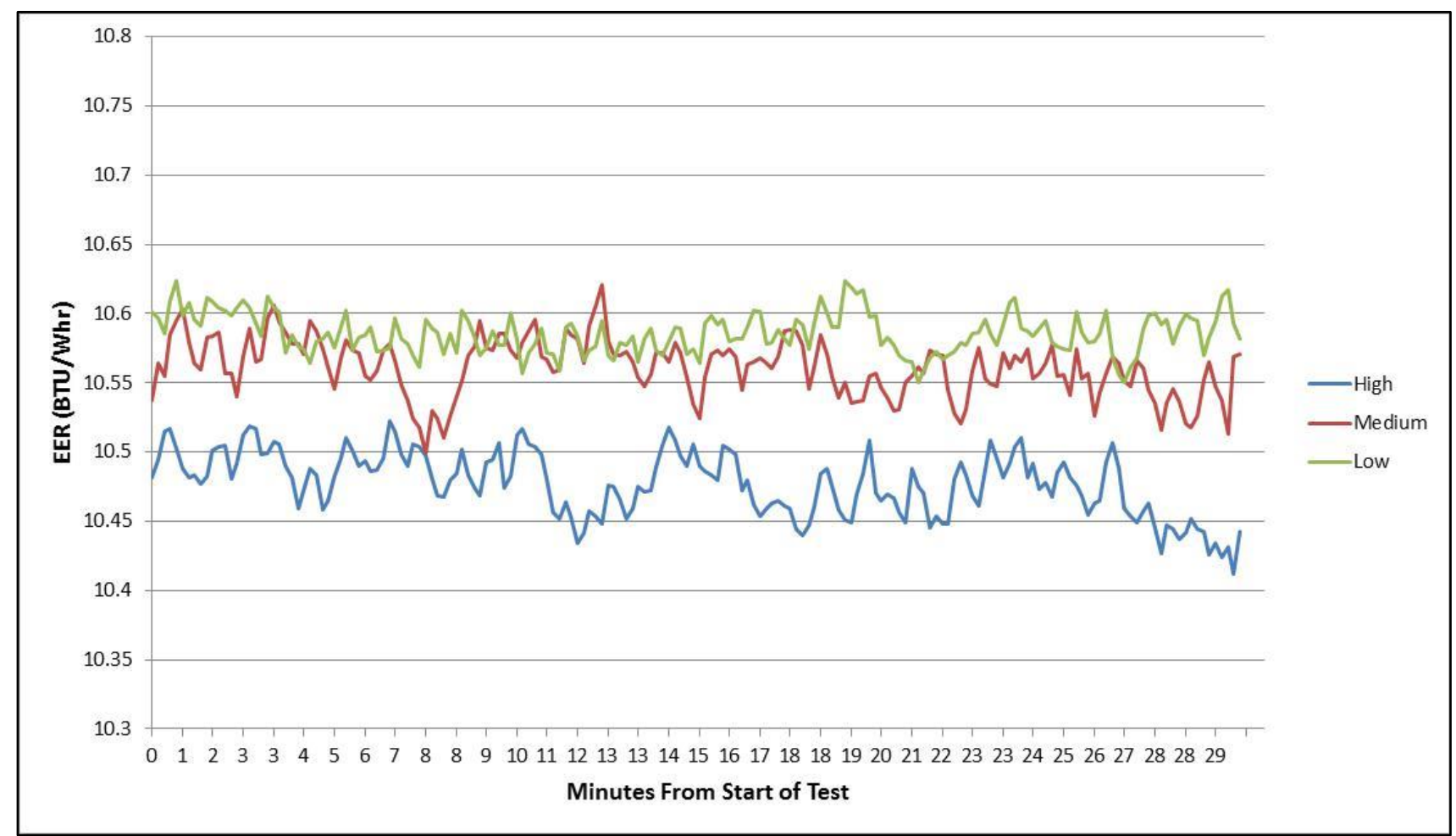

Figure 16: EER for standard indoor/outdoor conditions at 3 fan speeds

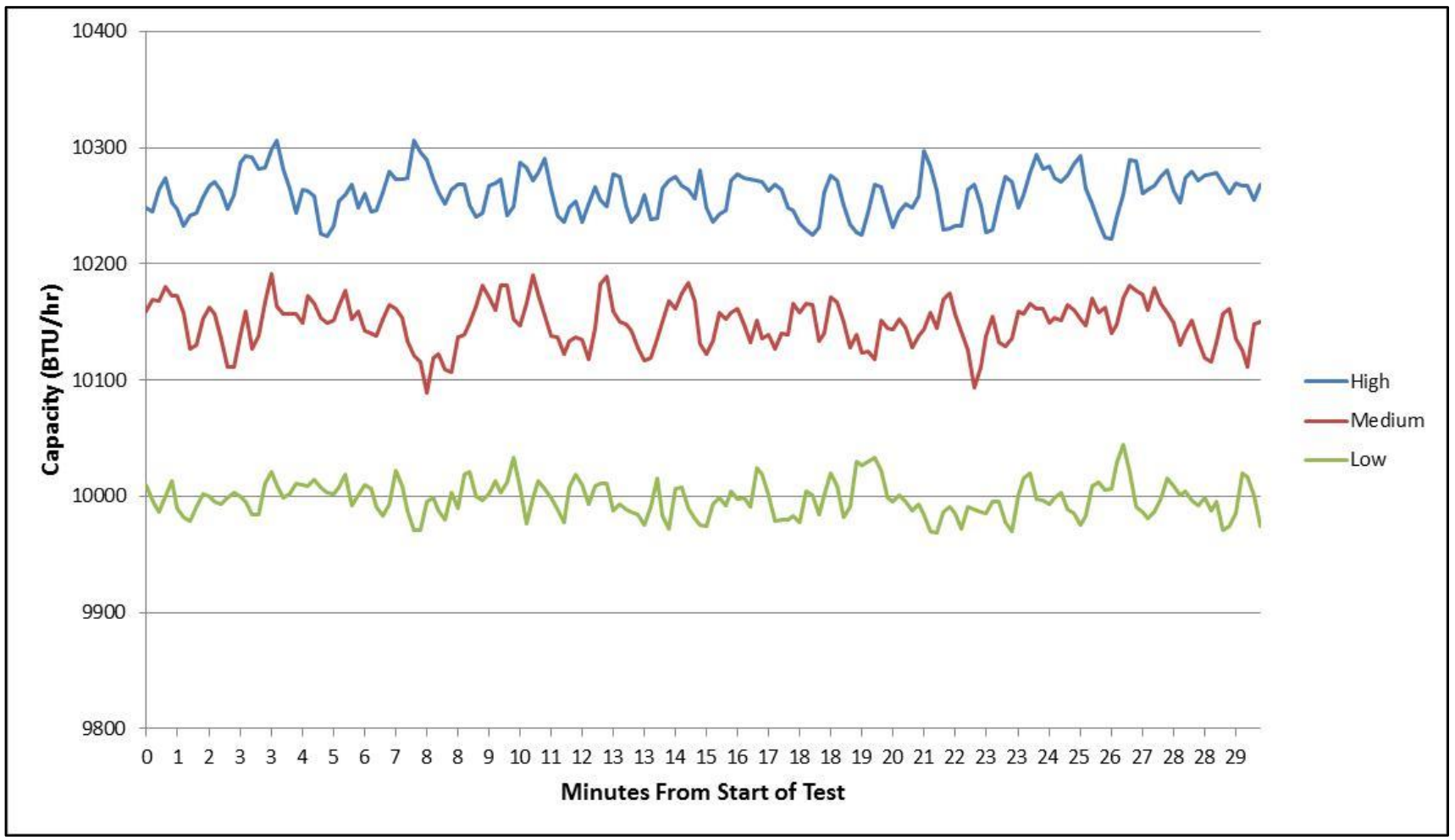

Figure 17: Capacity for standard indoor/outdoor conditions at 3 fan speeds 


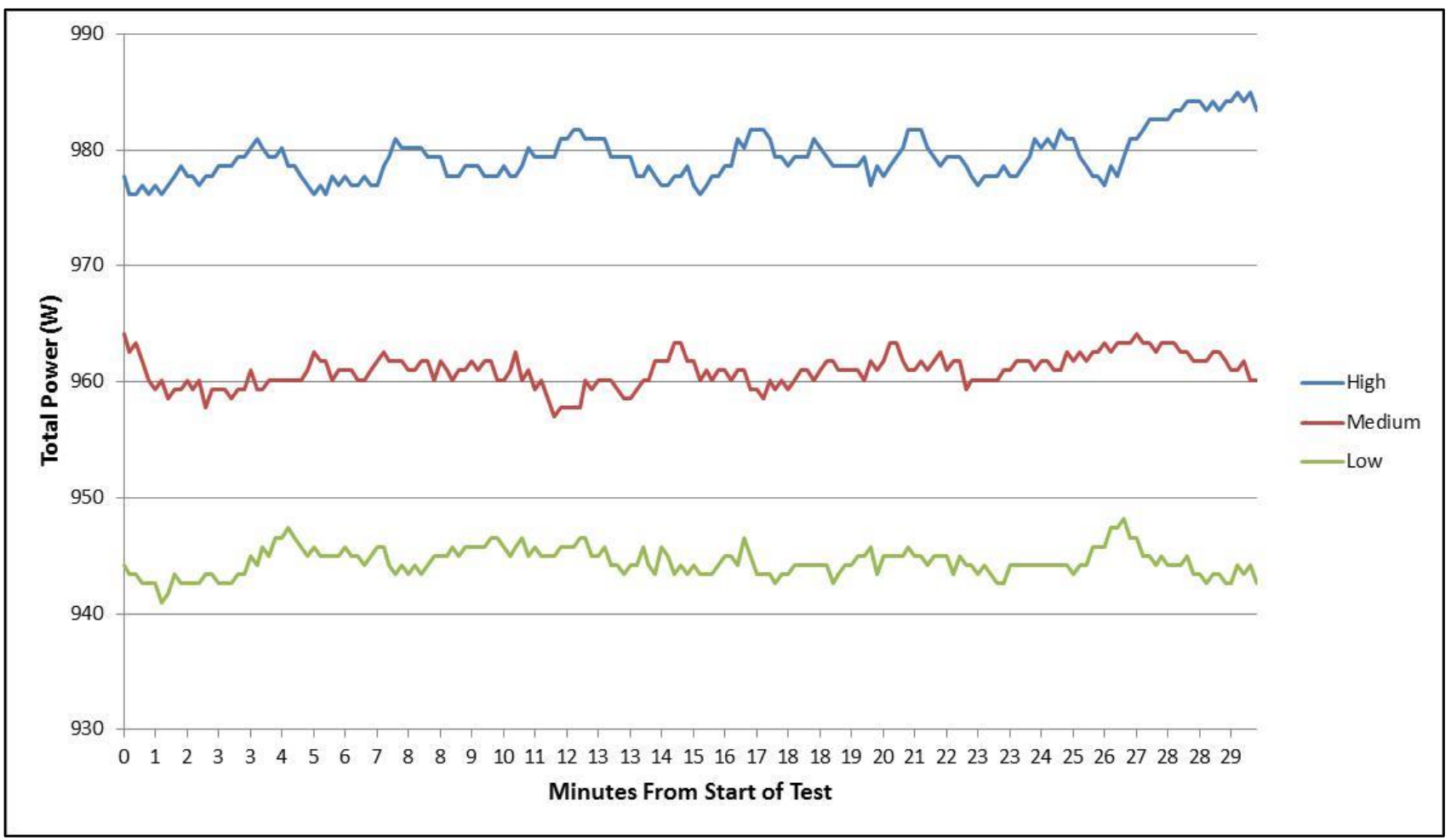

Figure 18: Total electrical power for standard indoor/outdoor conditions at 3 fan speeds

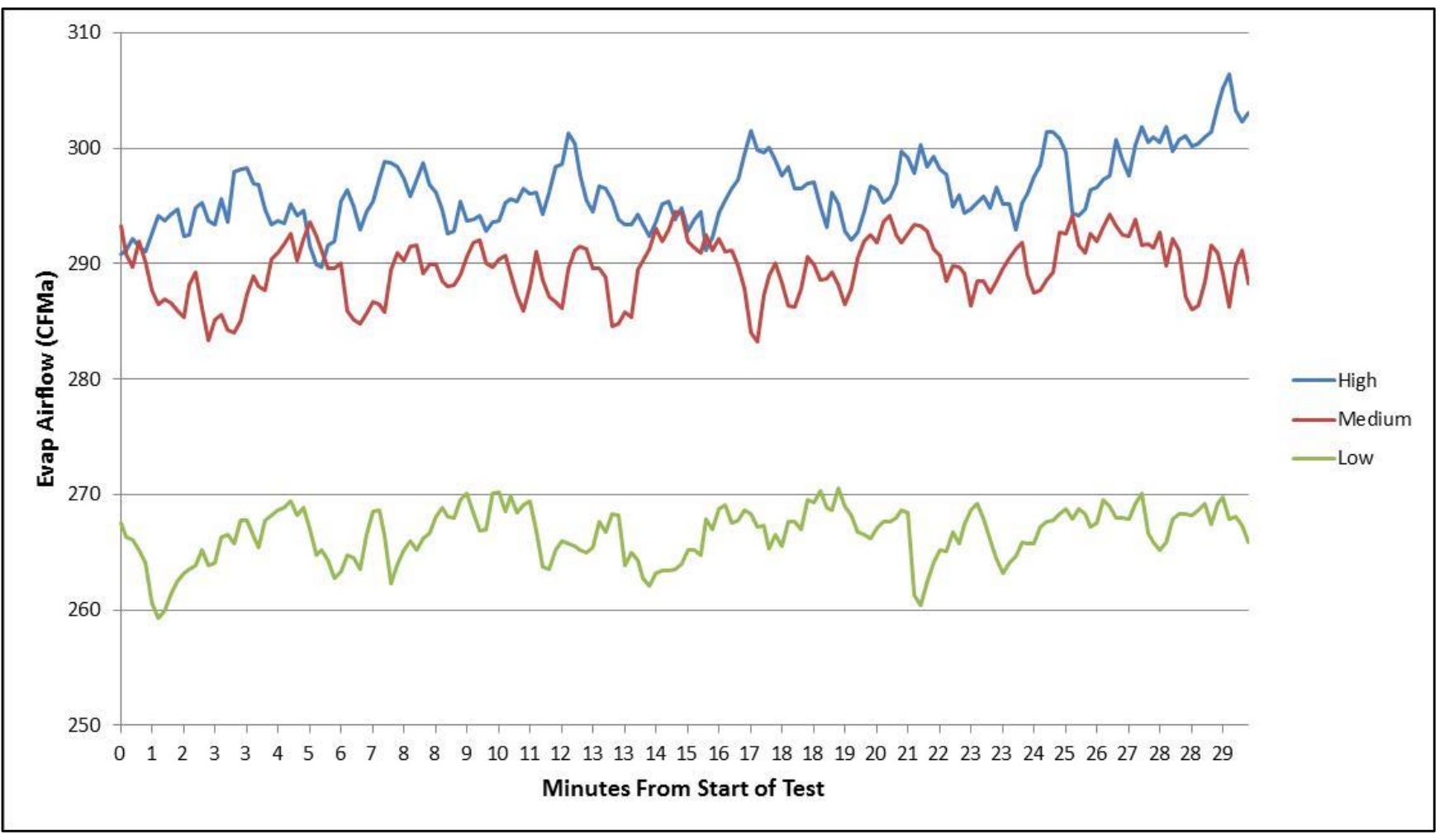

Figure 19: Evaporator airflow for standard indoor/outdoor conditions at 3 fan speeds 


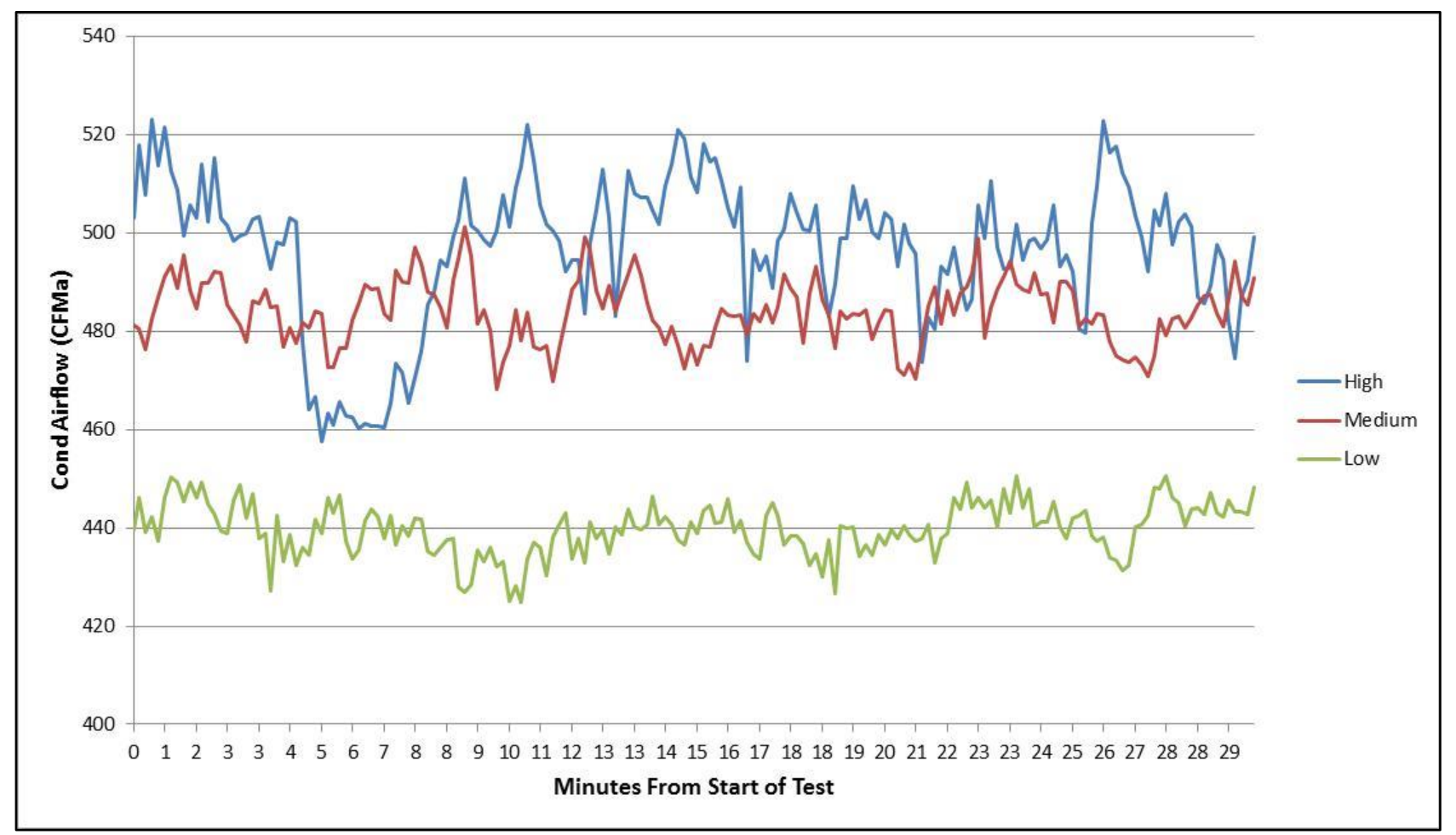

Figure 20: Condenser airflow for standard indoor/outdoor conditions at 3 fan speeds

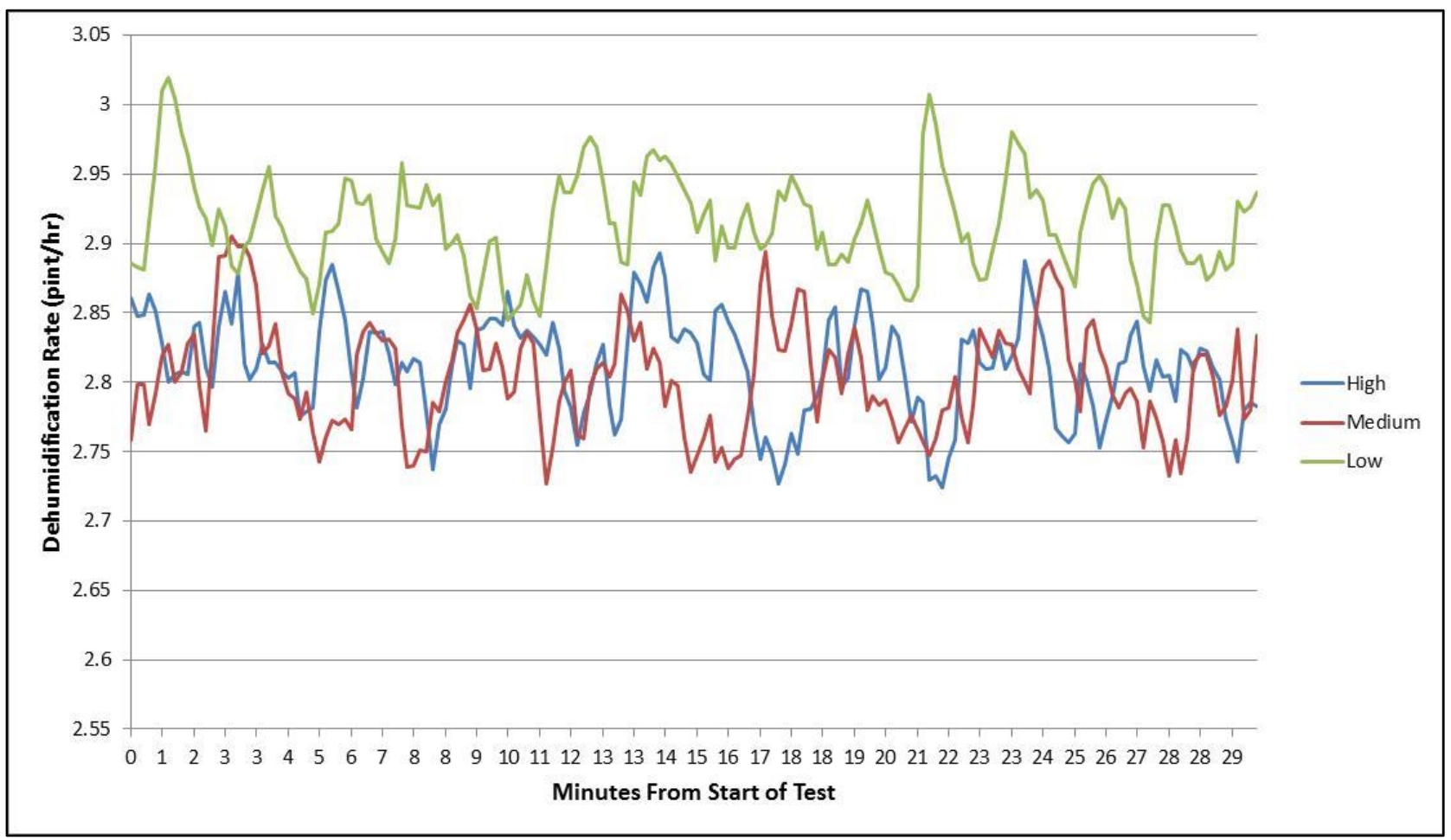

Figure 21: Dehumidification rate for standard indoor/outdoor conditions at 3 fan speeds 
The results at the rated condition are summarized in Table 7.

Table 7 Comparison of experimental values to rated performance

\begin{tabular}{|c|c|c|c|c|c|}
\hline & \multicolumn{2}{|c|}{ Outdoor $=95 \mathrm{~F}, 41 \% \mathrm{RH}$} & \multicolumn{2}{|c|}{ Indoor $=80 \mathrm{~F}, 52 \% \mathrm{RH}$} & In Speed= High \\
\hline & $\begin{array}{c}\text { EER } \\
\text { (BTU/Whr) }\end{array}$ & $\begin{array}{l}\text { Capacity } \\
\text { (BTU/hr) }\end{array}$ & $\begin{array}{l}\text { Evap Airflow } \\
\text { (CFMa) }\end{array}$ & $\begin{array}{l}\text { Cond Airflow } \\
\text { (CFMa) }\end{array}$ & $\begin{array}{l}\text { Dehumidification } \\
\text { (pint/hr) }\end{array}$ \\
\hline Rated & 10.80 & 10000 & 300 & 500 & 2.5 \\
\hline $\begin{array}{l}\text { Experimental } \\
\text { (30 min avg) }\end{array}$ & 10.48 & 10261 & 296 & 497 & 2.8 \\
\hline Difference & $-3.0 \%$ & $+2.6 \%$ & $-1.4 \%$ & $-0.6 \%$ & $+10.7 \%$ \\
\hline
\end{tabular}

\section{DISCUSSION}

As shown in Table 7, the experimental EER and capacity values are in relatively close agreement with the published numbers for the unit. The unit efficiency was measured to be within $3 \%$ of the rated value but was for all test cases on the lower side of the mark. Based upon the superheat values observed, it is felt that for these initial baseline tests, the unit could have been slightly undercharged.

The calculated airflow rates and dehumidification rates are also in relatively good agreement with the published values. As was discussed in the previous section, in general it is felt that the estimate of the evaporator airflow is more valid than that for the condenser. Not only is the measurement uncertainty much lower, the simplifying assumptions are a far better fit to the indoor side than to the outdoor. Methods of achieving better mixing of the condenser outlet air are currently being explored and could possibly be implemented in future tests.

Over the course of the instrumentation and initial testing of the unit, some observations were made regarding achieving the eventual goal of 13 EER. The first of these relates to the fan motor efficiency. The tests show that the motor consumed a relatively steady $185 \mathrm{~W}$ at the highest fan speed setting. The rated mechanical output of the motor is $95 \mathrm{~W}$, for an efficiency of only around $50 \%$. In the case of window air conditioners, the benefits of increased motor efficiency are essentially twofold. Not only is less energy used to produce the same airflow, but there is less heat is being dissipated in the chassis to increase the temperature of the condenser inlet air. For these reasons, improving fan efficiency expected to be one of the first modifications made to the baseline unit. In addition to the inefficiency of the current fan motor, the airflow through the condenser was found to be highly non-uniform, with a major dead spot at the center caused by the fan hub. 


\subsection{VALIDATION OF HPDM WITH TEST DATA OF BASE WINDOW AIR CONDITIONER}

\section{Test Procedure}

Determination of Optimum Charge: A study was conducted to determine the optimal refrigerant charge for the test unit due to the increased volume of the system after the sensors were installed. The system was initially filled with the factory charge of $24 \mathrm{oz}$ and the charge was then added in $1 \mathrm{oz}$. increments to achieve the maximum EER and a superheat of around $10 \mathrm{~F}$ at the standard rating conditions.

As can be seen from Figure 22 that initially, the level of superheat (left axis) and subcooling (right axis) would respectively decrease and increase substantially with the incremental charge but would eventually become asymptotic with subsequent additions at refrigerant charge of about $790 \mathrm{gm}$. The corresponding EER and the system capacity are ploted in Figure 23, where it may be noted that although efficiency continued to increase beyond this point, the system parameters would never fully stabilize indicating wet compression. This exercise was repeated a few times but with similar results. Hence, the charge level prior to this asymptotic behavior was considered optimum for future modifications. Therefore, the optimim charge was found to be $790 \mathrm{gm}$ of R410A. At this point, the system EER was experimentally found to be 10.8. This number correlates well with both the manufacturers published value of 10.8 as well as earlier tests at similar charge levels.

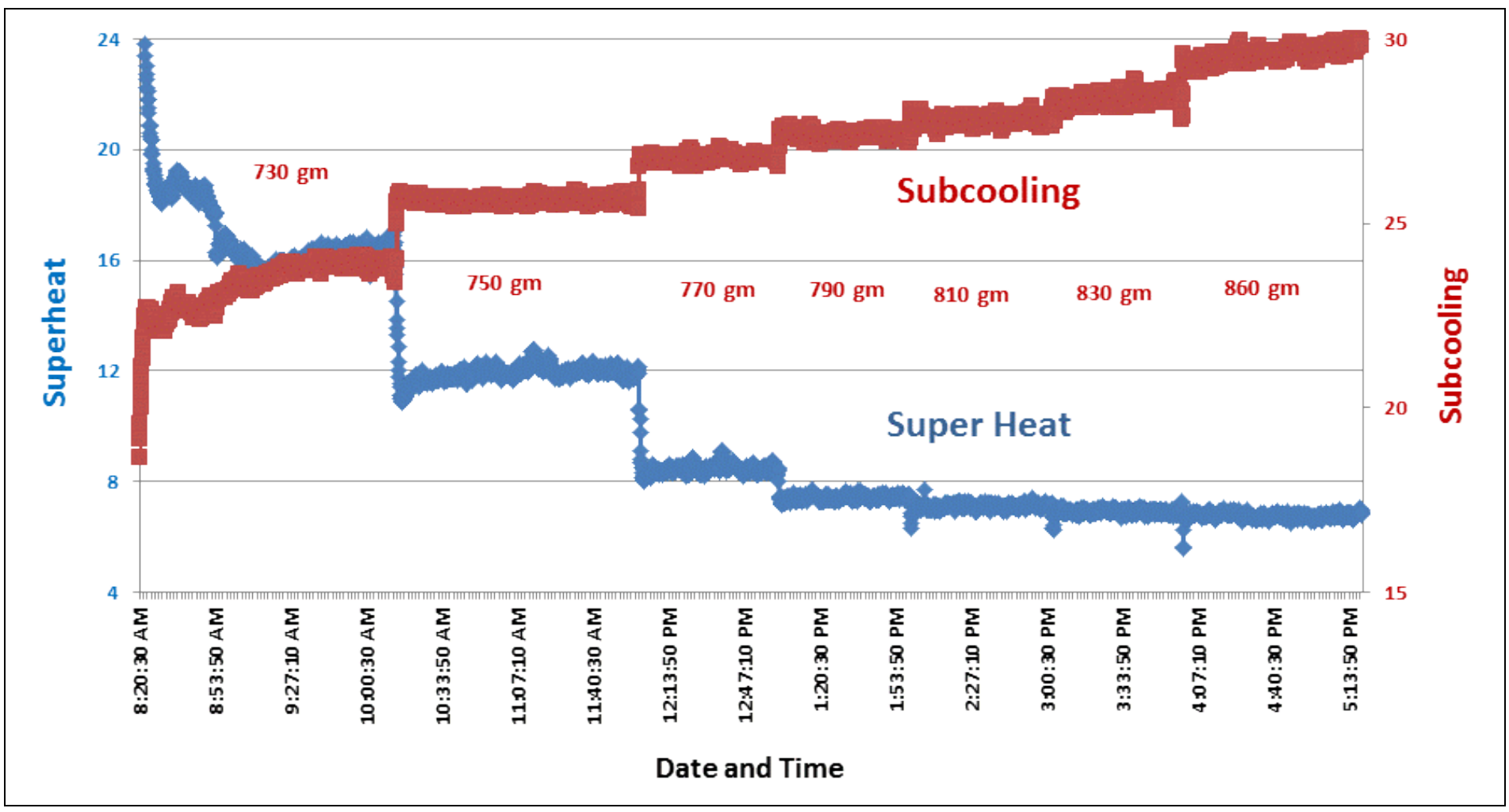

Figure 22: Variation of superheat and subcooling with refrigerant charge 


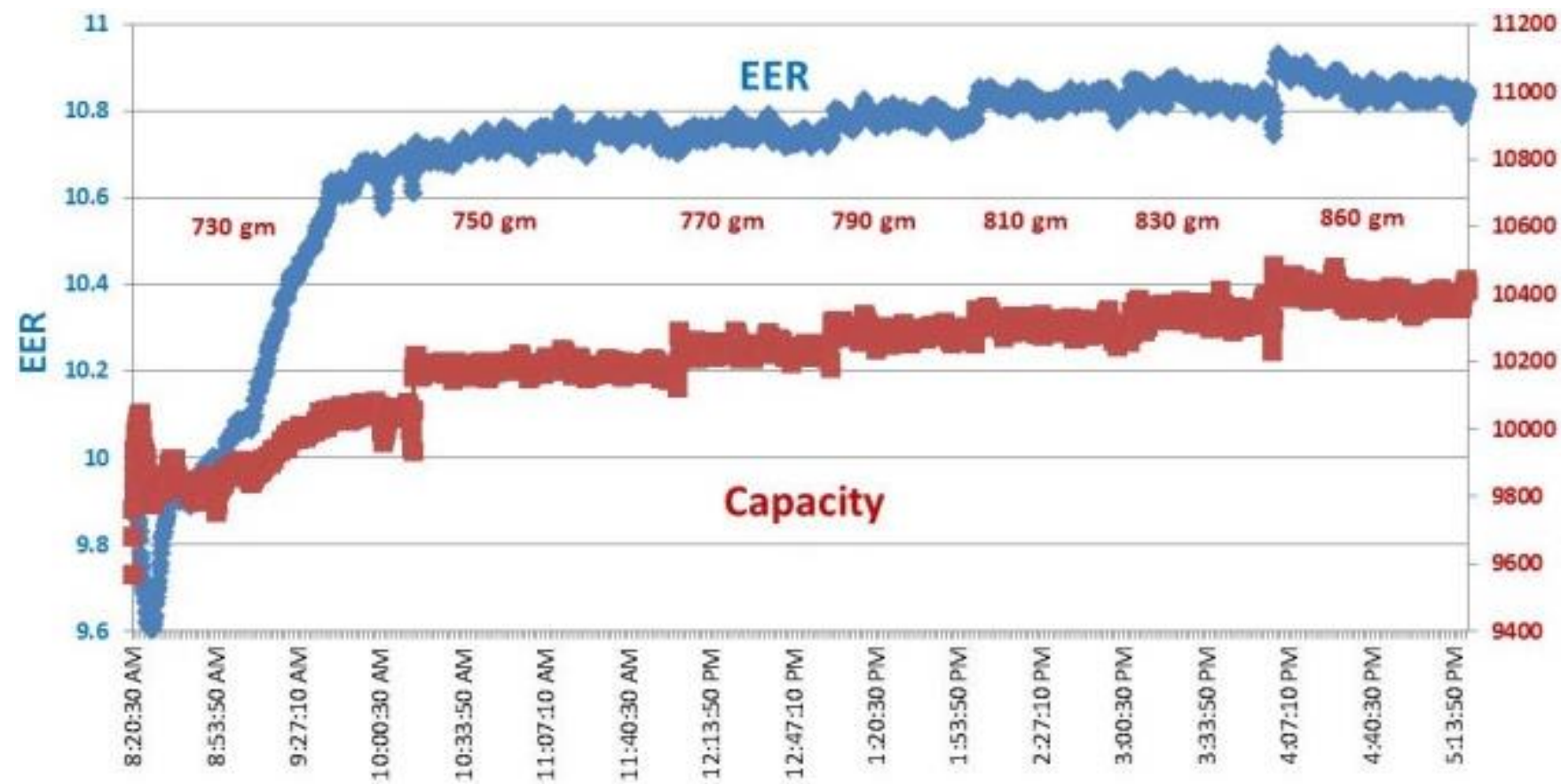

Date and Time

Figure 23: Variation of EER and evaporator capacity with refrigerant charge

Performance at Design and off-design Test conditions: Upon determining the optimum charge level, the baseline and off design tests were run one final time. Although the rated EER is calculated at a single set of conditions, a series of 6 tests were run, for modeling purposes, for the two sets of outdoor conditions specified by AHAM at two different fan speeds. The test matrix is shown in Table 8.

Table 8 Test matrix

\begin{tabular}{|c|c|c|c|}
\hline Indoor & Outdoor & \multicolumn{2}{|c|}{ Fan Speed } \\
\hline $80 \mathrm{~F}, 51.5 \% \mathrm{RH}$ & $90 \mathrm{~F}, 45 \% \mathrm{RH}$ & High & Low \\
\hline $80 \mathrm{~F}, 51.5 \% \mathrm{RH}$ & $95 \mathrm{~F}, 40.1 \% \mathrm{RH}$ & High & Low \\
\hline $80 \mathrm{~F}, 51.5 \% \mathrm{RH}$ & $110 \mathrm{~F}, 24.4 \% \mathrm{RH}$ & High & Low \\
\hline
\end{tabular}

The comparison of the corresponding EER and the system capacity at high $(\mathrm{H})$ and low $(\mathrm{L})$ flow rates is shown in Figure 24. Although the EER shows a slight increasing trend by about $0.8 \%$, the capacity reduces by about $3 \%$, mainly due to fan power that reduces by over $21 \%$ at low flow rates. 


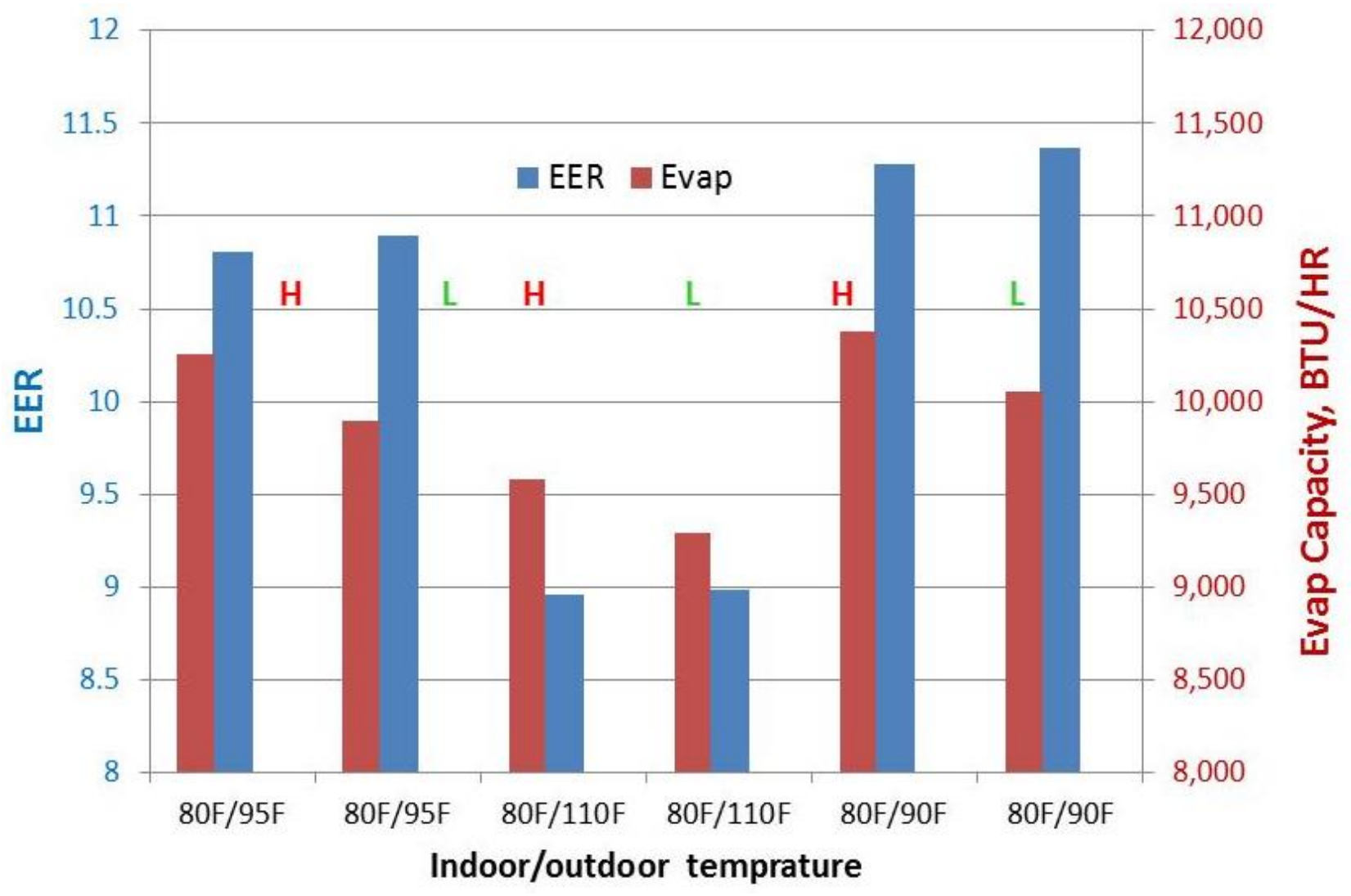

Figure 24: Comparison of EER and system capacity at high $(\mathrm{H})$ and low $(\mathrm{L})$ air flow rates and off-design conditions

Insulating the exposed suction line: To investigate the effect of the increased surface area of the liquid line caused by the addition of the mass flow sensor, the refrigerant flow meter was insulated and the unit was re-tested at the standard conditions. However, no appreciable change in either the EER or the system capacity was noted over the uninsulated case, and hence this exercise was discontinued in future tests.

Elineating the "sling" effect: In order to assess the effect of "slinger" on the performance of the window air-conditioner (WAC), a hole was drilled at the bottom of the WAC in the condenser pan that allowed the condensed water to be collected in a bucket and the fan blowing the air over the condenser without water. The system was run at the standard test conditions and was allowed to reach steady state. The system efficiency was found to decrease by approximately $8 \%$ from the baseline data. No noticeable change was observed in the fan power. The condensate production rate was measured to be about 1 liter/hr.

\section{EXTENSION OF ORNL HPDM TO INCLUDE SPECIFIC FEATURES OF WINDOW AIR CONDITIONER AND ITS VALIDATION}

\section{FEATURES OF ORNL Heat Pump Design Model (HPDM)}

The ORNL's HPDM is a steady-state simulation model that covers most categories of residential and light commercial space cooling, space heating and water heating components, like compressors, heat exchangers, pumps, fans, etc. It is a component-based model that uses Newton-Raphson method to solve simultaneous system equations. The heat exchanger $(\mathrm{HX})$ models are based on fundamentally principles and can simulate detailed geometry and circuitry, and 
accept real air-side (or water side) and refrigerant-side boundary conditions. The component HX models have different levels of complexity, which fall into three categories, i.e. bulk models, phase-to-phase models, and discretized models. The bulk models are usually based on Effectiveness-NTU or UA-LMTD approach, to simulate the component as a whole. The phase-to-phase models separate the refrigerant into vapor, two-phase and liquid regions, with each region having individual air side and refrigerant side entering states. The discretized models use segment-to-segment approach, which divides a heat exchanger into numerous mini-segments with each segment having individual refrigerant and air entering parameters. Such a model may consider possible phase separation; with mini segments being basic building blocks. These are used to build a heat exchanger having arbitrary circuitry, geometry, and represent any boundary conditions. All phase-to-phase and segment-to-segment heat exchanger models are capaable to calculate refrigerant charge inventory. For the system modeling, a component-based modeling framework has been developed that allows connecting steady-state component models in any manner, e.g. simulating a vapor compression system with coupled desiccant wheel and indoor coil; simulating a parallel air-to-refrigerant condenser and water heater, etc. Details of some of the component models are given below.

\section{Compressors:}

- Single-speed Compressor: The model uses AHRI's 10-coefficient compressor map to calculate mass flow rate and power consumption. It simulates energy balance from inlet to outlet using the calculated power and given heat loss ratio; and it also considers the actual suction state to correct the map mass flow and power predictions.

\section{Heat Exchangers:}

- Segment-to-segment fin-and-tube heat exchanger: In a segment-to-segment modeling approach, each tube segment has individual air side and refrigerant side entering states, and may have possible phase transition. Within each segement, an $\varepsilon$-NTU approach is used for heat transfer calculations and air-side fin is simplified as an equivalent annular fin. Both refrigerant and air-side heat transfer and pressure drops are considered. The coil model can simulate arbitrary tube and fin geometries and circuitries and any entering and exit states of refrigerant, misdistribution, two-dimensional air side temperature, and local inputs of humidity and velocity. The tube circuitry and

2-D boundary conditions are provided by an input file. The segment-to-segment modeling approach is also capable of simulating the dehumidification process of water condensing on an $\mathrm{HX}$ coil (i.e. evaporator) by following Braun et al. (1989) methodology, where the driving potential for heat and mass transfer is the enthalpy difference between the inlet air and the saturated air at the refrigerant temperature.

- Segment-to-segment micro-channel HX: In the segment-to-segment modeling approach of a micro-channel HX, each micro-channel port segment has individual air-side and refrigerant-side entering states, and may have possible phase transition. The coil model can simulate arbitrary port (round, triangle, etc.), fin geometries and circuitries (serpentine, slab, etc.), any refrigerant side entering and exit states, misdistribution, and can accept inputs of twodimensional air side temperature, humidity and local air velocity. In addition, the model is also capable of simulating the dehumidification process.

\section{Expansion Devices:}

- Idealized TXV: The degree of superheat at the compressor suction as well as the degree of subcooling at condenser outlet is explicitly specified. 


\section{Fans and Blowers:}

- Single-speed fan: For a given airflow rate, the model uses the fan curve to simulate static head, power consumption, and calculate air-side temperature increment from inlet to outlet.

- Variable-speed fan: The model accepts multiple sets of fan curves, and does linear interpolation between speed levels.

\section{Extension of HPDM to include specific feartures of Window Air Conditioner- HPDM-Flex}

The original ORNL'S HPDM was modified to include the two specific features that are unique to window air conditioner. The water condensed at the evaporator is collected in a water pan at the bottom of the window air conditioner. Due to its low temperature, the condensed water firstly provides subcooling to the submerged subcooler tubing inside this pan, and secondly, this water is sprayed through a 'slinger' over the condenser surface to enhance the condenser air side heat transfer [LBNL (1997)]. The first effect is called the 'enhanced subcooling' and the second is called the 'sling' effect. The new model was named as HPDM-Flex-7.a.1.

\section{ORNL Model HMDP-Flex.7.a.1 Validation}

The HPDM-Flex-7.a.1 was caliberated against the experimental data of the window air conditioner at both the design and the off-design conditions i.e. different ambient conditions.

\section{Multipliers or correction factors}

One of the factors that need to be correlated is the ratio of the measured power to the map power of the compressor. This is shown in Figure 25, where the 'solid line' represents the correction factor for the compressor-map predicted power that would need to be added into the model in order to predict the correct compressor power at different ambient conditions.

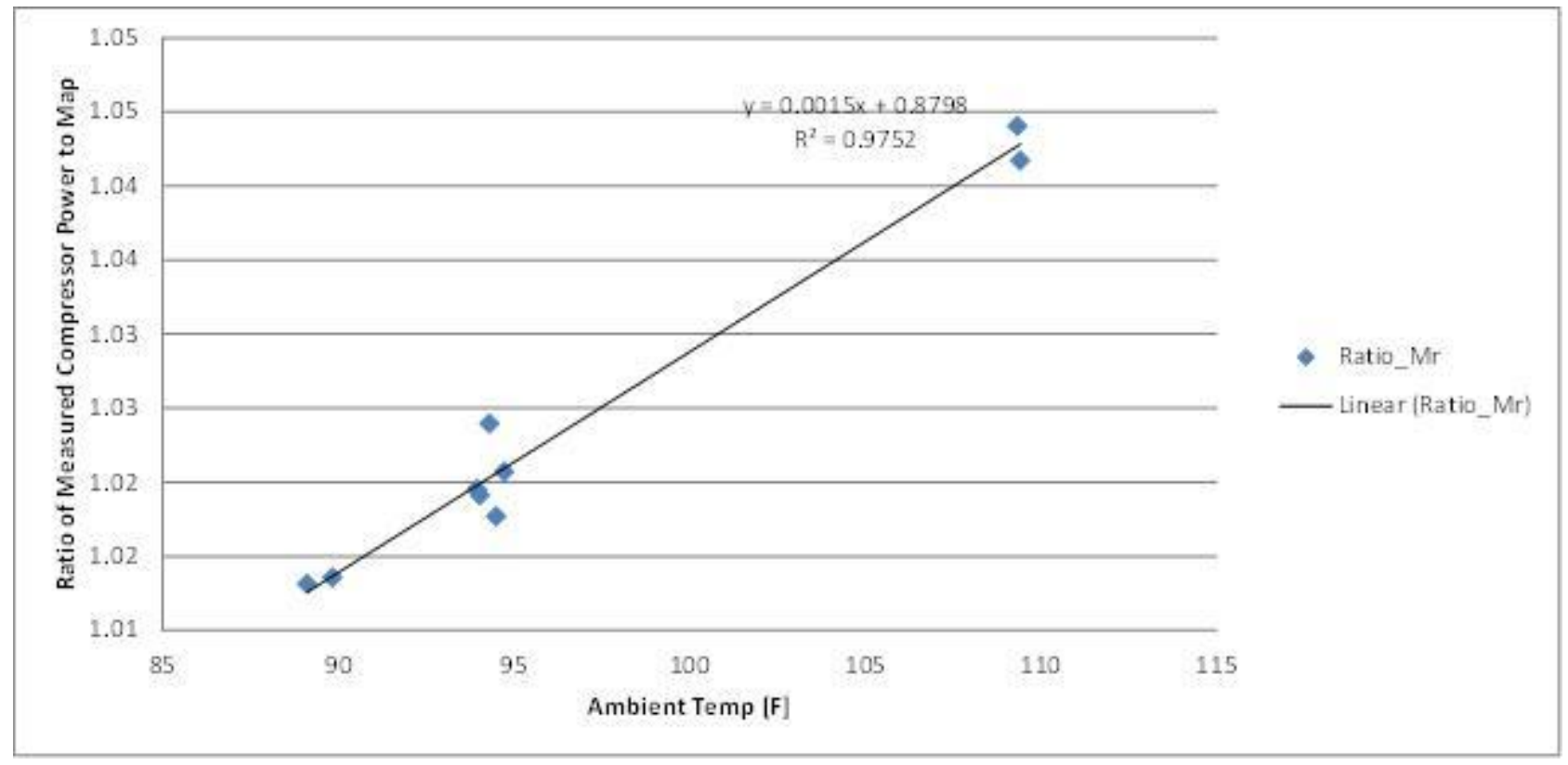

Figure 25: Variation of 'ratio of measured compressor power' to 'map power' at different ambient temperatures 
The condenser heat transfer enhancement ratio due to the sling effect at different ambient temperatures is shown in Figure 26. It may be noted here that the condenser heat transfer is enhanced by a factor between 1.5 and 2.5 due to the sling effect, which is rather high.

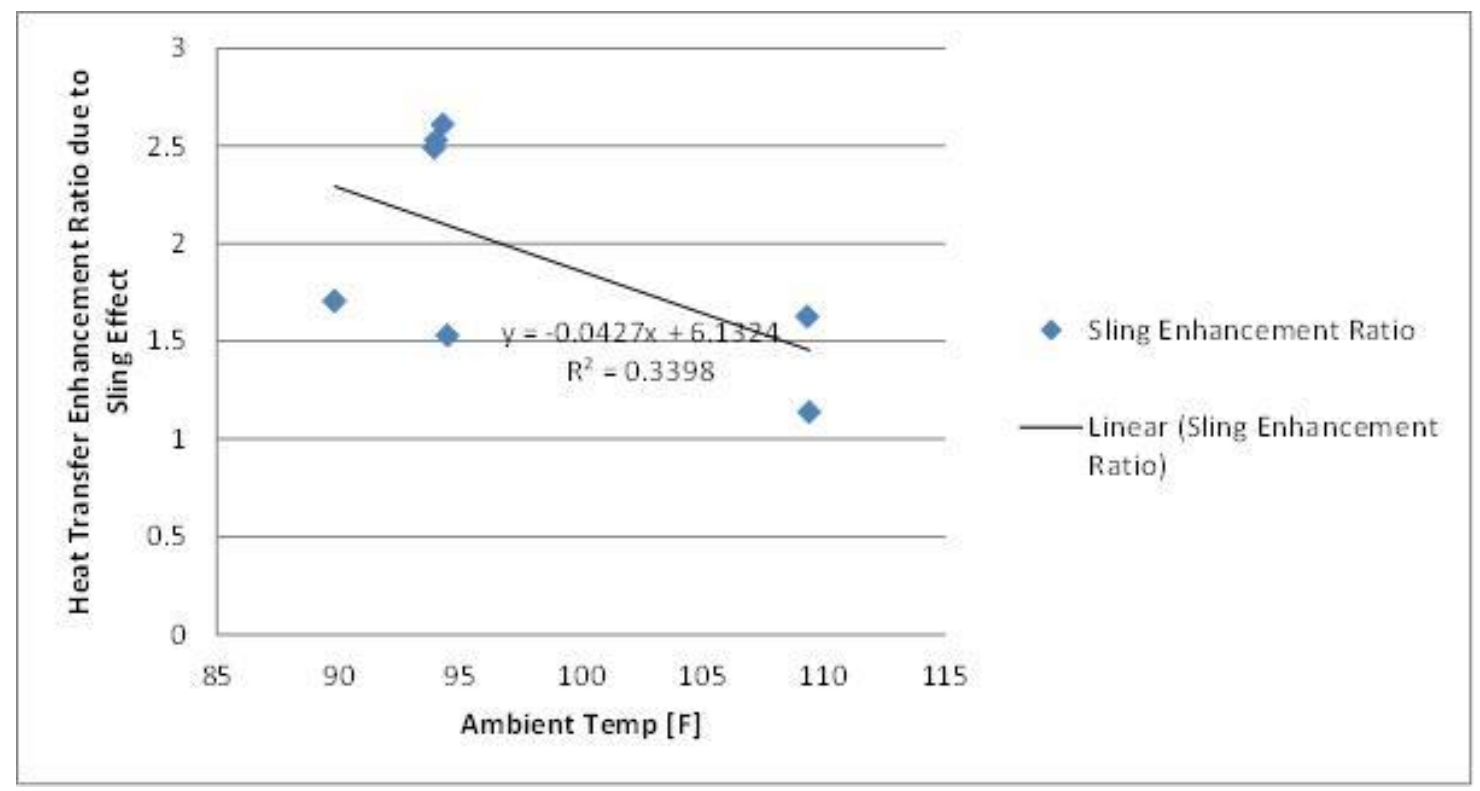

Figure 26: Variation of 'Heat transfer enhancement ratio' to 'sling effect' at different ambient temperatures

The ratio of the compressor heat loss to the compressor power input at different ambient conditions is plotted in Figure 27. It is surprising to note that the compressor shell heat loss is varying between 65 and $90 \%$. This is significantly higher than the heat loss that is generally observed to being less than $40 \%$ in a normal compressor. This occurs due to 'sling effect' and the moist air blowing over and around the compressor.

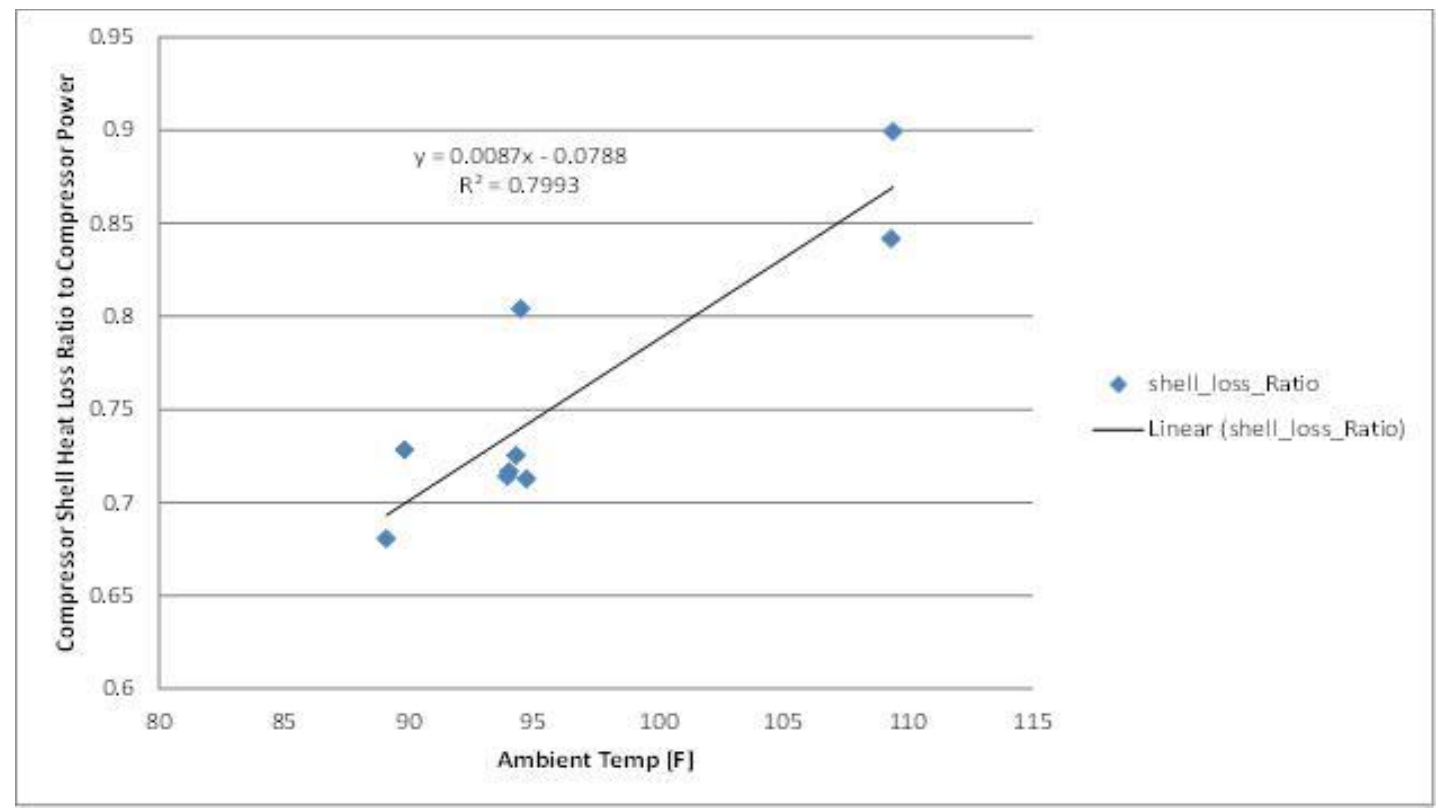

Figure 27: Variation of 'compressor shell heat loss ratio' to 'compressor power' at different ambient temperatures 


\section{Comparison of ORNL Model HMDP-Flex.7.a.1 With the Test Data}

After the model had been validated with some of the experimental data, the model predictions were compared with all test data. The measured EER is plotted against simulated EER in Figure 28 . The model predictions agree to within $-0.5 \%$ to $+6.5 \%$ with a standard deviation being limited to $2.7 \%$. This result is quite encouraging.

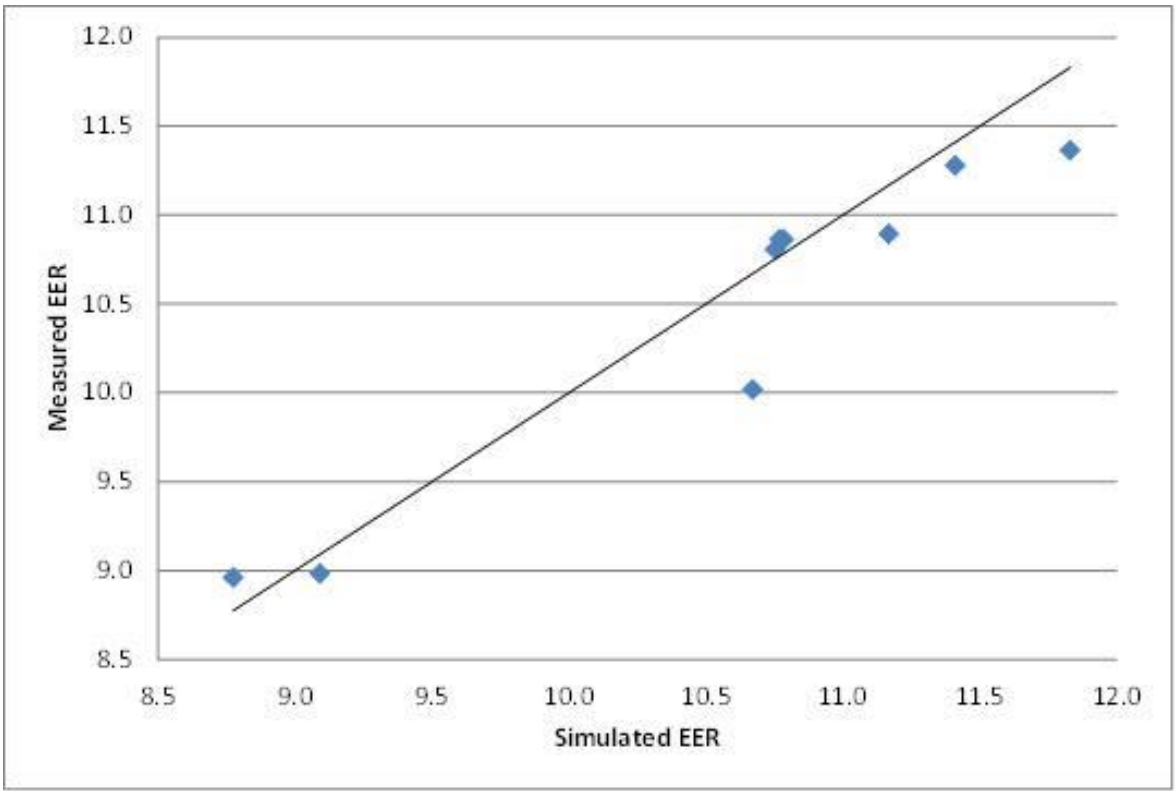

Figure 28: Variation of 'measured EER' with 'simulated EER' at different ambient temperatures

The validated model was used to predict the system performance with different system features in order to achieve the targeted EER of 13. This variation is shown in a bar chart in Figure 29. The first bar shows the baseline EER (=10.8) of the current design that has been tested and simulated. The next bar shows that the system EER may be improved (to 10.95) but only slightly if the air flow distributions were improved in the two heat exchangers. This is because the indoor $\mathrm{HX}$ was already oversized and the better heat transfer strategy may not enhance the efficiency noticably. The next bar shows the enhancement in EER (to 11.7) if the current fan motor was replaced with an ECM motor that is currently available in the open market with $55 \%$ less power input. The fourth bar shows the system EER $(=12.2)$ if the current compressor (with EER=9.7) is replaced with an higher EER $(=10.2)$ compressor that is also available in the open market. Finally the last bar shows that the target EER (of 13) may be achieved by replacing the 10.2 EER compressor with an 11 EER compressor. 


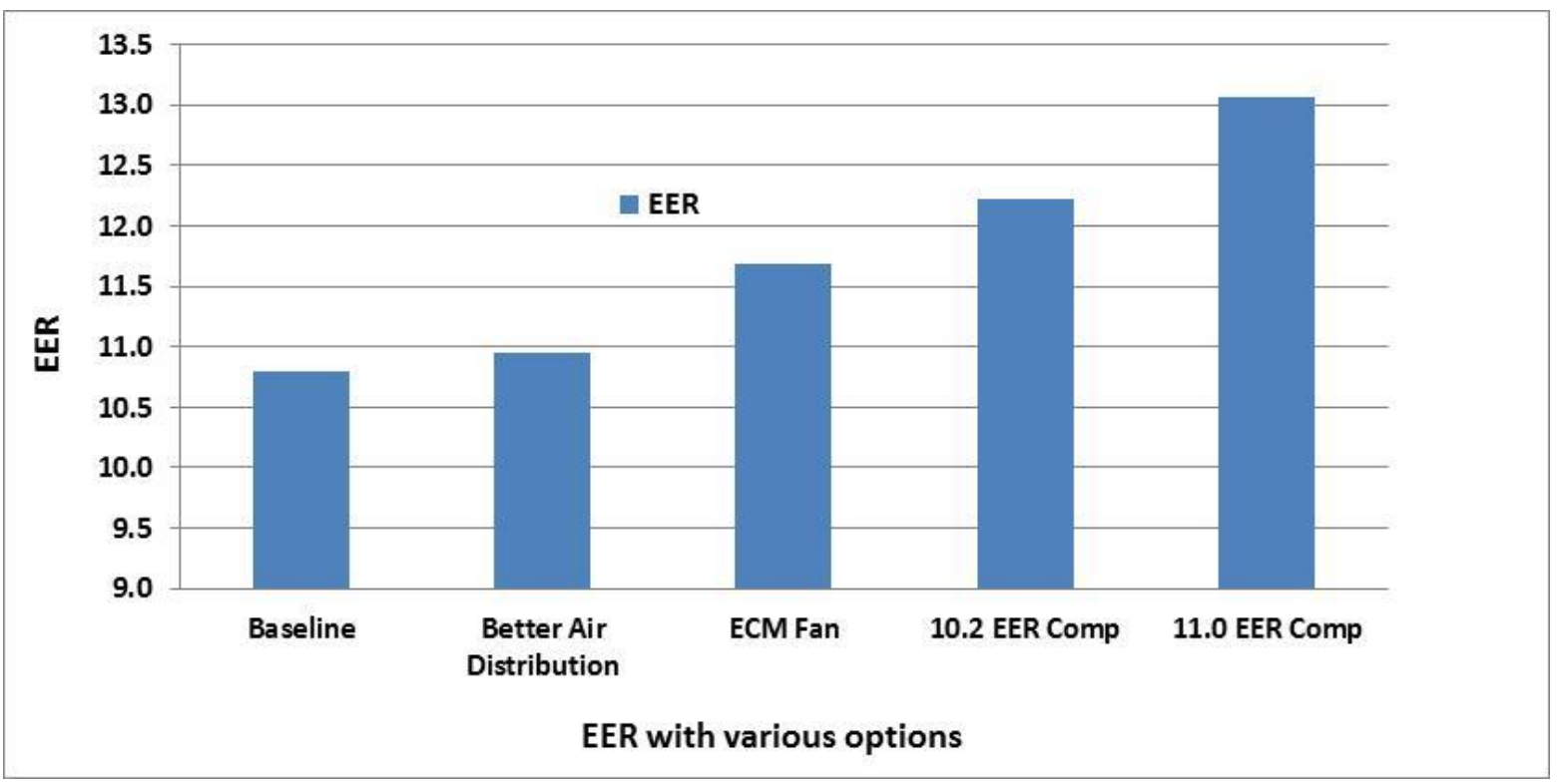

Figure 29: System EER with individual component design improvements 


\subsection{EFFICIENCY ENHANCEMENT OPTIONS AND TESTING OF THE PROTOTYPE}

In order to develop high efficiency WAC, several primary design strategies were considered, including the following-

(1) Use of micro-channel heat exchangers (MCHXs)

(2) Reducing thermal bridging and internal air leakage through the divider wall

(3) Use of high EER compressor

(4) Use of brushless DC fan motor in place of AC induction fan motor

(5) Reduce unit capacity from 10,000BTU/hr to $8000 \mathrm{BTU} / \mathrm{hr}$ by downsizing its compressor

(6) Increase the molar concentration of R32 (from $70 \%$ to $85 \%$ ) in R410A

MCHX: Since the current designs of micro-channel heat exchangers (MCHXs) use lower fin density (e.g. 16 fins per inch on evaporator) and the chaises of the WAC has fixed dimensions, it is difficult to match the face area of the round tube plate fin coils with that of the micro-channel. Therefore, despite having higher expectations from MCHXs for most HVAC\&R applications, MCHXs are not as deep as the copper tube heat exchangers and therefore, offer lower performance (i.e. less capacity and less EER) than the round tube plate fin coils heat exchanger. Additionally, MCHXs result in higher pressure drops, lower refrigeration capacity and hence lower EER. Therefore, this feature was found to be impractical to improve the efficiency of a WAC.

Reducing thermal bridging and internal air leakage: Although some of the low efficiency units may suffer from thermal bridging and internal air leakage through the divider wall, the unit under investigation was well engineered and had hardly any room for reducing either the thermal bridging or the internal air leakage through the divider wall.

With a solid baseline established, the focus of work was shifted to the development of the high efficiency prototype. To this end, the following modifications were made to the unit and the performance increase of various combinations of these evaluated.

(7) Replace AC induction motor with brushless DC motor

(8) Reduce unit capacity from 10000BTU/hr to 8000BTU/hr

(9) Increase the molar concentration of R32 (from $70 \%$ to $85 \%$ ) in R410A

\section{TESTING AND RESULTS}

\section{ECM Fan Motor}

The first modification which was tested is the replacement of the stock AC induction motor with a permanent magnet ECM. The factory motor is a permanent split capacitor type, which has a rated output of 95W. During the baseline tests, the motor was found to consume 177W, 158W and 137W at the high (1343 RPM), medium (1256 RPM), and low (1150 RPM) fan speeds respectively. The motor which was used to replace this, is a sensorless ECM and is rated at $100 \mathrm{~W}$ mechanical output. To drive the ECM, a Texas Instruments TMS320C2000, high voltage motor development kit was used. The hardware supplied with the kit uses a flux integration method to control commutation of the motor and the software is set up to automatically measure the physical characteristics of a specific motor (resistance, inductance, etc.) such that the commutation algorithm is tuned to the ECM being used. The motor drive box has two power inputs which 
are plugged into a two socket extension cord. A current transformer on the extension cord is used to measure the total AC power used by the ECM motor and the drive box. It is worthwhile to note here that all power use for any of the ECM motors presented in this study include the inverter box parasitic power. Additionally, due to the importance of accurate power measurements to this study, the readings given by the power tranducers which are integrated with the DAQ system are periodically validated during each test using a separate handheld meter. The ECM driver used for the fan motor is shown in Figure 30.

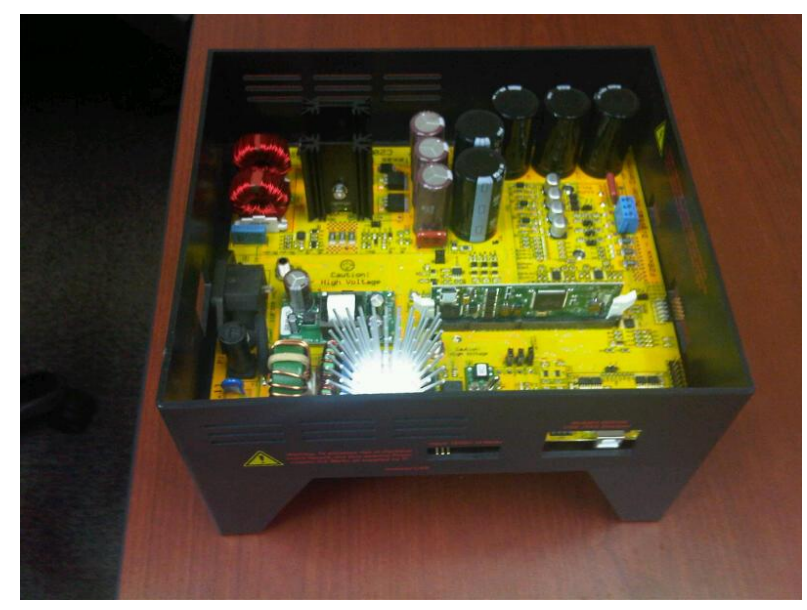

Figure 30: Driver for Brushless DC motor

The initial tests using the ECM fan motor keep the rest of the components stock. The system was charged to the same level as the baseline case and the test chambers were run at the AHAM/ASHRAE condition (95F 40.1\%RH outdoor, 80F $50.5 \% \mathrm{RH}$ indoor). The ECM fan motor was then run at the same RPM as the high and low settings of the stock fan. Data was collected at $5 \mathrm{~s}$ intervals for 30 minutes at each speed and 30 minutes was allocated for the system to stabilize after the RPM is changed. Figure 31 shows the results of this initial test.

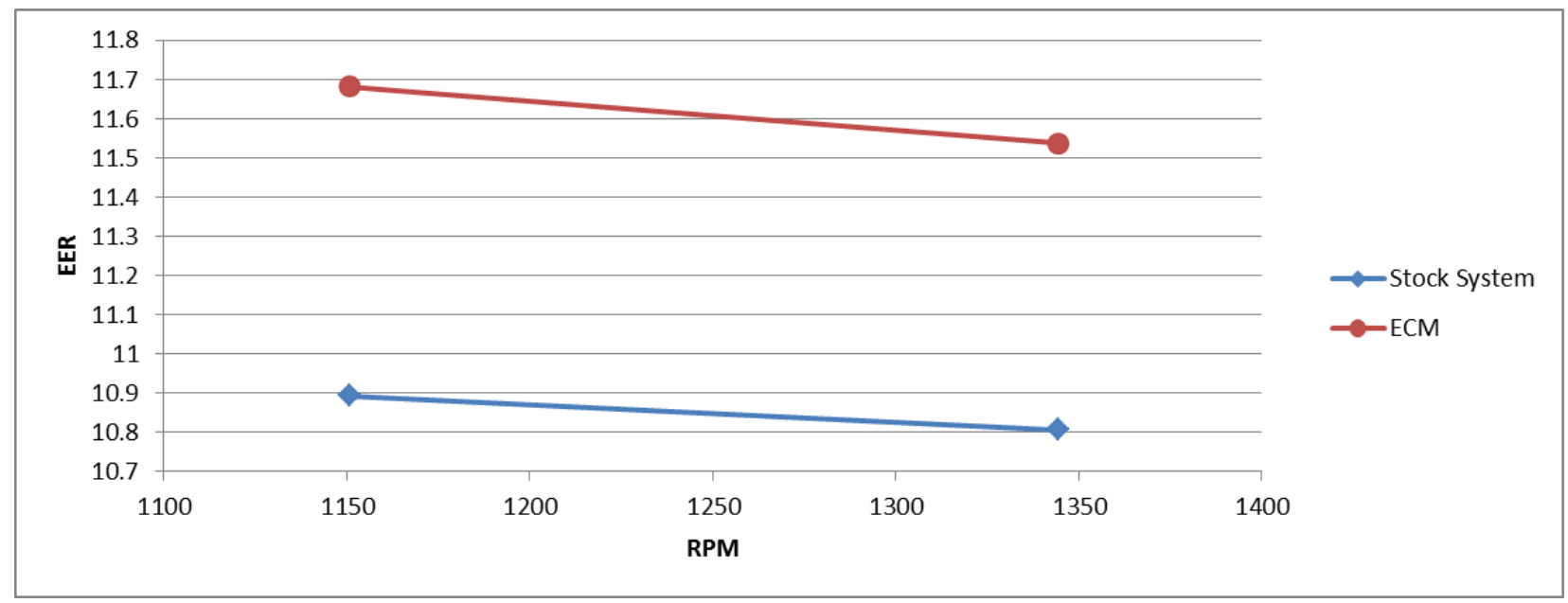

Figure 31: Variation of EER with Fan Speed for Stock System and System with ECM Fan

As shown, a significant increase in system efficiency was possible through this change alone. One observation which was made during the analysis was the apparent dual nature of the improvement. The immediate effect of the swap was the decrease in the power consumed by the fan. In addition to this savings, the fact that the ECM is more efficient than the 
stock induction motor means that significantly less heat is generated inside of the condenser section of the unit for a given fan RPM. This effect manifested itself in a lower condenser air inlet temp and a subsequently lower condensing pressure with the ECM installed.

\section{System Capacity Reduction}

In an attempt to further increase system efficiency, the stock $10000 \mathrm{BTU} / \mathrm{hr}$ compressor was replaced with one rated at $8000 \mathrm{BTU} / \mathrm{hr}$. The stock heat exchangers were maintained and because they were essentially oversized for the derated unit, the system can be run at a lower pressure ratio than the stock system. To control this, the capillary tube on the baseline unit was replaced with a fine adjust needle valve. A sight glass was also added at the compressor suction of the system to avoid slugging the compressor by opening the valve too far. Figures 32 and 33 show the needle valve and sight glass installed on the test unit.

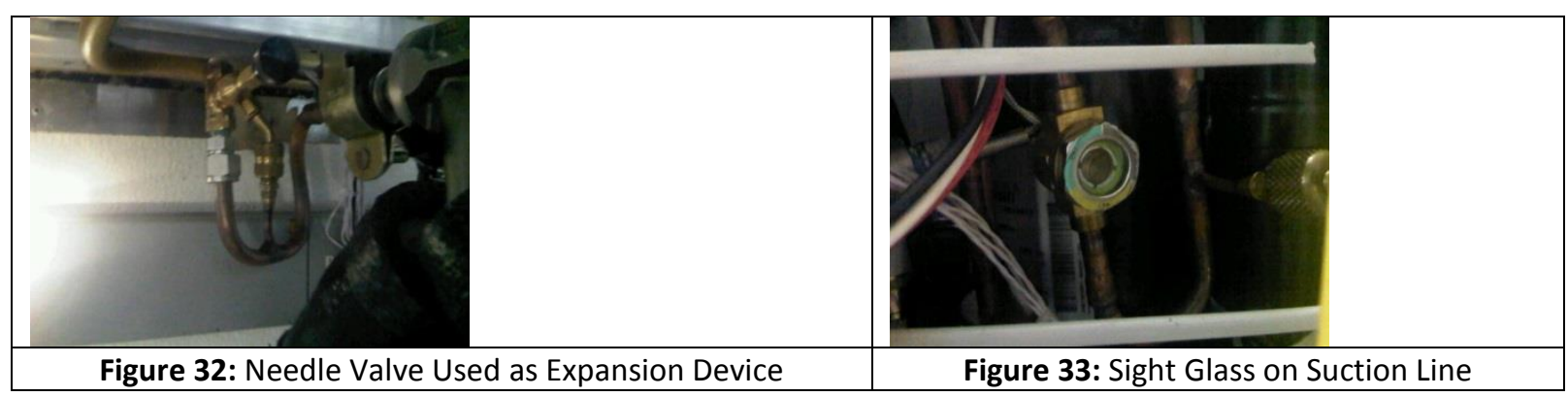

Because the system volume is changed by the integration of the smaller compressor, a charge study similar to that performed with the baseline unit was performed. The system was initially charged to $680 \mathrm{gm}$. The chamber was brought up to the rated conditions and the stock AC motor fan was run at the high setting. It is worthwhile to note here that the measured fan RPM was slightly higher than it was for the stock system (1420 RPM vs 1343 for stock). One possible reason for this is that the lower capacity unit has less dehumidification capacity than stock so the water level in maintained in the pan would be lower. This would result in less drag on the condenser fan and a possible increase in speed. Charge was then added in increments of $20 \mathrm{gm}$ and the needle valve adjusted to maintain a suction side superheat of around 8F. After the adjustment the system was allowed to stabilize for $1 / 2$ an hour and then a half hour of data collected. Figure 34 shows the variation of system efficiency with charge.

As shown, a maximum efficiency of 11.46 was achieved at a charge level of $680 \mathrm{gm}$. This represents a $6.2 \%$ improvement in efficiency over the stock case, at a capacity of $8626 \mathrm{BTU} / \mathrm{hr}$. One point which is worthwhile to mention, is that while the charge study does show some degree of variation of efficiency with changes in charge, since the superheat is being maintained at a constant value with the needle valve, these changes were relatively small over the range tested. 


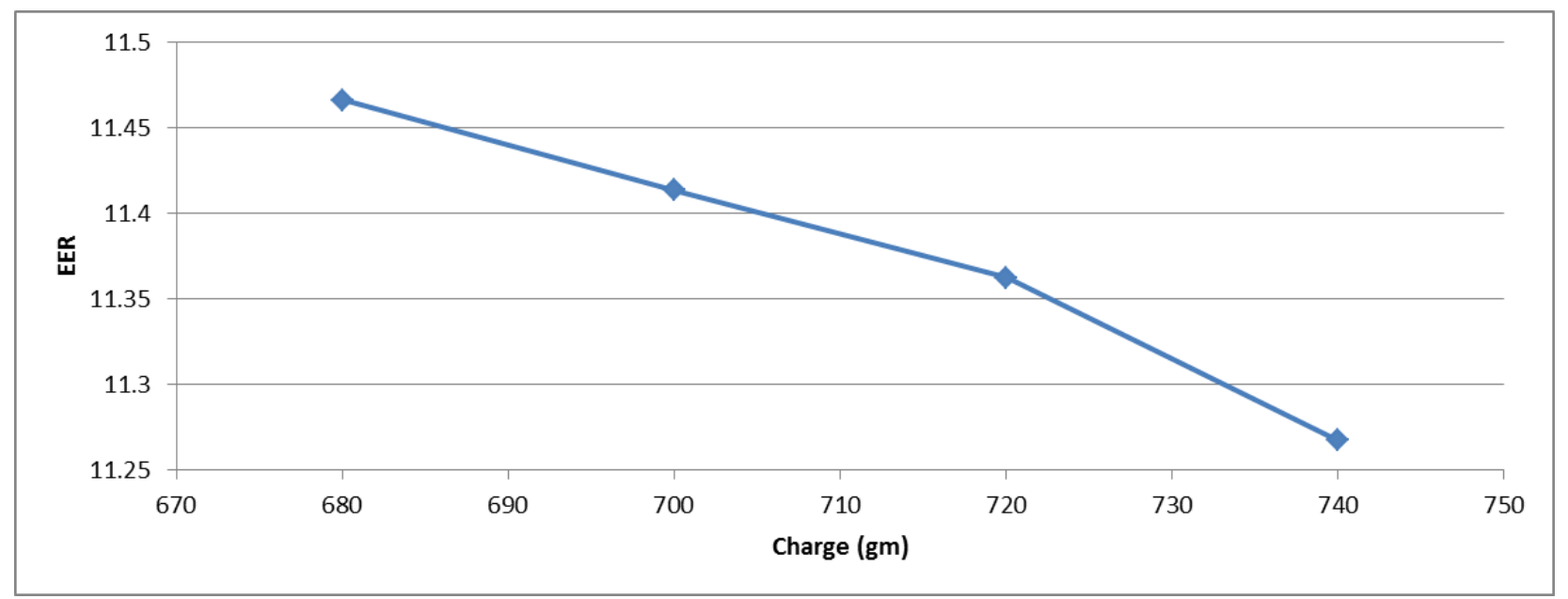

Figure 34: Variation of Efficiency with Charge for the Reduced Capacity System

\section{System Capacity Reduction and ECM Fan Motor}

With the incremental improvement from the smaller compressor quantified, the same reduced capacity system is tested with the ECM fan motor. The unit was charged to $690 \mathrm{gm}$ and the airflow was varied between 1050 and 1400 RPM, again with time allocated for the unit to stabilize between changes. The needle valve was adjusted at each airflow rate to maintain between $7.5 \mathrm{~F}$ and 8.0F suction superheat. Figure 35 shows the variation of system efficiency with fan RPM.

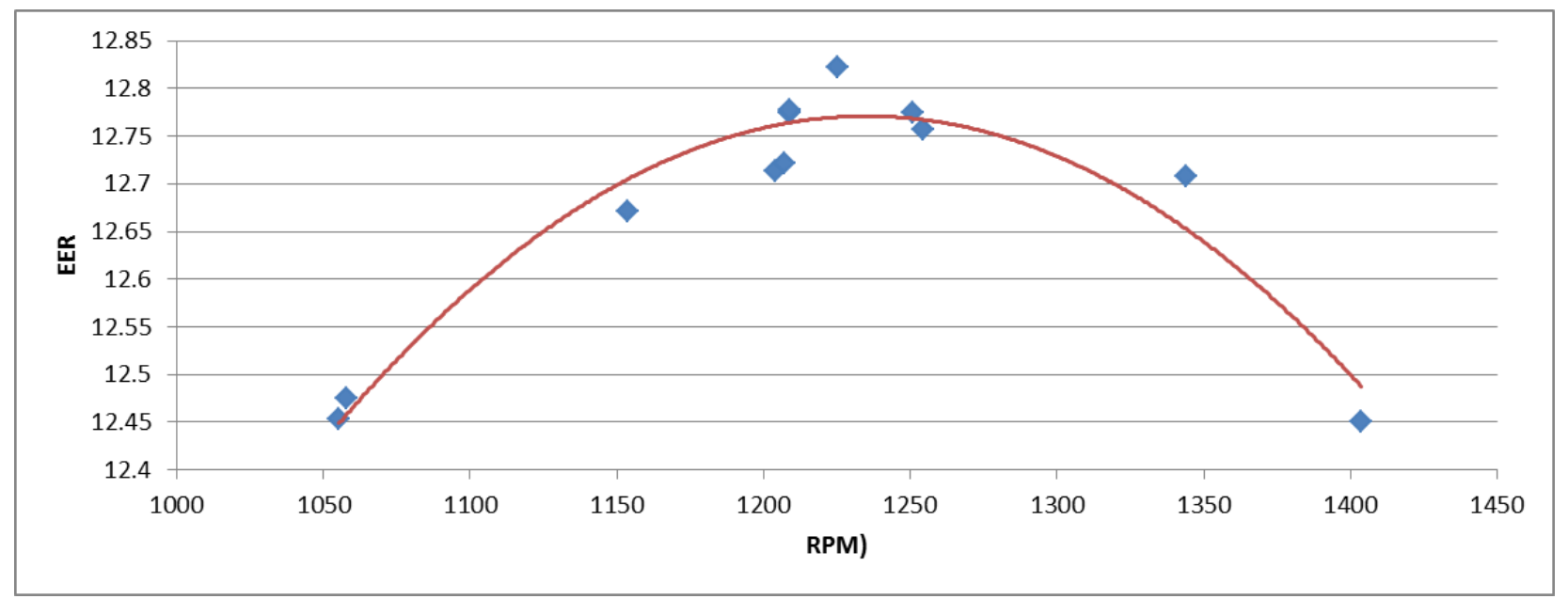

Figure 35: Variation of Efficiency with Fan RPM for the Reduced Capacity System with ECM Fan

The test data is fit with a $2^{\text {nd }}$ order polynomial which predicts a maximum efficiency of 12.76 at a fan speed of 1230 RPM. The corresponding capacity is $8350 \mathrm{BTU} / \mathrm{hr}$. This represents a $18.1 \%$ improvement in efficiency over the stock case. 


\section{System Capacity Reduction, ECM Fan Motor, and 85\% R32}

The refrigerant R410A is a binary 70/30 (by mole) mixture of the two pure substances R32 and R125. An increase in the concentration of R32 has the potential to increase system capacity for a given mass flow rate at the expense of the mixture becoming more flammable. To explore the effects of the higher R32 concentration, the unit was evacuated and charged with a an 85/15 molar mix of the two refrigerants. Due to time constraints, this test was run with the 8000 BTU/hr compressor and ECM fan instead of starting with the stock compressor and AC fan motor. As before, a charge study was conducted with the optimum charge being found to be $620 \mathrm{gm}$. Tests were run at two airflow rates with varying degrees of suction superheat. Figures 36 and 37 show the results of these tests.

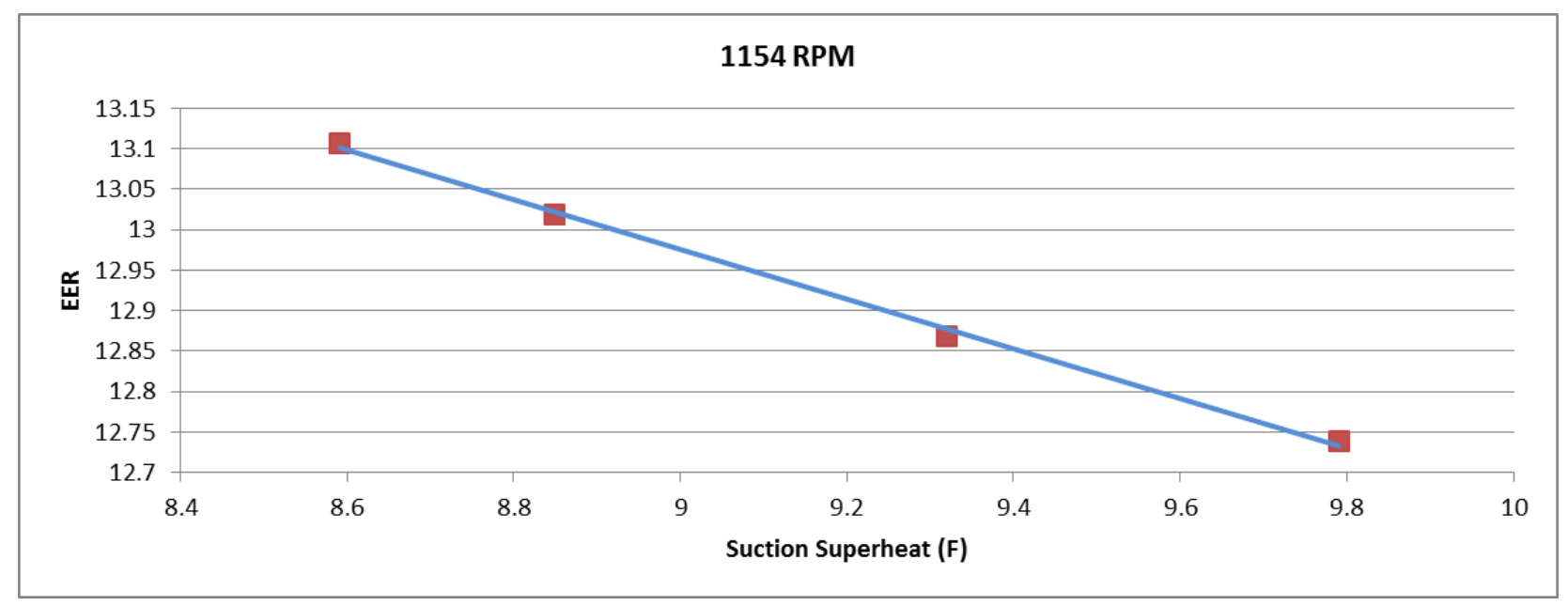

Figure 36: EER vs. Superheat for Reduced Capacity System with 85/15 Mix at Low ECM Fan Speed

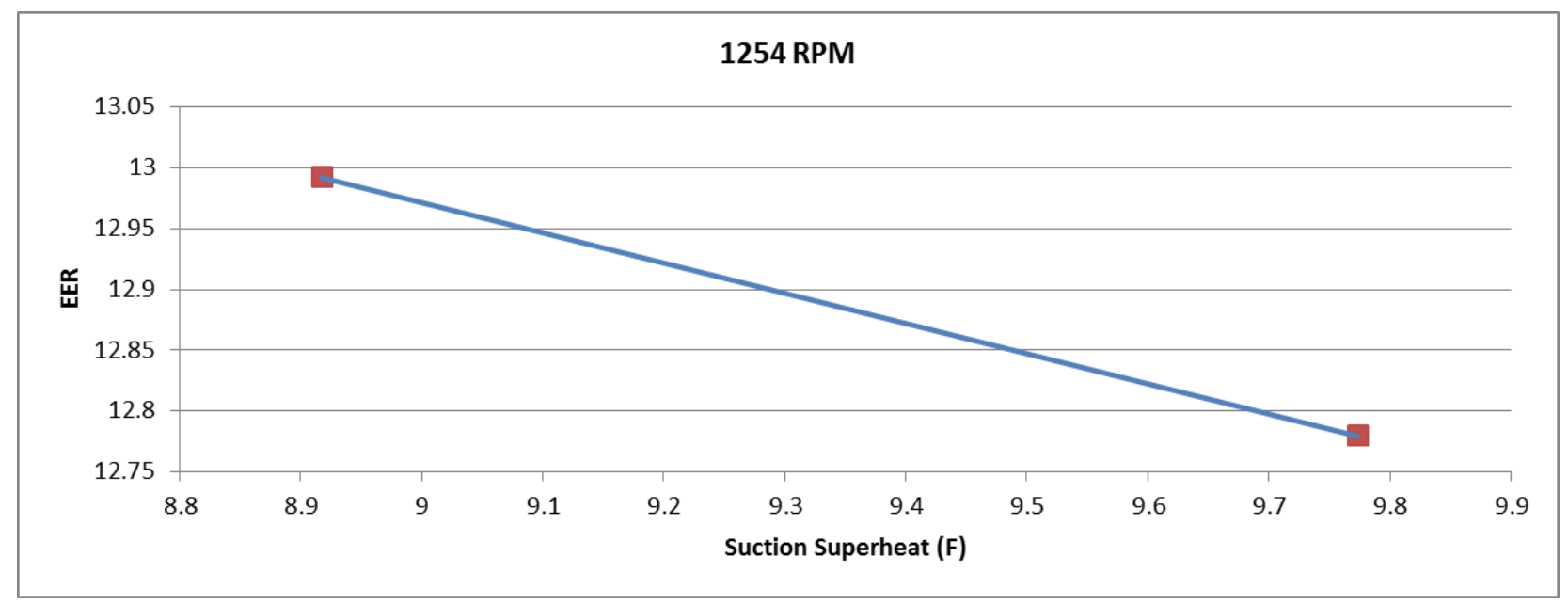

Figure 37: EER vs. Superheat for Reduced Capacity System with 85/15 Mix at High ECM Fan Speed

As shown, a maximum EER of 13.11 was measured at the lower airflow and a superheat of around $8.6 \mathrm{~F}$. This represents an $21.4 \%$ improvement over the stock case. It is important to note here that, while the target EER of 13 was exceeded in this test, the EER may be lower for the official air side 'energy balance' test and also higher superheat being desirable when using a mixture with higher R32 concentration. 
With the performance of the stock system established, several performance enhancing strategies were identified and tested over the course of the past several months. Table 9 summarizes the tests conducted and the percent improvement of each over the baseline performance., while Figure 38 displays the increamental EER enhancements and the corresponding system capacity for each option from stock (base unit) to the mixture of R32 ( $85 \%$ by mole) and R125 (15\% by mole).

Table 9: Summary of test results of the prototype

\begin{tabular}{|l|l|l|l|l|l|}
\hline \multicolumn{1}{|c|}{ Test } & ECM Fan & Reduced Cap & \multicolumn{1}{|c|}{ R32 } & $\begin{array}{c}\text { Max EER } \\
\text { Tested }\end{array}$ & $\begin{array}{c}\text { \% Increase } \\
\text { over stock }\end{array}$ \\
\hline Baseline & no & no & no & 10.80 & $0 \%$ \\
\hline Test 1 & yes & no & no & 11.54 & $6.9 \%$ \\
\hline Test 2 & no & yes & no & 11.46 & $6.2 \%$ \\
\hline Test 3 & yes & yes & no & 12.77 & $18.1 \%$ \\
\hline Test 4 & yes & yes & yes & 13.11 & $21.4 \%$ \\
\hline
\end{tabular}

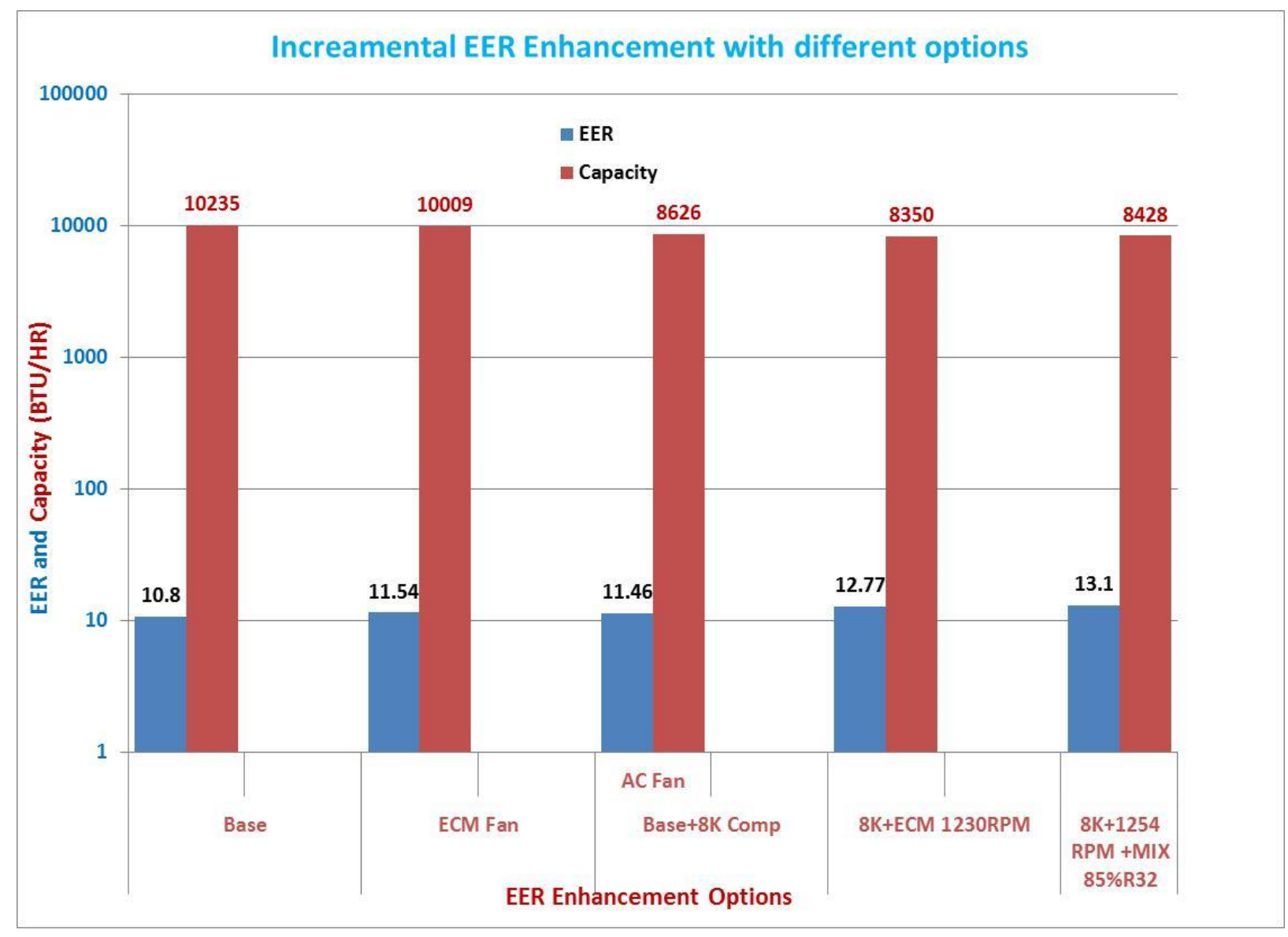

Figure 38: Increamental enhancement in EER with corresponding system capacity with different options 


\section{Discussion and the way forward}

Each of the modifications tested here under laboratory conditions, comes with its own incremental cost and engineering challenges with regards to the eventual goal of producing a marketable, high-efficiency window air conditioner. The most straightforward approach, would be to simply run the unit at the reduced capacity as in test 2 . This strategy would only involve changing the compressor to the smaller unit and resizing the capillary tubes to obtain a unit which would run near $8626 \mathrm{BTU} / \mathrm{hr}$ at an EER of around 11.47. Although this case was not tested, this number could most likely be further improved by running the stock AC induction fan motor at either the low or medium settings such that the airflow of the unit is scaled back along with the capacity. A unit like this could most likely be produced for at or near the same cost as the stock 10K system although its efficiency would not meet the target EER of 13.

The ECM fan motor was found to be a major improvement over the AC induction motor both for its main effect of using less power as well as the secondary effect of not dumping as much heat into the condenser section of the unit. From an engineering perspective, the integration of the ECM was straightforward as the dimensions of the motor used were well matched to the existing shroud assembly. For the tests, the motor was driven using an external inverter. The development of a marketable window unit would require the development of an inverter which would fit in the existing controls section of the stock chassis. This is not deemed an insurmountable obstacle both in terms of available space in the unit or the development of a suitable motor commutation algorithm. Additionally, although it is recognized that the ECM fan and its controller would be more expensive than the motor and controller in the stock system, it is felt that this incremental increase in the unit production cost does not put this solution out of the realm of feasibility.

For the cases tested, the increase in the R32 concentration of the refrigerant was found to give an incremental improvement over the standard R410a mixture. While this approach requires very little in the way of hardware changes and would not significantly add to the cost of the unit, the increased flammability of the mix and the fact that it is different than that which everything else uses could be detrimental to its widespread acceptance.

The tests conducted show that an efficiency of 11.54 EER can be achieved through the integration of an ECM fan motor, maintaining essentially the same capacity and airflow as the stock unit. This represents an increase of $6.9 \%$ over the baseline performance.

For the case where the capacity was reduced (by incorporating an 8000BTU/hr compressor and running with the stock fan motor and airflow rate), the best measured efficiency was found to be 11.47 EER at a capacity of 8626 BTU/hr. This represents an increase of $6.2 \%$ over the baseline. When the ECM fan was incorporated into the reduced capacity unit and the airflow scaled down to match the lower output, a maximum efficiency of 12.76 EER was measured at a capacity of $8350 \mathrm{BTU} / \mathrm{hr}$ for an increase of $18.1 \%$ over stock. A final test of the reduced capacity unit was performed using the higher concentration of R32 ( $85 \%$ by mole) than the standard R410A mix. This change in conjunction with the ECM fan at reduced RPM yielded a maximum efficiency of 13.11 EER at a capacity of $8428 \mathrm{BTU} / \mathrm{hr}$ for an efficiency improvement of $21.4 \%$. It is worthwhile to mention that all efficiencies and capacities presented here are based upon the refrigerant side energy balance, which may lower on the air-side energy balance.

The tests suggest that achieving an EER of 13 or greater in a window air conditioner is feasible using currently available technology. With the potential efficiency increase of each proposed modification quantified, the feasibility (both engineering and economic) of incorporating each into a marketable product would now be further explored. 


\subsection{ASSESSMENT OF ALTERNATIVE REFRIGERANT OPTIONS USING HPDM-Flex-}

\section{7.a.1}

Due to the efficiency improvement measured using the $85 \%$ molar R32 mixture, some thought was given to other alternative refrigerant possibilities which could potentially improve performance or reduce GWP. Although a number of alternative refrigerant options were available to replace R410A [such as R134a, mixture of R32(85\% by mole) and R125 (15\% by mole), R32, R600a, R290, R1234yf, R1234ze], these, except R134a, are all slightly flammable and there is no rotary compressor currently available in the open market at this stage that could run at $115 \mathrm{~V}$ and $60 \mathrm{~Hz}$. Due to the compact size configuration and small refrigerant charge in a WAC, however, the flammability of the refrigerant is less of a concern than it would be for larger systems. Because of this, these refrigerants were evaluated as a potential alternative to R410A using modified ORNL heat pump design model with WAC features. The model was calibrated based on the test data, and was used to perform the parametric study to assess the performance of the WAC for the base capacity of 10,000 BTU/HR with above mentioned alternative refrigerants. The associated effects of each refrigerant were investigated on the system efficiency, component sizing, compressor discharge temperature etc.

Alternative Refrigerants- R134a, R32, Mixture of R32(85\% by mole) and R125 (15\% by mole), Natural Refrigerants (R600a, R290), and HFOs (R1234yf and R1234ze). The GWPs of these refrigerants are given in Table 10. All refrigerant properties were calculated using REFPROP 9.1 [NIST 2014]. The comparisons are presented in terms of efficiency, compressor displacement volume, heat exchanger saturation temperature changes, and compressor discharge temperature.

Table 10: Global Warming Potential (GWP) of the Alternative Refrigerants

\begin{tabular}{|l|l|l|l|l|l|l|l|l|}
\hline & R410A & R32 & R134a & R600a & R290 & R1234yf & R1234ze & R32-90\%/R125-10\% \\
\hline GWP & 2079 & 675 & 1430 & 20 & 20 & 4 & 6 & 1251 \\
\hline
\end{tabular}

Assumptions: In order to perform the modelling, following assumptions were made for consistent comparison of each refrigerant for the same operating conditions-

1. Both the isentropic and the volumetric efficiencies of the compressor were assumed to be the same as that of R410A compressor, and

2. The compressor volume was adjusted to match the same cooling capacity of $10,000 \mathrm{BTU} / \mathrm{HR}$

The "slinger" Effect: The slinger sprays water droplets into the air stream flowing over the condenser coil surface. Instead of modeling the heat and mass transfer process, a simple approach was adopted here to treat the slinger effect as an air side heat transfer enhancement factor from the experimental data. Figure 39 compares the model predicted air side heat transfer enhancement multipliers due to the sling effect to laboratory data deduced heat transfer multipliers, as a function of the ambient temperature. The laboratory data deduced heat transfer multipliers were obtained by adjusting air side heat transfer coefficient of the condenser model to match the measured performance, assuming no sling effect. Since there is a large dispersion in the laboratory measurements, deviations between the laboratory deduced and model predicted heat transfer multipliers can be up to $30 \%$. However, the average multipliers are close; with laboratory data deduced multiplier being 1.33, and the model predicted average multiplier being 1.24. 


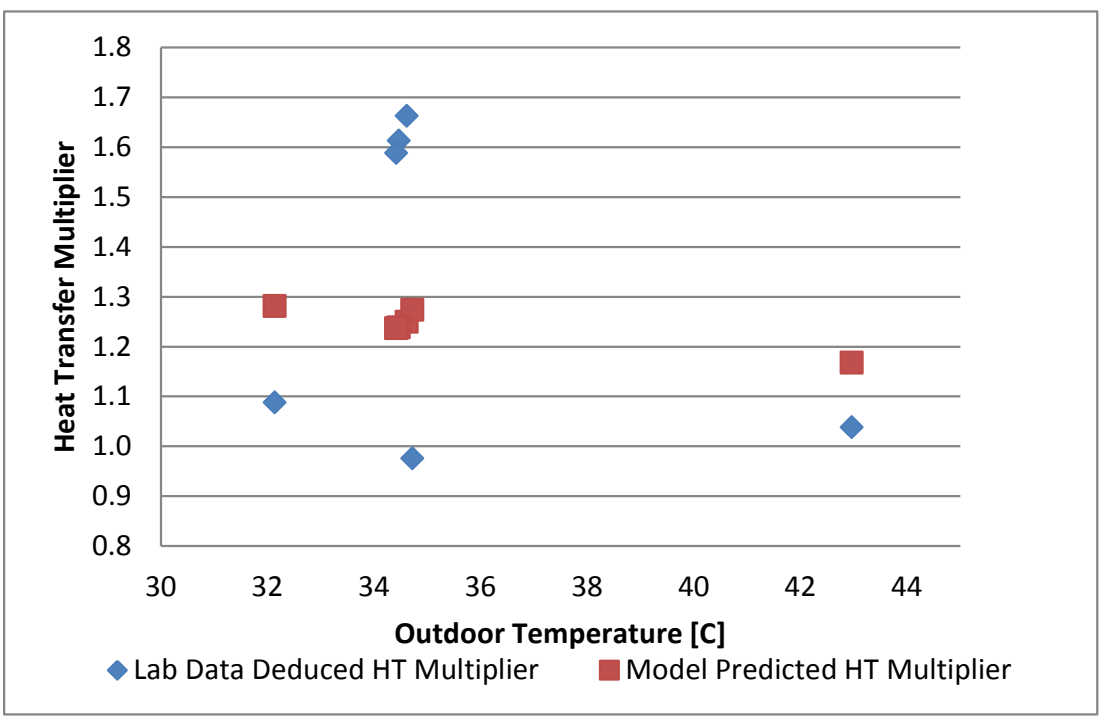

Figure 39: Heat transfer enhancement ratio due to 'sling effect' vs. outdoor temperature

\section{OPTIMIZATION OF HEAT EXCHANGER CIRCUITRY}

In order to identify the best potential replacement for R410A in WACs, simulations were performed at the standard outdoor and indoor dry bulb/wet bulb temperature conditions specified earlier. The compressor displacement volume was automatically adjusted to facilitate the same cooling capacity of $10,000 \mathrm{Btu} / \mathrm{h}(2.93 \mathrm{~kW})$, for various refrigerants, while assuming the same isentropic efficiency of $66 \%$ and volumetric efficiency of $86 \%$ as determined for the WAC with R410A. The degrees of condenser sub-cooling and the evaporator superheat are held at $10 \circ \mathrm{R}$ (5.6-K). All the simulations were run with the submerged sub-cooler and slinger. The relationship between the pressure loss and the drop in saturation temperature drop is unique for any refrigerant. To have a fair comparison among various refrigerants and to achieve the best efficiency of the WAC, the heat exchanger surface area and tube numbers were fixed both for the evaporator and condenser and parametric simulations were performed to optimize the number of circuits of the condenser and evaporator for each alternative refrigerant. Both the evaporator and condenser circuitries were optimized to maximize the system cooling EER while maintaining a constant cooling capacity. Figure 40 shows the optimized evaporator and condenser circuit numbers of all the refrigerant types.

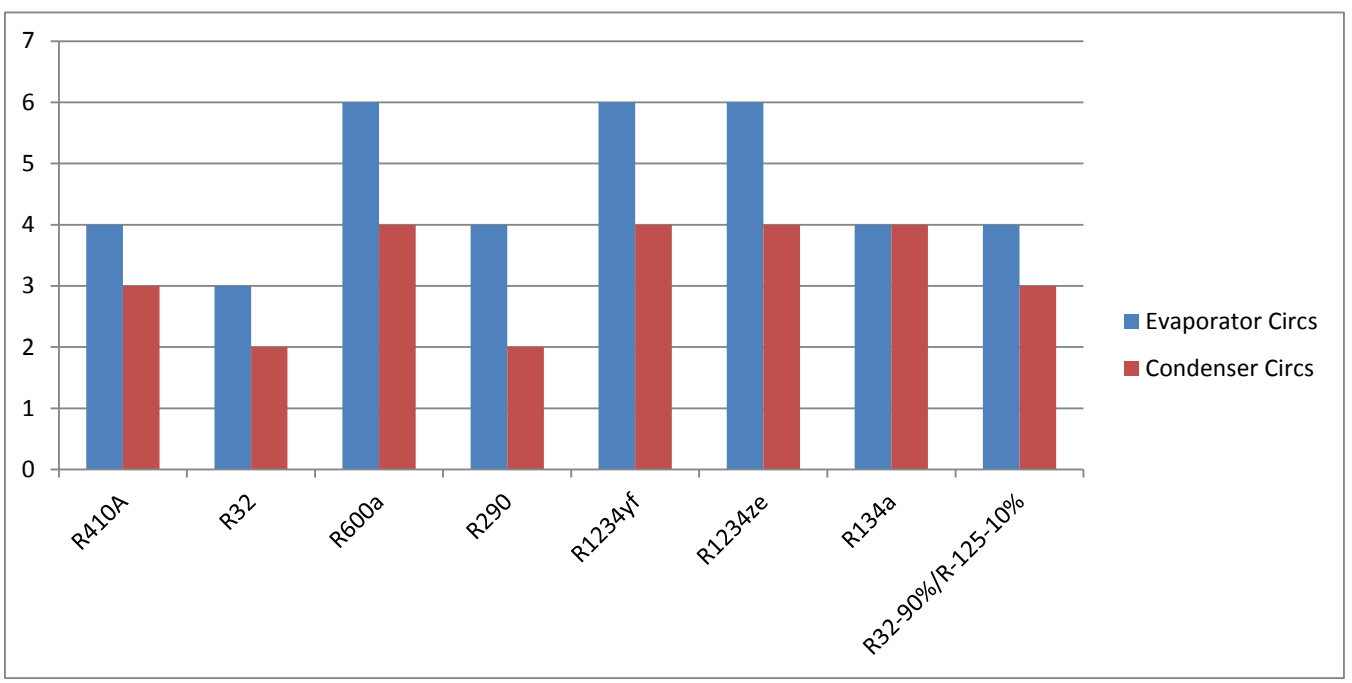

Figure 40: Optimized number of circuits in condenser and evaporator for various refrigerants

Comparison of Required Compressor Displacement Volumes: Figure 41 illustrates the required compressor 
displacement volumes to achieve the cooling capacity of 10,000 Btu/h (2.93 kW) for each refrigerant, with the optimized circuit numbers. It can be seen that R410A, R32, and R32-90\%/R125-10\% require similar displacement volumes. It means that R32, and R32-90\%/R125-10\% can be suitable near "drop-in" replacements for R410A using the same compressor size. However, other refrigerants require a noticeably larger displacement volume, which implies that new compressors will need to be designed if these refrigerants were to be considered for WACs.

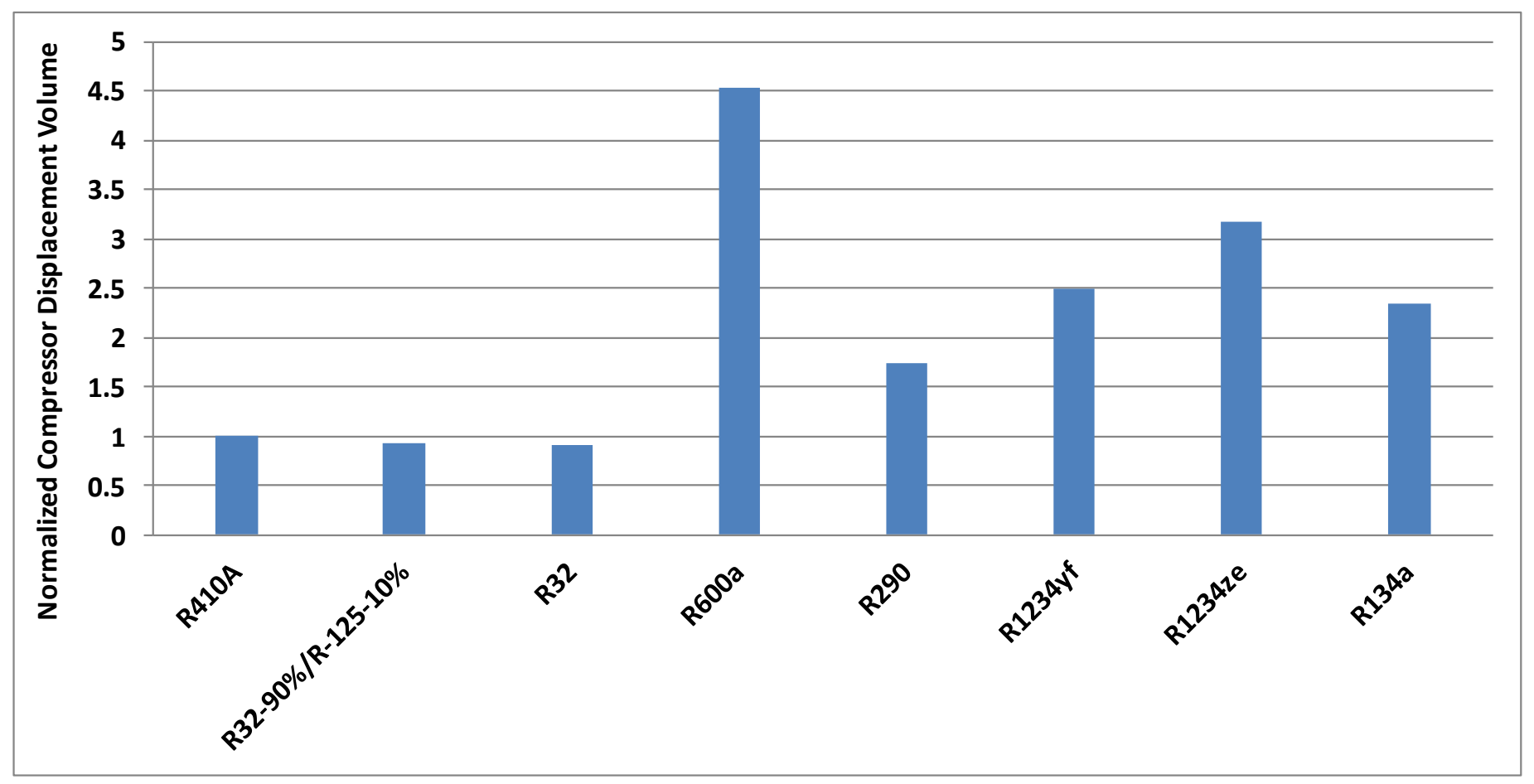

Figure 41: Normalized Compressor Displacement Volumes of Various Refrigerants

Comparison of Heat Exchanger Configurations: Figures 36 and 37 show the comparison of the drop in saturation temperatures in the evaporator and condenser respectively for various refrigerants, with the original and the optimized circuit numbers. In Figure 42, it can be seen that the drop in saturation temperature in the evaporator is more significant for R134a, R600a, R1234yf, and R1234ze. However, with the optimized evaporator circuitry, the corresponding drop in saturation temperature in the evaporator is reduced noticeably. Similar is the pattern for optimized circuitry in the condenser as shown in Figure 43, where the notable feature is that the optimized condenser circuitries prefer fewer circuit numbers and larger refrigerant velocity that resulted in larger drop in the saturation temperature. This occurs due to the fact that the submerged subcooler and the water slinger enhance the condenser heat transfer, and the condenser heat transfer is less prone to the saturation temperature drop, and the large refrigerant side velocity benefits the heat transfer in both the condenser and the subcooler. 


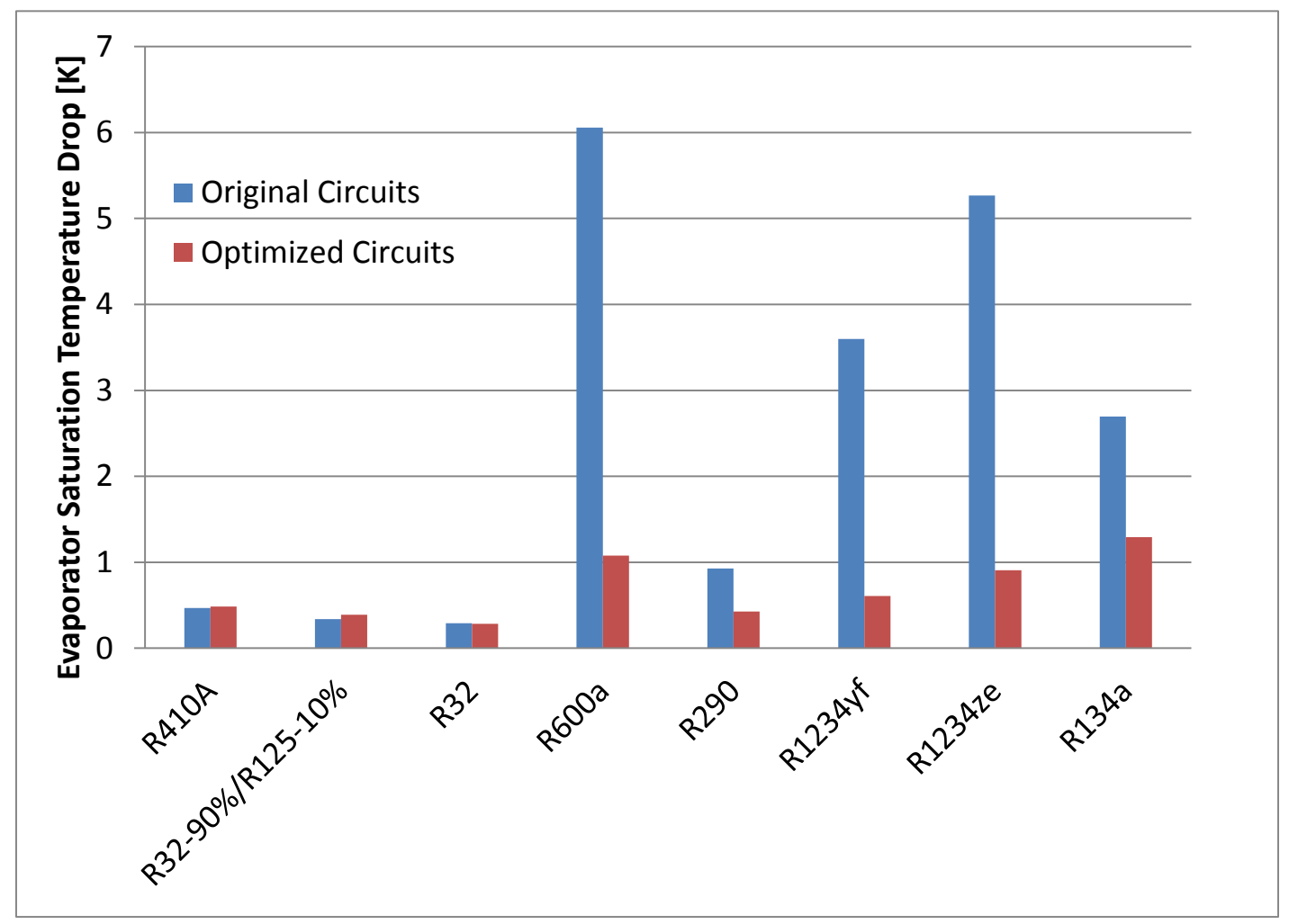

Figure 42: Drop in evaporator saturation temperature between optimized and original circuits for various refrigerants.

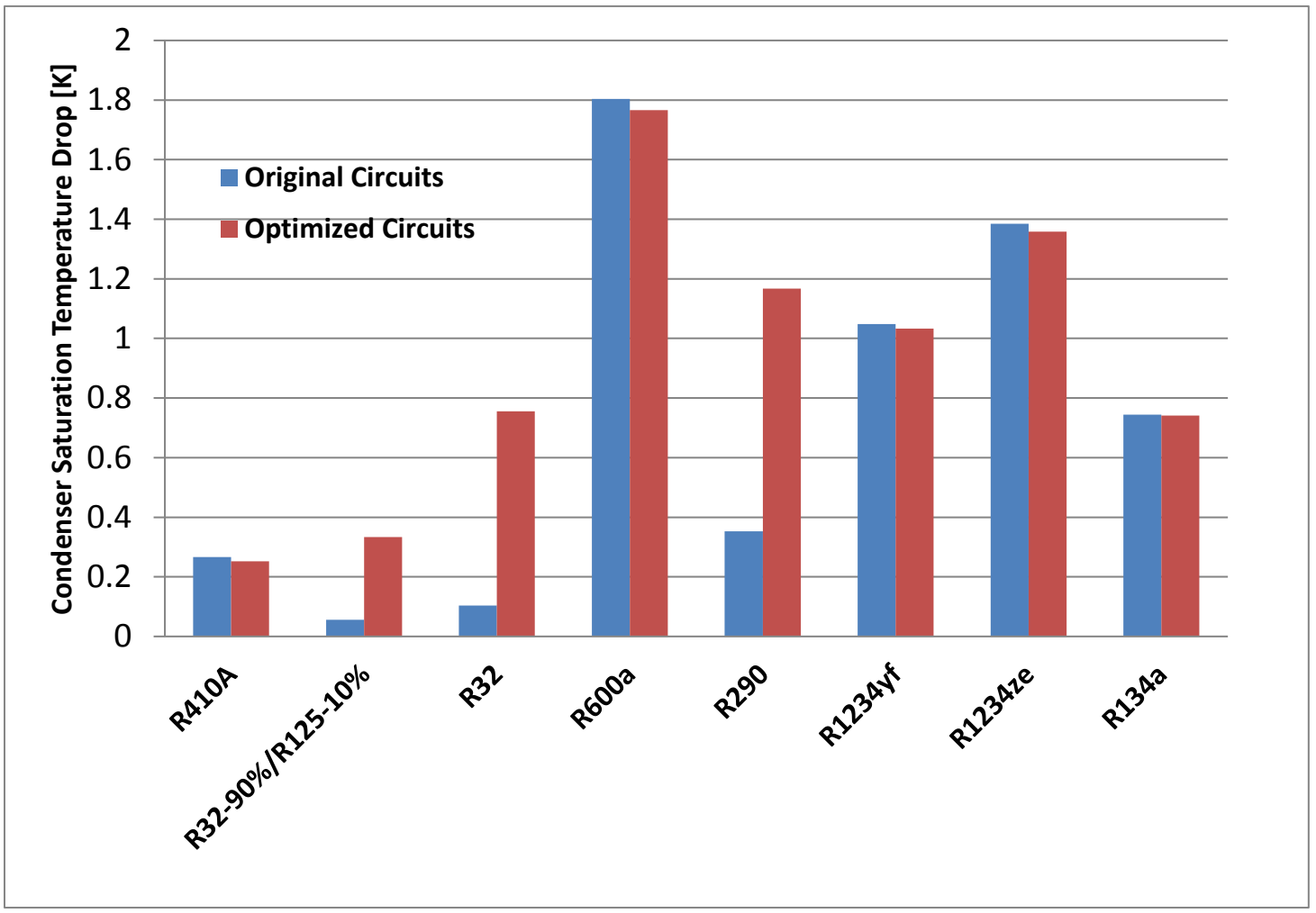

Figure 43: Drop in condenser saturation temperature between optimized and original circuits for various refrigerants 
Comparison of Compressor Discharge Temperatures: The variation of discharge temperatures of various refrigerants has been exhibited in Figure 44, where R32 shows the highest discharge temperature, which is about 30ㅇ (16.7으) higher than R410A. It should be noted here that the "slinger" is effective in a number of ways, including reducing the condenser saturation temperature, and the discharge temperature by about 7으 (3.9ㅇ) .

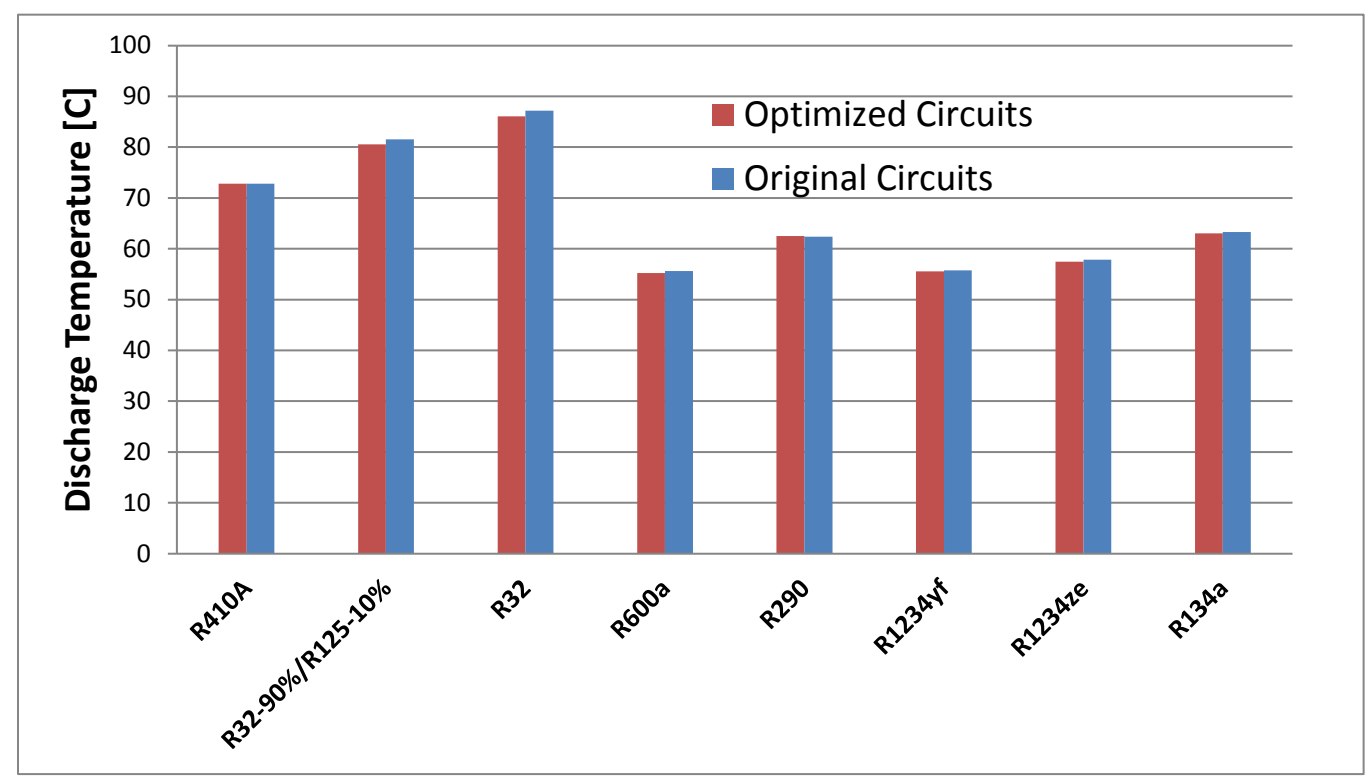

Figure 44: Compressor Discharge Temperatures of Various Refrigerants

Comparison of Energy Efficiency Ratio (EER): Figure 45 illustrates the normalized EERs of alternative refrigerants at the outdoor temperature of $95 \mathrm{O} F(35 \mathrm{O} C)$ - normalized to the EER of the R410A unit with the original WAC circuitry using R410A). It can be seen that R32 results in the highest EER with the same heat exchangers' surface area as that of the base unit. This is followed by the mixture of R32(90\%)/R125(10\%), R290, while all other refrigerants perform worse than R410A. The study revealed that R32 offers the best efficiency improvement with a $67.5 \%$ lower GWP.

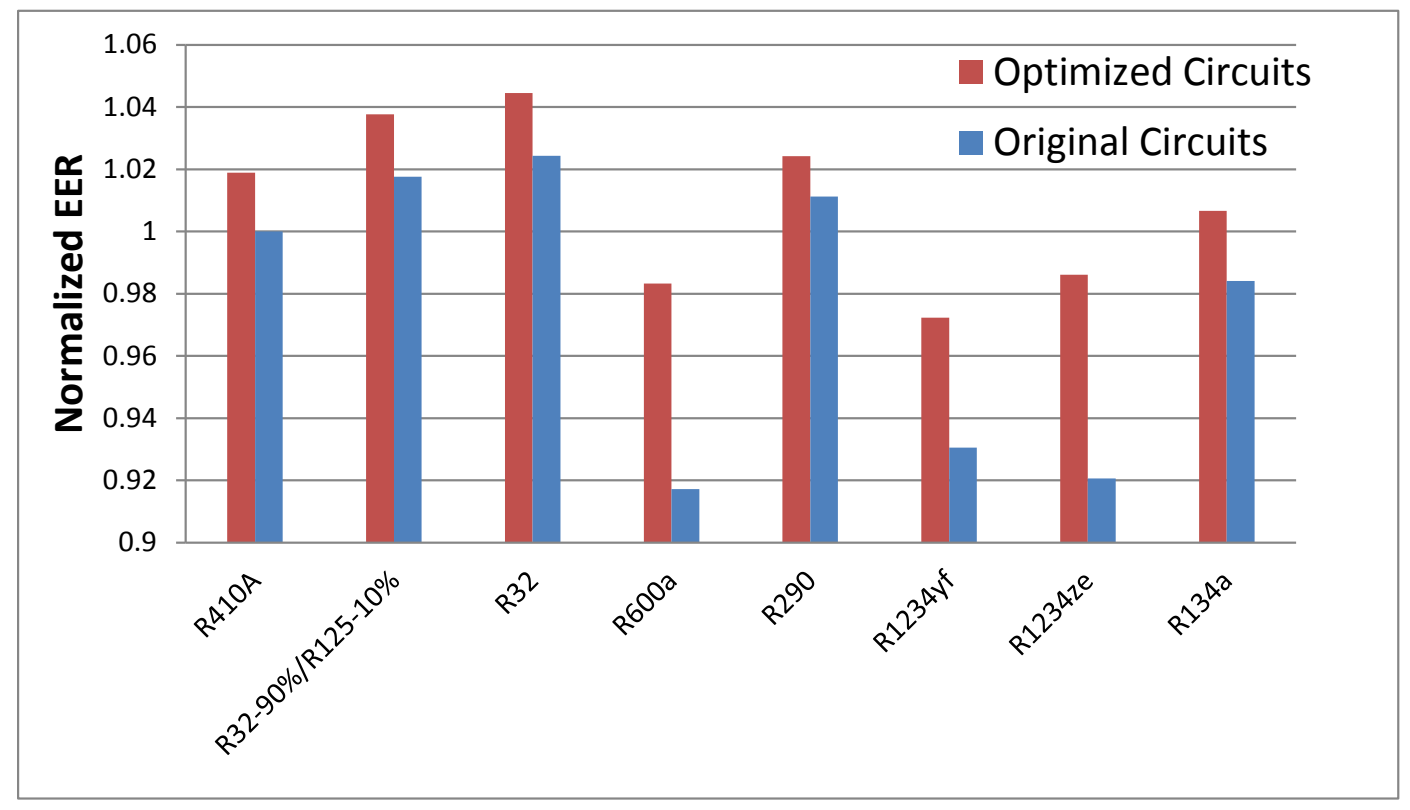

Figure 45: Normalized EERs of various refrigerants at 95ㅇ $\left(35^{\circ} \mathrm{C}\right)$ ambient temperature with respect $\mathrm{R} 410 \mathrm{~A} E \mathrm{E}=1.00$ 


\subsection{DESIGN PRODUCTION READY HIGH EFFICIENCY WINDOW PROTOTYPE}

Based upon ORNL's laboratory test results and the discussions with the CRADA partner, the design of the production ready prototype was finalized. The prototype was fabricated by modifying the original $10,000 \mathrm{BTU} / \mathrm{Hr}$ window unit with the following modifications-

(1) Reduce the unit capacity from $10,000 \mathrm{BTU} / \mathrm{hr}$ to $8,000 \mathrm{BTU} / \mathrm{hr}$ by replacing the original compressor with a high efficiency (EER=9.7) compressor having 8,000 BTU/hr capacity

(2) Replace the AC induction fan motor with a brushless DC (ECM) fan motor

(3) Replace the capillary tube with a needle valve to better control refrigerant flow and set points.

Both the chassis and the heat exchangers of the original 10,000 BTU/Hr unit were retained and the unit was charged with a "drop-in" mixture of R32 (90\% molar con.) and R125 (10\% molar conc.). All design details are given in Table B1.

Procedure for fabrication of new prototype: During the modification process, the electrical control panel from the original unit was removed and replaced with digital controls for fan speed and compressor power. The original AC fan motor was replaced with an ECM brushless and sensor-less motor by removing the old fan housing, attaching the fan and blower to the new motor, and remounting the fan assembly to the housing. The fan housing was replaced by a computer designed 3D printed housing to accommodate the larger ECM fan motor. This was followed by replacing the original 10,000 BTU/H compressor with an 8,000 BTU/HR compressor. The capillary tube expansion device was replaced by an adjustable needle expansion valve. A digital mass flow meter was installed after the sub-cooler and before the needle vale to measure refrigerant flow. This flow device was then bolted onto the frame with copper tube connecting to the condenser and evaporator. Finally, pressure transducers, thermocouples, relative humidity (RH) and rpm sensors were placed around the system to monitor the state of the unit. On the refrigerant side, thermocouples and pressure transducers were placed between each of the refrigeration cycle components: evaporator, compressor, condenser, and expansion device. These sensors allowed for refrigerant property estimation of the state during the cycle. Additional thermocouples were placed in the middle of the condenser and evaporator for midpoint readings. The design was intended to provide readings throughout the entire process and allow for an in depth determination of the efficiency on a component and entire unit basis. Also installed were thermocouple arrays and RH sensors on both air-sides of the evaporator and the condenser to measure the refrigeration capacity. A thermocouple array was installed after the fan, but before the condenser to verify a temperature drop from the slinging.

Testing with the New Prototype: The unit was evacuated and tested for leaks and was charged with a 590 gm of the blend of R32/R125 refrigerant. The fan was operated at $1200 \mathrm{rpm}$ that corresponded to air flow rates to match 8,000 BTU/hr capacity. The tests were conducted following DOE test conditions (Indoor- $80^{\circ} \mathrm{F}, 51.5 \% \mathrm{RH}$; Outdoor- $95^{\circ} \mathrm{F}, 41.1 \%$ $\mathrm{RH})$. The unit was allowed to reach steady state before collecting useful data.

This unit was expected to achieve high EER but during initial testing, it struggled to achieve 8,000 BTU/HR capacity (refrigerant-side) and yielded only 12.1 EER (on average). These experiments were performed over a large span of time with different charges and conditions, however, the unit performed unsatisfactorily with most tests being unrepeatable. Upon investigation, it was revealed that the needle valve was choking in the morning which reduced the refrigerant flow rate. This possibly caused a reduction in the flow rate when test was repeated the next morning and required adjustment to achieve the prior conditions. Therefore, this valve was replaced with a new needle valve with a larger adjustment range; which interestingly performed well at least during its initial testing. Initial tests with this needle valve 
on three consecutive days (09/16/2014 to 09/18/2014) consistently exhibited the refrigeration-side capacity of up to $8700 \mathrm{BTU} / \mathrm{hr}$, refrigerant flow rate of $89 \mathrm{lbm} / \mathrm{hr}$ and the maximum EER of 13.38 (see Figure 46).

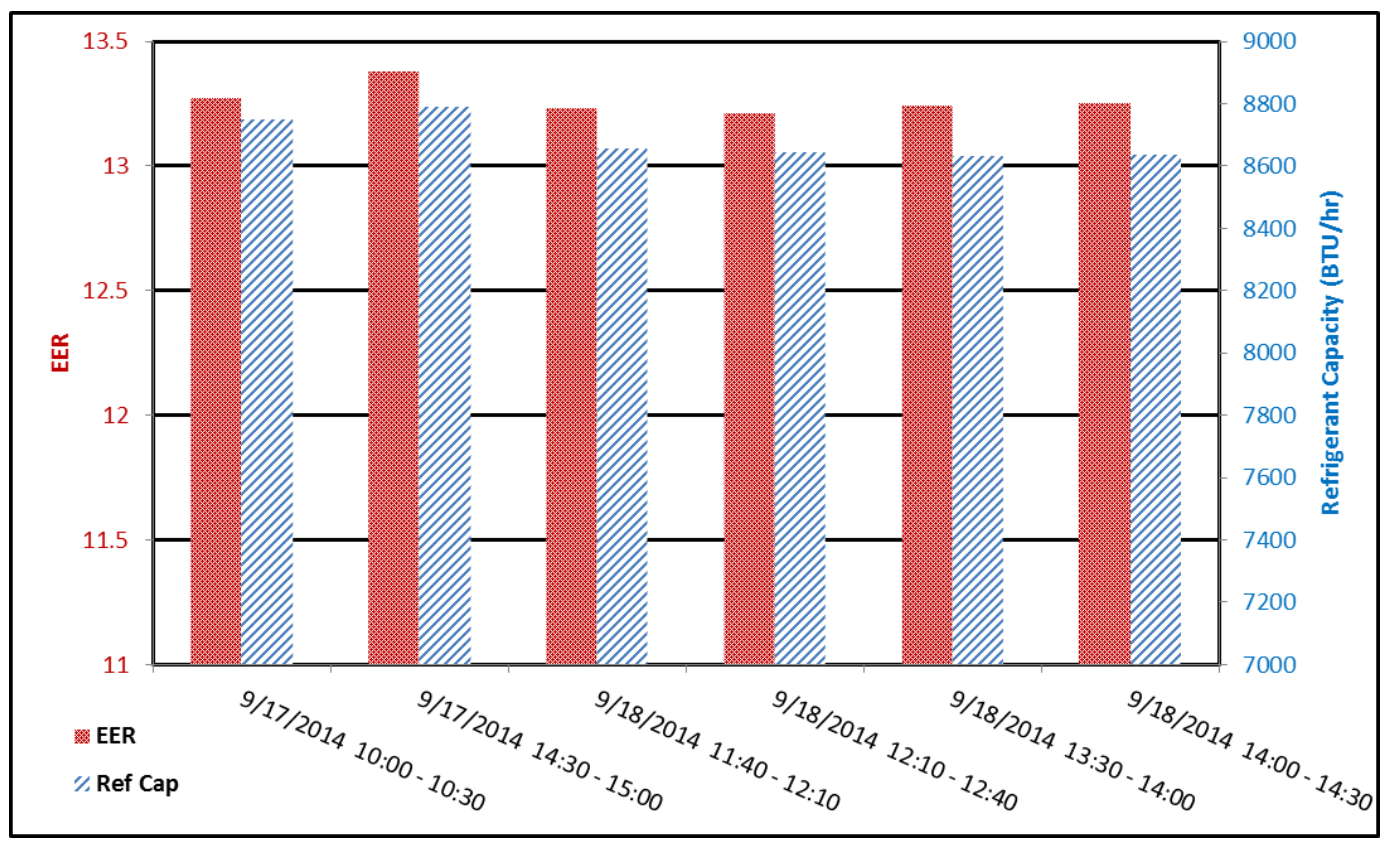

Figure 46: Averaged EER of the window unit during 09/17/2014 - 09/18/2014 (good days)

Following this, before the unit could be shipped for independent testing, it was charged one last time on 09/26/2014 with $590 \mathrm{gm}$ of the refrigerant mixture (90\% mole conc. of R32 and $10 \%$ mole conc. of R125) for final testing during $09 / 26 / 2014$ to $09 / 29 / 2014$ to ensure that it was still working as expected. However, as experienced before, the unit again performed poorly. The unit suffered from the same problem of flow choking (flow rate reducing to between 79 and $87 \mathrm{lb} / \mathrm{hr}$ as opposed to $89 \mathrm{lb} / \mathrm{hr}$ in previous tests) and achieving much less capacity and hence low EER (ranging between 11.6 and 12.3). The EER for tests on 09/26/2014 to 09/29/2014 (bad days) at different time intervals is displayed in Figure 47.

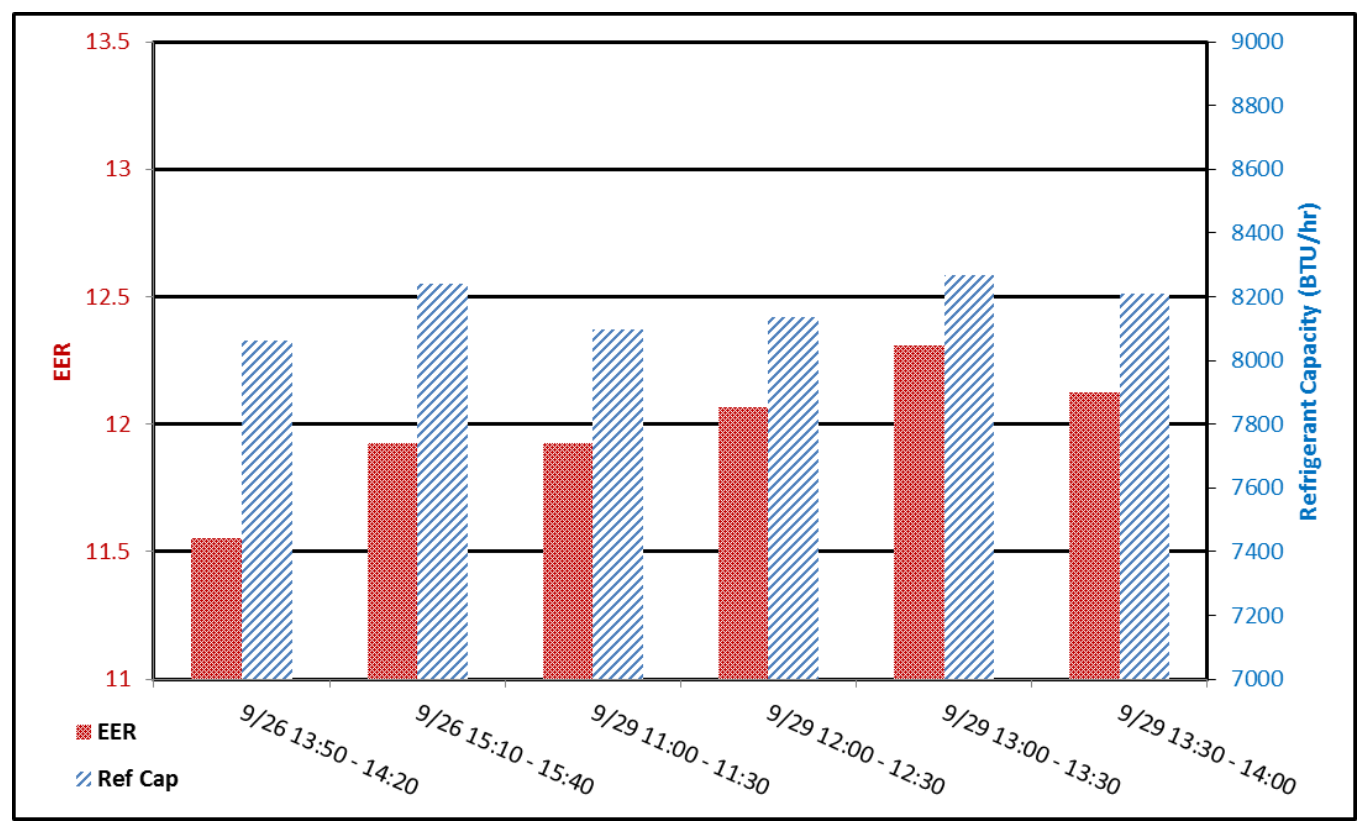

Figure 47: Averaged EER of the final prototype experimented on 09/26/2014 - 09/29/2014 (bad days) 


\section{Data Analysis and Performance Insights of Window Air Conditioner After Changing Needle Valve}

Due to the discrepancies in results, an extensive data analysis was performed on the unit over the 30 minute intervals during 09/16/2014 to 09/18/2014 (good days) and on 09/26/2014 to 09/29/2014 (bad days). Some of the performance variables are given below-

1. Refrigerant side capacity

2. EER

3. Air temperature drop across the evaporator

4. Pressure drop from the evaporator to condenser

5. Mass flow rate

Refrigerant Capacity: The refrigerant capacity is a measure of the heat extracted from the indoor room. Following the RSS method for the experiment on 09/16/2014 to 09/18/2014 (good days), the uncertainty and the standard deviation of the refrigeration capacity was calculated to be $\pm 69.83 \mathrm{BTU} / \mathrm{hr}$ and $132.49 \mathrm{BTU} / \mathrm{hr}$ respectively. For the experiment on 09/26/2014 to 09/29/2014 (bad days), the corresponding uncertainty and the standard deviation of the refrigeration capacity was calculated to be $\pm 70.61 \mathrm{BTU} / \mathrm{hr}$ and $202.90 \mathrm{BTU} / \mathrm{hr}$ respectively. These uncertainties are based on the random errors of the sensors based the specified dates.

The air flowing through the evaporator experiences a drop in its temperature (see Figure 48) as it transfers heat to the refrigerant. Therefore, the temperature drop of air increases as the refrigerant capacity increases. However the lower refrigerant capacity for experiment on 09/26/2014 to 09/29/2014 (bad days) still result in the same temperature drop range compared to the experiment on 09/16/2014 to 09/18/2014 (good days) for a vast majority of data points. This is displayed in Figure 42 against the refrigerant capacity for both 09/16 - 9/18 (good days) and 09/26 - 9/29 (bad days) intervals. This suggests the possibility of an erroneous measurement in refrigerant capacity.

Refrigerant Mass Flow Rate: The refrigerant mass flow rate (see Figure 49) is a direct multiplier in the calculation of the refrigerant capacity that differed significantly between the experiments. In the experiments on 09/26/2014 09/29/2014 (bad days), the evaporator superheat became unstable at $89 \mathrm{lbm} / \mathrm{hr}$ that led to the adjustment of the refrigerant mass flow rate to a lower value. The same pressure changes from the evaporator to the condenser on the bad days corresponded to a much lower mass flow rate compared to the good days for a majority of data points. This supports the possibility of a flaw in the refrigerant mass flow rate measurements, or a system related flow restriction. Either would propagate to a distorted refrigerant capacity. These discrepancies are displayed in Figure 49 for both 09/16/2014 - 09/18/2014 (good days) and 09/26/2014 - 09/29/2014 (bad days) intervals.

Energy Efficiency Ratio (EER): For the experiments on 09/16/2014 to 09/18/2014 (good days), the uncertainty and the average standard deviation in the EER (capacity based on refrigerant side) was determined to be $\pm 0.22 \mathrm{BTU} / \mathrm{Whr}$ and 0.34 BTU/Whr respectively. For the experiments on 09/26/2014 to 09/29/2014 (bad days), the uncertainty and the standard deviation in the EER (capacity based on refrigerant side) was determined to be \pm 0.19 BTU/Whr and 0.62 BTU/Whr respectively. These uncertainties are based on the random errors of the sensors. There is also data available to calculate the EER based on the airside capacity, however, the airside capacity has been calculated by estimating the volumetric flow rate. This volumetric flow rate must remain constant because the RPM of the ECM fan was fixed at 1200. 


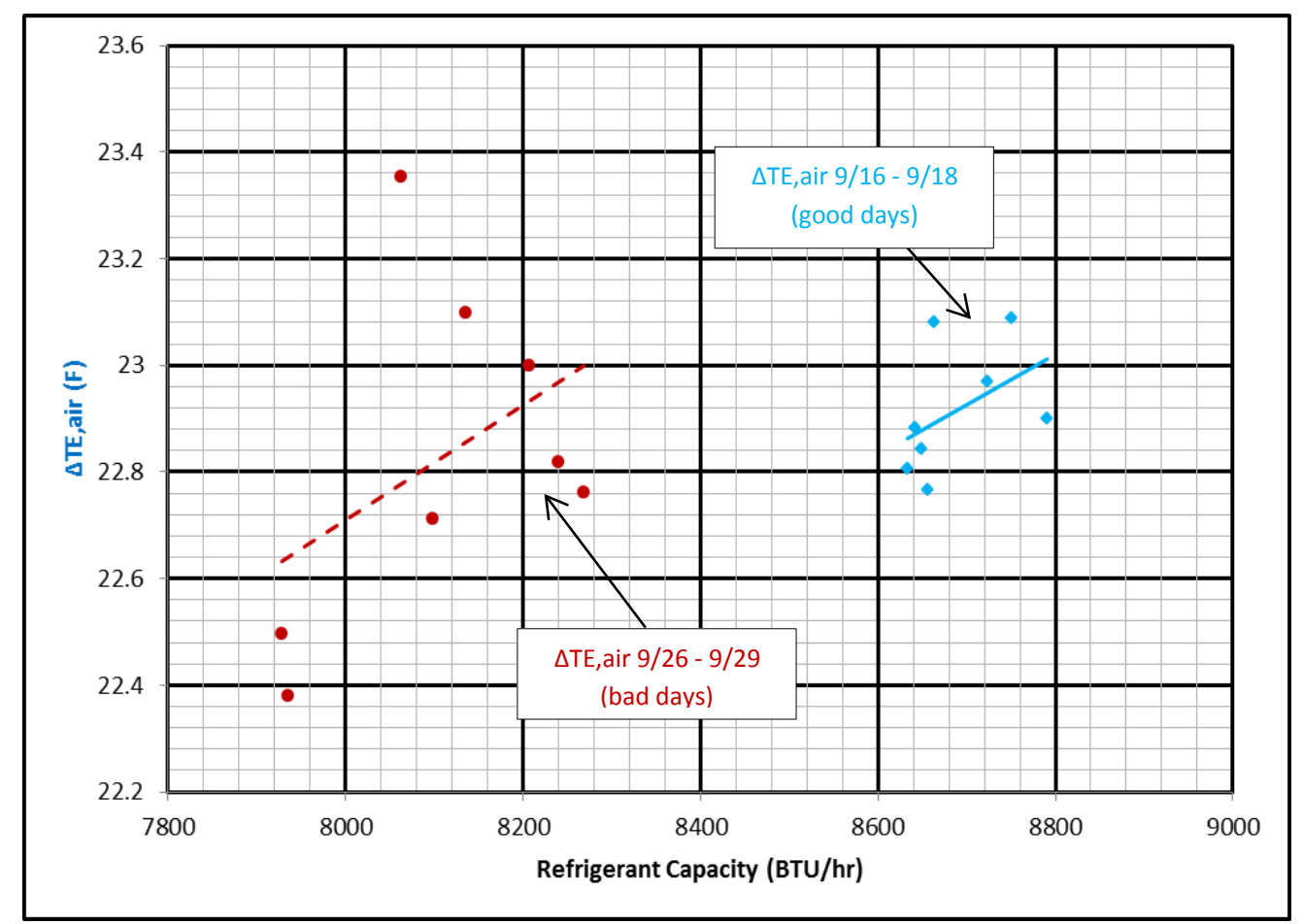

Figure 48: Average air temperature drop across evaporator (varying between $22.4^{\circ} \mathrm{F}$ and $23.4^{\circ} \mathrm{F}$ ) against refrigerant capacity on 09/16/2014 - 09/18/2014 (good days) and 09/26/2014 - 09/29/2014 (bad days).

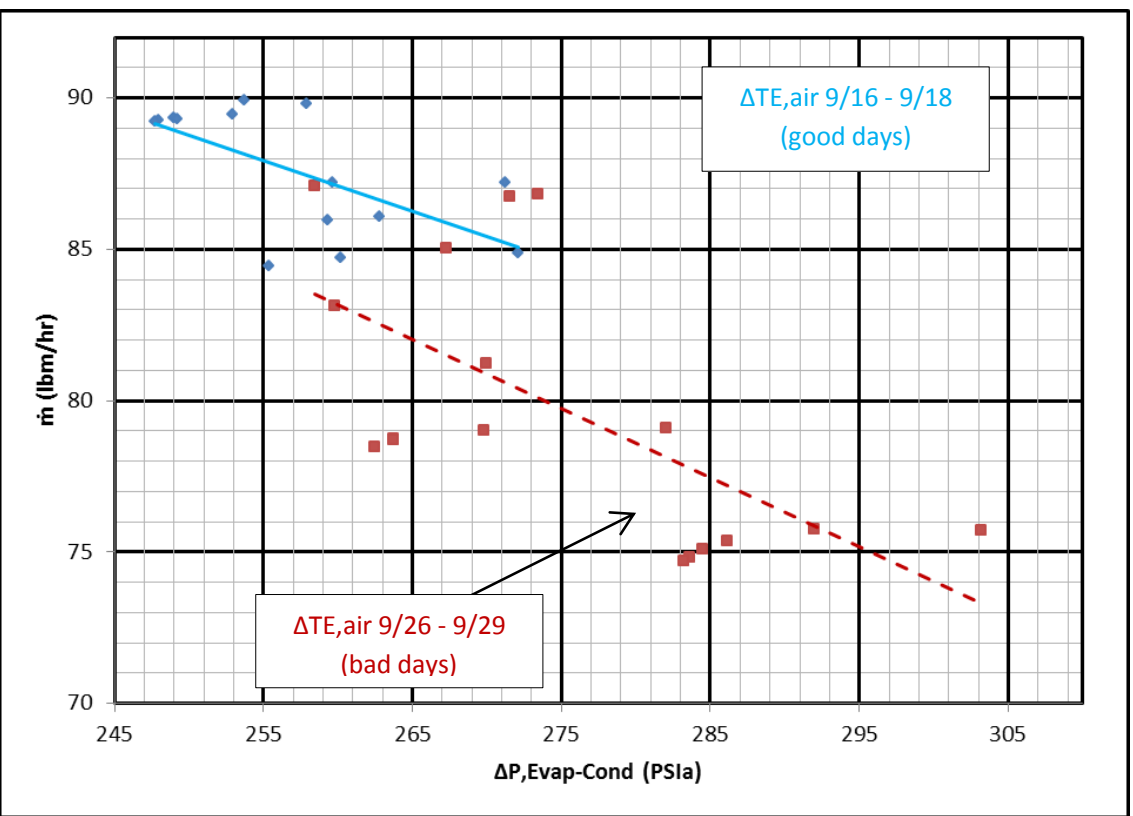

Figure 49: Refrigerant mass flow rate, $\dot{\mathrm{m}}$, against refrigerant pressure increase a evaporator to condenser, $\Delta \mathrm{P}_{\mathrm{Evap}-\mathrm{Cond}}$, on 09/16/2014 - 09/18/2014 (good days) and 09/26/2014-09/29/2014 (bad days).

Unknown CFM of the Fan and the Related Uncertainty: The fan CFM for 10,000 BTU/hr unit was about 300 but its value was unknown when the unit capacity was reduced to $8,000 \mathrm{BTU} / \mathrm{hr}$. To calculate air-side capacity, the CFM value was assumed to be 224 that was based on some measurements using a hotwire anemometer with up to $30 \%$ uncertainty. 
Based on the assumed value of CFM at 224, both the refrigeration-side and air-side EERs and capacities were compared on various days as shown in Figure 50 and Figure 51 respectively. For all the data shown in Figures 50 and 51 for both the good days and bad days, one striking feature that is noticeable is that both the refrigerant-side and the airside EERs and capacities tend to follow exactly the same trend aside from one data point (9/26 13:50 - 14:20). The airside EER seems to vary between 12.3 to 12.6 (good days) while it varies between 12.1 to 12.7 (bad days), while the corresponding variation of refrigerant-side EER is 13.0 to 13.4 (good days) and 11.5 to 12.3 (bad days). The averages of the airside EER are 12.45 and 12.43 on the good and bad days respectively, while the corresponding averages of the refrigerant side EER are 13.19 and 11.91 on the good and bad days respectively. This suggests that the mass flow discrepancy had a significantly lower effect (if any) on the airside EER compared to the refrigerant side EER. If the unit actually experienced a reduction in the rate of refrigerant mass flow, the air should not have experienced the same amount of heat transfer (see Figure 51), and the airside EER should have dropped with the refrigerant EER. This supports the possibility of erroneous measurements in either the refrigerant mass flow rate or the refrigerant temperature at the evaporator outlet. A system related problem could be the flow restriction due to any debris or non-condensable gases.

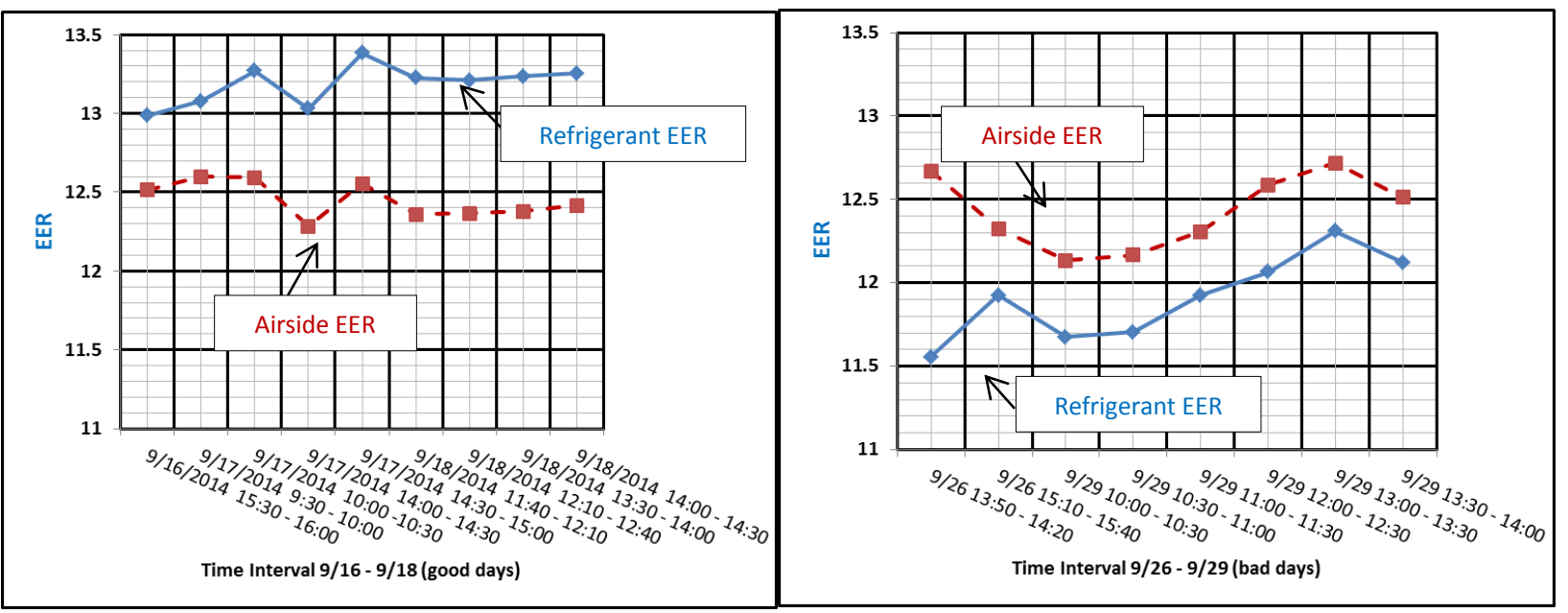

Figure 50: Refrigerant and airside EER against time intervals on 09/16/2014 - 09/18/2014 (good days) and 09/26/2014 - 09/29/2014 (bad days) over 30 minute steady intervals.

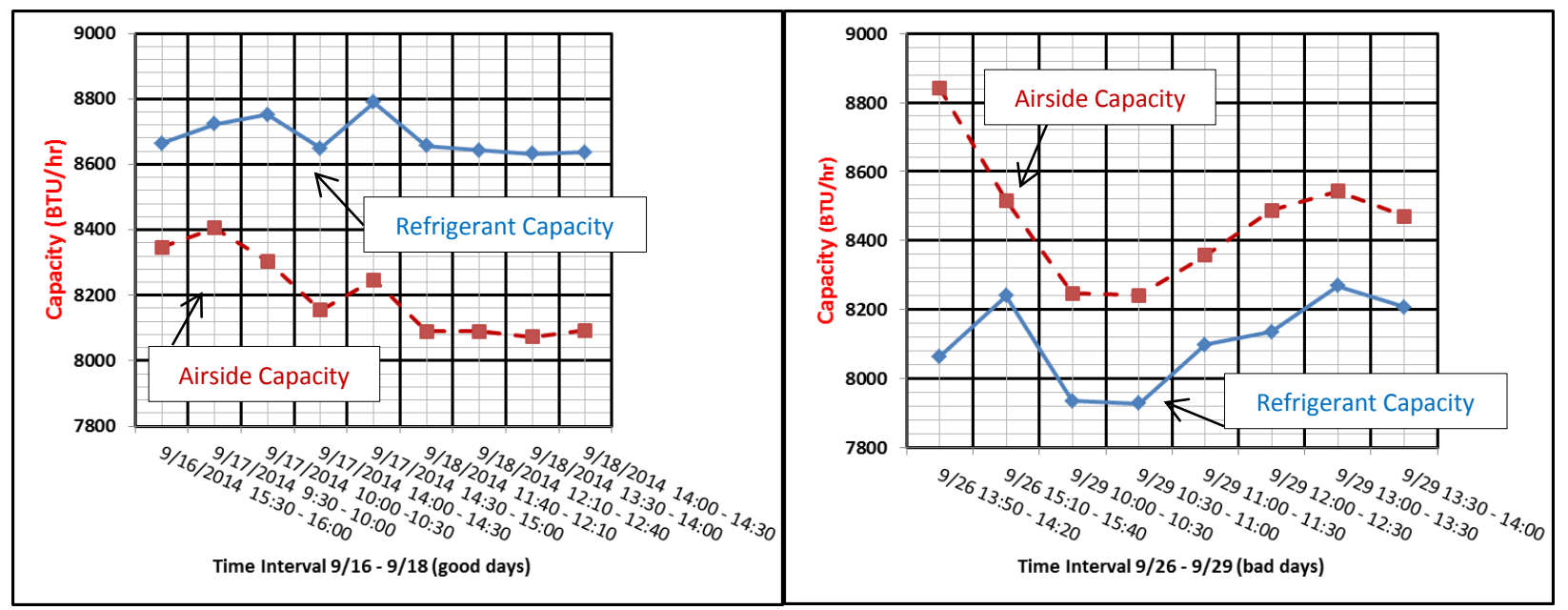

Figure 51: Refrigerant and airside capacities against time intervals on 09/16/2014 - 09/18/2014 (good days) and 09/26/2014 09/29/2014 (bad days) over 30 minute steady intervals. 
The above observations further suggest that the airside capacities may be more reliable for the calculation of the EER. However, the modelling of the new WAC prototype suggest an EER of 13.0; several tuning and testing were conducted to verify and validate the model.

Independent Testing of the WAC Prototype: The WAC prototype (with 8,000 BTU/HR capacity) was shipped to Intertek for independent testing at the DOE test condition in early October 2014. Due to the heavy usage of the climatic chambers at Intertek, there was a long waiting time for any unit to be tested at Intertek, and hence our WAC could only be tested in late January 2015. By that time, our WAC unit unfortunately lost charge of the R32/R125 (90\%/10\%) blend and could not perform at the expected level. Intertek were not willing to charge the unit with the refrigerant blend of R32/R125 (90\%/10\%) due to slightly higher flammability of R32 and hence this testing had to be abandoned. The WAC unit was, however, evacuated, recharged with R410A and tested at DOE conditions. Although the WAC prototype was optimized for R32/R125 blend and not for R410A, an EER of 12.1 was achieved for the unoptimized R410A WAC prototype.

In the meantime, GE had advised that they have already designed a high efficiency WAC unit (with 8,000 BTU/HR capacity) using R410A refrigerant with an EER of 12.1. GE will be commercializing this new unit during 2015. This new unit, however, neither uses ECM fan motor nor the refrigerant blend. This suggests that our WAC should yield much higher EER than the GE's new WAC due to these two important parameters. Although the final EER of the unit could not be verified through an independent testing, both the modelling and the experimental evaluations indicate that this WAC offers $12-20 \%$ energy savings in comparison to the state-of-the-art basine unit. 


\subsection{COMMERCIALIZATION POSSIBILITIES}

The research investigation in this project has revealed that the efficiency of a room window air conditioner can be improved significantly, resulting in 12-20\% energy savings per annum. One of the novel elements responsible for this enhanced energy efficiency was the use of a "drop-in" refrigerant blend of R32/R125 (90\%/10\% molar concentration) in place of R140A as a refrigerant. The modelling results have indicated that R32 would enhance the nergy efficiency even further, however, due to the limited flammability issues with R32, it was not experimentally investigated in the project. Although R32 is a popular refrigerant and is frequently used in air conditioners in other parts of the world (e.g. Asia, Europe, ...), the US regulating agencies, such as the Environmental Protection Agency and UL Underwriters, are working to address the fllamability issues and there is a strong possibility that R32 may be allowed to be used in small systems such as a window air conditioner in the near future.

The CRADA partner is interested in further development and commercialization of A2L refrigerants in smaller units with limited refrigerant charges. This may allow them to commercialize a real world product by advancing the results from this CRADA project in the future.

\subsection{PLANS FOR FUTURE COLLABORATION}

The CRADA partner GE is investigating the technical as well as economic potential of the high efficiency room window air conditioner. The results of this projects would be highly relevant and useful to DOE standard body to raise the minimum energy efficiency levels for room air conditioners. This would encourage manufacturers to implement the research developed as a part of this project.

The CRADA partner GE will be keen to work with ORNL to extend this collaboration. There may be a possibility to perform a field study of the new high efficiency prototype as a part of the Residential Building Integration program, where future collaboration with GE may be warranted.

\subsection{CONCLUSIONS}

This project was undertaken as a CRADA project between UT-Battelle and General Electric Company and was funded by Department of Energy to design and develop of a high efficiency room air conditioner. A number of novel elements were investigated to improve the energy efficiency of a state-of-the-art WAC with base capacity of 10,000 BTU/h. One of the major modifications was made by downgrading its capacity from $10,000 \mathrm{BTU} / \mathrm{hr}$ to $8,000 \mathrm{BTU} / \mathrm{hr}$ by replacing the original compressor with a lower capacity $(8,000 \mathrm{BTU} / \mathrm{hr})$ but high efficiency compressor having an EER of 9.7 as compared with 9.3 of the original compressor. However, all heat exchangers from the original unit were retained to provide higher EER. The other subsequent major modifications included- (i) the AC fan motor was replaced by a brushless high efficiency ECM motor along with its fan housing, (ii) the capillary tube was replaced with a needle valve to better control the refrigerant flow and refrigerant set points, and (iii) the unit was tested with a 'drop-in' environmentally friendly binary mixture of R32 ( $90 \%$ molar concentration)/R125 (10\% molar concentration). The WAC was tested in the environmental chambers at ORNL as per the design rating conditions of AHAM/ASHRAE (Outdoor-95F and $40 \% \mathrm{RH}$, Indoor- $80 \mathrm{~F}, 51.5 \% \mathrm{RH})$. Both the modelling and the experimental evaluations suggest that this WAC offers $12-20 \%$ energy savings in comparison to the state-of-the-art baseline unit. 


\section{ACKNOWLEGEMENTS}

Special thanks are due to a number of contributors for their invaluable contributions and support during this project, including Mr. Edward Vineyard, Dr. Chris Halford, Dr. Bo Shen, Mr. Brice Bowley, Mr. Charles Smith, Mr. Jiancheng Zong, Mr. Tim Ao, Dr. Detlef Westphalen, Mr. Paul Lin, Mr. Mark Hoehne, Dr. Keith Rice, Mr. Van Baxter, Mr. Randall Linkous, Mr. Neal Durfee, Mr. Jeff Ormston, Mr. Brian Goins, Mr. Randall Witherington, Mr. Philip Boudreaux, Mr. Edwin Figueroa, Mr. Chase Davani and Mr. Amar Mohabir. Support from General Electric (our CRADA partner) is also gratefully acknowledged.

\section{REFERENCES}

Bansal, P. K. and Shen, B., 2014, "Analysis of environmentally friendly refrigerant options for window air conditioners, Science and Technology for the Built Environment (under review).

Bolaji, B. O., 2011, Performance investigation of ozone-friendly R404A and R507 refrigerants as alternatives to R22 in a window air-conditioner, Energy and Buildings, 43, pp 3139-3143.

Braun. J.E., Klein. S.A, and Mitchell, J.W., 1989, "Effectiveness models for cooling towers and cooling coils", ASHRAE Transactions, 95(2), pp. 164-174.

Devotta, S., Padalkar, A. S., and Sane, N. K., 2005, Performance assessment of HC-290 as a drop-in substitute to HCFC-22 in a window air conditioner, International J Refrigeration, 28, pp 594-604.

DOE, 2011, "Residential Clothes Dryers and Room Air Conditioners Direct Final Rule Technical Support Document", 4/18/2011; updated on 03/02/2012, http://www1.eere.energy.gov/buildings/appliance standards/residential/residential clothes dryers room ac dire ct final rule tsd.html

e-CFR Title 10: "Energy, Part 430- Energy conservation program for consumer products", 2014, http://www.ecfr.gov/cgibin/text-idx?SID=19211021fb068617aba13063da4e959a\&node=10:3.0.1.4.18.3.9.2\&rgn=div8

EIA (2009); Residential Energy Consumption Survey, US DOE Energy Information Administration, http://www.eia.gov/consumption/residential/data/2009/

Goswami, D.Y., Mathur, G. D., Kulkarni, S. M., 1993, Experimental investigation of performance of a residential air conditioning system with an evaporatively cooled condenser, Journal of Solar Energy Engineering 115, $206-211$.

Hajidavalloo, E., 2007, Application of evaporative cooling on the condenser of window-air-conditioner, Applied Thermal Engineering, 27, pp 1937-1943.

Jabaraj, D.B., Avinash, P., Mohan Lal, D. and Renganarayan, S., 2006, Experimental investigation of HFC407C/HC290/HC600a mixture in a window air conditioner, Energy Conversion and Management, 47, pp 25782590

Naphon, P. 2010, On the performance of air conditioner with heat pipe for cooling air in the condenser, Energy Conversion and Management, 51, pp 2362-2366.

Lawrence Livermore National Laboratory (LBNL), 1997, "Technical support document for energy conservation standards for room air conditioners: Volume 2 - Detailed analysis of efficiency levels", Docket Numbers EE-RM-90-201 \& EERM-93-801-RAC, September. 
Nogueira, L A H, 2013, "Package of measures to promote efficient air conditioning", ADEME, World Energy Council Study, http://www.wec-policies.enerdata.eu/Documents/cases$\underline{\text { studies/Measures to promote efficient air conditioning.pdf }}$

NIST, 2014, National Institute of Science and Technology Standard Reference Database 23, REFPROP 9.1, Gaithersburg, USA, http://www.nist.gov/srd/nist23.cfm

Rice, C. K., Jackson, W. L. , Fischer, S. K. and Ellison, R. D. , 1981, Design optimization and the limits of steady-state heating efficiency for conventional single speed air-source heat pumps, Contract No. W-7405-eng-26, ORNL/CON-63, Department of Energy.

Sawant, A. P., Agrawal, N. and Nanda, P, 2012, Performance assessment of an evaporative cooling-assisted window air conditioner, International J low-carbon technologies, 7, pp 128-136.

Shen, B. and P. K. Bansal, 2014, Assessment of environmentally friendly refrigerants for window air conditioners, ID2275, Proc. $15^{\text {th }}$ International Refrigeration and Air Conditioning Conference, Purdue University, West Lafayette, July 1417.

Winkler, J., C. Booten, D. Christensen and J. Tomerlin, 2013, "Laboratory performance testing of residential window air conditioners", NREL/TP-5500, 57617, July. 
APPENDIX A

\section{Uncertainty Analysis (MathCAD 14)}

\section{Air Side}

Condenser inlet (fixed)

Condenser Outlet

RH1 $:=42.9$ T_air_1 $:=(93.9+459.67) \mathrm{R}$

$\mathrm{RH} 2:=21.7 \quad$ T_air_2 $:=(117.1+459.67) \mathrm{R}$

Evaporator Inlet (fixed)

Evaporator Outlet

RH3 $:=52.1 \quad$ T_air_ $3:=(80+459.67) \mathrm{R}$

$\mathrm{RH} 4:=90.9 \quad$ T_air_4 $:=(57.7+459.67) \mathrm{R}$

\section{Refrigerant Side}
T_ref_1 := $(146+459.67) \mathrm{R}$
T_cond $:=(118.8+459.67) R$
T_evap $:=(50.7+459.67) \mathrm{R}$
mdot $:=132.3 \frac{\mathrm{lbm}}{\mathrm{hr}}$
T_ref_ $2:=(90+459.67) R$
T_ref_4 := $(63+459.67) \mathrm{R}$

\section{Electrical}

$P_{-}$fan $:=184.5 \mathrm{~W}$

P_comp $:=792.9 \mathrm{~W}$

\section{Uncertainties in base measurements}
u_P_ref $:=.6 \mathrm{psi}$
u_T_ref $:=.25 \mathrm{R}$
u_RH : $=1.4$
u_Patm $:=8.897 \cdot 10^{-3} \mathrm{psi}$
u_T_air $:=\frac{\text { u_T_ref }}{\sqrt{6}}$
$u_{-}$fan $:=2 \mathrm{~W}$
$u_{-}$comp $:=10 \mathrm{~W}$
u_mdot $:=.7 \frac{\mathrm{lbm}}{\mathrm{hr}}$

Refrigerant lookup

R410A_Sat_lookup :=

....R410A_Sat_Data.c5v

R410A_Sat_lookup $:=$ R410A_Sat_lookup ${ }^{T}$

$i:=0,1 \ldots$ rows $($ R410A_Sat_lookup $\langle 0\rangle)-1$

$T_{1}:=32+i \quad P_{i}:=100+i$

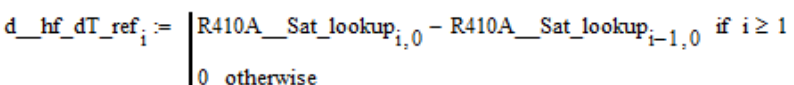




$$
\begin{aligned}
& \text { d_hg_dT_ref }_{i}:=\mid \begin{array}{l}
\text { R410A_Sat_lookup } \\
0 \text { otherwise }
\end{array} \\
& \text { d_Pf_dT_ref }{ }_{i}:=\mid \begin{array}{l}
\text { R410A_Sat_lookup } \\
i, 2-R 410 A \_ \text {Sat_lookup } \\
0 \text { otherwise }
\end{array} \\
& \text { d_Pg_dT_ref }{ }_{i}:=\mid \begin{array}{l}
\text { R410A_Sat_lookup } \\
i, 3 \\
0 \text { otherwise }
\end{array} \\
& \text { d_If_dP_ref }{ }_{i}:=\mid \begin{array}{l}
\text { R410A_Sat_lookup } \\
0 \text { otherwise }
\end{array} \\
& \text { d_Ig_dP_ref }_{i}:=\mid \begin{array}{l}
\text { R410A_Sat_lookup } \\
0 \text { otherwise }
\end{array} \\
& \text { d__hf_dP_ref }{ }_{i}:=\mid \begin{array}{l}
\text { R410A_Sat_lookup } \\
i, 6 \\
0 \text { otherwise }
\end{array} \\
& \text { d__hg_dP_ref }_{i}:=\mid \begin{array}{l}
\mathrm{R} 410 \mathrm{~A} \_ \text {Sat_lookup } \\
0 \text { otherwise }
\end{array} \\
& \text { P_ref_1 }:=\operatorname{linterp}\left(T, R 410 \mathrm{~A} \_ \text {Sat_lookup }\left\langle\frac{\mathrm{T} \text { _cond }}{\mathrm{R}}-459.67\right) \mathrm{psi}\right. \\
& \text { P_ref_3 }:=\operatorname{linterp}\left(T, R 410 \text { A_Sat_lookup }\langle 3\rangle, \frac{T \text { _evap }}{R}-459.67\right) \text { psi } \\
& \text { T_ref_3 }:=\operatorname{linterp}\left(P, R 410 \text { A_Sat_lookup }\langle 5\rangle \frac{\text { P_ref_3 }}{\mathrm{psi}}\right) \mathrm{R} \\
& \text { P_ref_2 := P_ref_1 } \quad \text { P_ref_4 }:=\text { P_ref_3 }_{-} \\
& h f_{-} \text {ref_3 }==\operatorname{linterp}\left(P, R 410 \text { A_Sat_lookup }\left\langle\frac{\left\langle P_{-}\right. \text {ref_3 }}{p s i}\right) \frac{\text { BTU }}{\mathrm{lbm}}\right.
\end{aligned}
$$

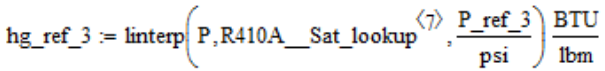

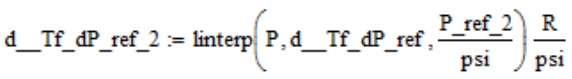




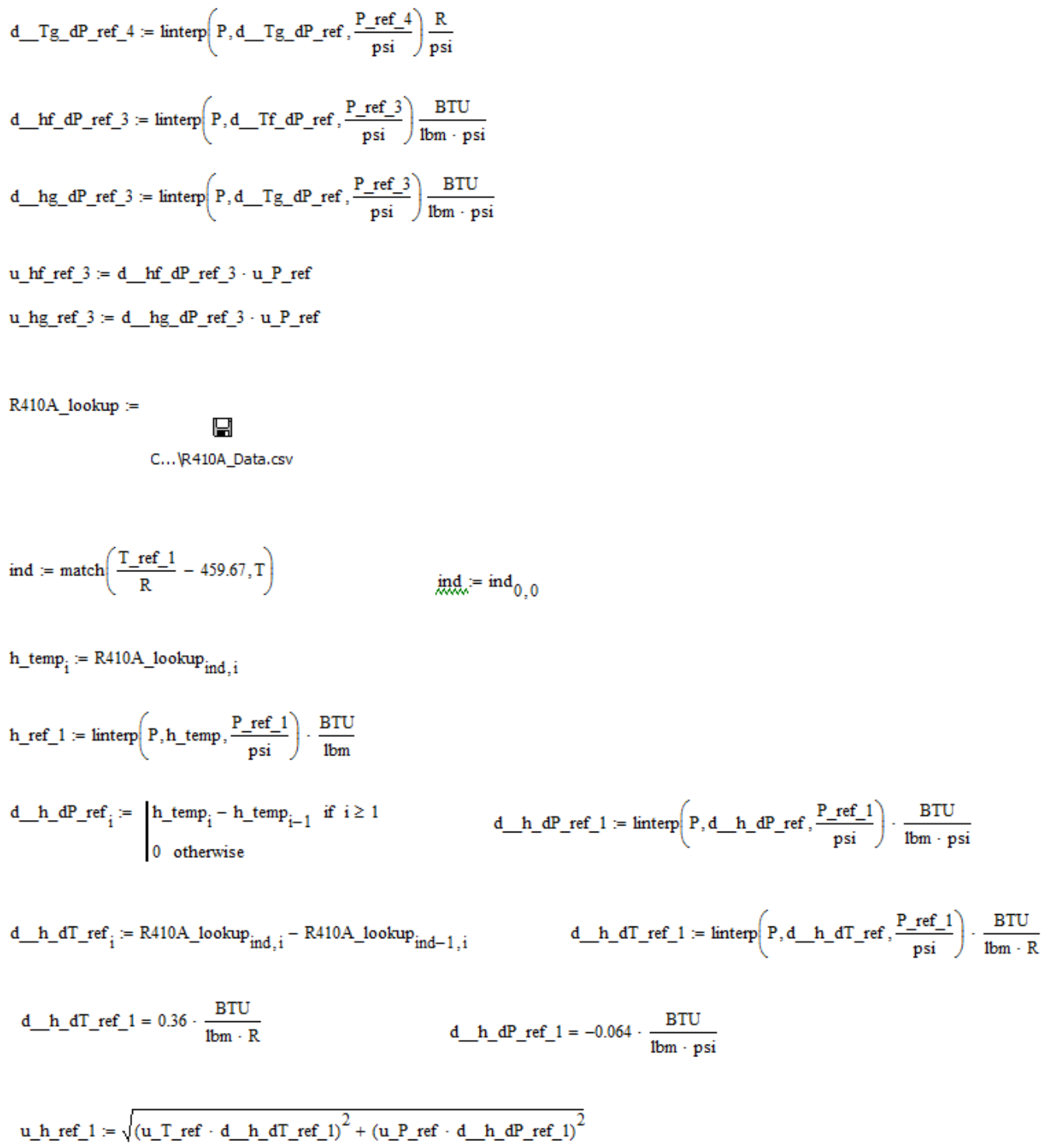




$$
\begin{aligned}
& \text { ind }:=\operatorname{match}\left(\frac{T_{-} \text {ref_2 }}{R}-459.67, \mathrm{~T}\right) \quad \text { ind }:=\text { ind }_{0,0} \\
& h_{-} \text {temp } p_{i}:=\text { R410A_lookup } \text { ind }, i_{i} \\
& \text { h_ref_2 }:=\operatorname{linterp}\left(P, \text { h_temp }_{-} \frac{\text { P_ref_2 }}{\text { psi }}\right) \cdot \frac{\text { BTU }}{1 \mathrm{bm}}
\end{aligned}
$$

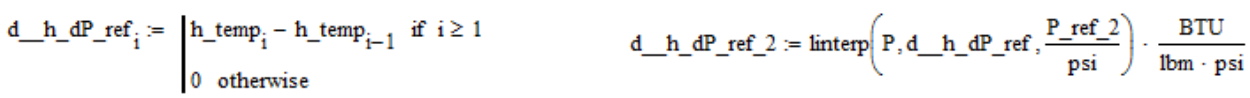

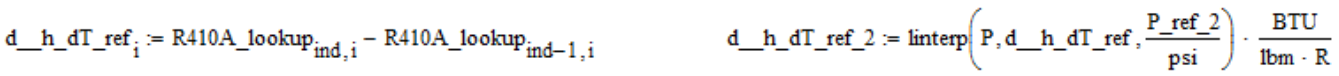

$$
\begin{aligned}
& \text { d__ } \_ \text {_d _ _ref_2 }=0.417 \cdot \frac{\mathrm{BTU}}{\mathrm{lbm} \cdot \mathrm{R}} \quad \text { d__h_dP_ref_2 }=-2 \times 10^{-3} \cdot \frac{\mathrm{BTU}}{\mathrm{lbm} \cdot \mathrm{psi}}
\end{aligned}
$$

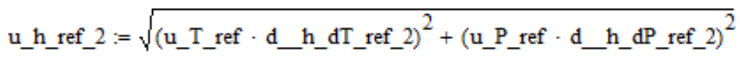

$$
\begin{aligned}
& \text { ind }:=\operatorname{match}\left(\frac{T_{-} \text {ref_4 }}{\mathrm{R}}-459.67, \mathrm{~T}\right) \quad \text { ind }:=\text { ind }_{0,0} \\
& h_{-} \text {temp } p_{i}:=R 410 \text { A_lookup } \text { ind }_{,} \mathrm{i} \\
& \text { h_ref_4 }:=\operatorname{linterp}\left(P, \text { h_temp }_{-} \frac{\text { P_ref_4 }}{\text { psi }}\right) \cdot \frac{\text { BTU }}{1 b m}
\end{aligned}
$$

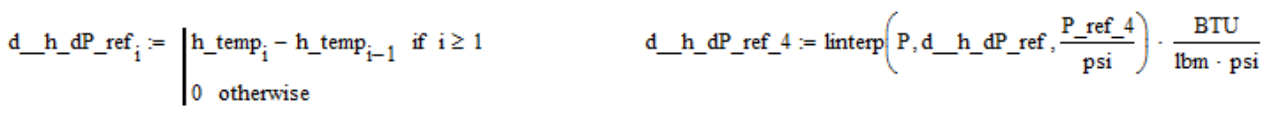

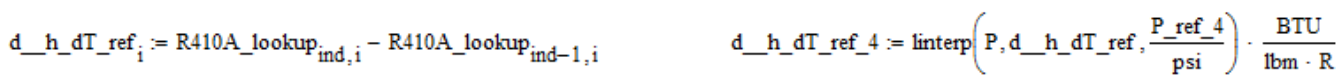

$$
\begin{aligned}
& \text { d__h_dT_ref_4 }=0.274 \cdot \frac{\mathrm{BTU}}{\mathrm{lbm} \cdot \mathrm{R}} \quad \text { d__h_dP_ref_4 }=-0.078 \cdot \frac{\mathrm{BTU}}{\mathrm{lbm} \cdot \mathrm{psi}}
\end{aligned}
$$




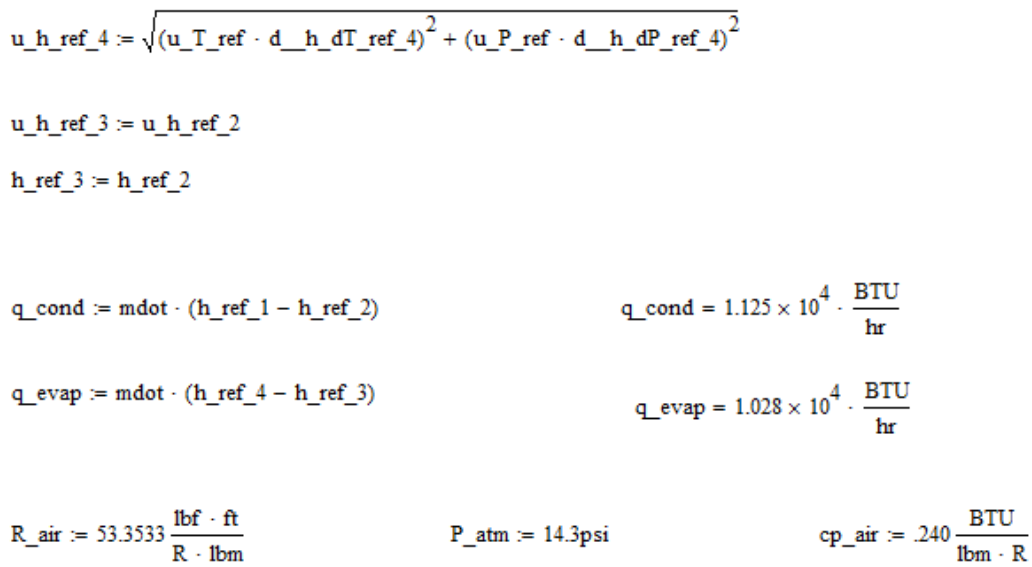

Water_Sat_lookup :=

$$
\text { C...IWater_Sat_Data.csv }
$$

Water Sat 100 kup $:=$ Water_Sat_lookup ${ }^{\mathrm{T}}$

$$
\mathrm{T}:=0
$$

$i:=0,1 .$. rows(Water_Sat_lookup) -1

$\mathrm{T}_{\mathrm{Mi}}:=32+\mathrm{i}$

$\mathrm{dP}_{-} \mathrm{dT}_{\mathrm{i}}:=\mid \begin{aligned} & \text { Water_Sat_lookup } \\ & \mathrm{i}, 2 \\ & 0 \begin{array}{l}\text { otherwise }\end{array}\end{aligned}$

dhg_dT $_{\mathrm{i}}:=\mid \begin{aligned} & \text { Water_Sat_lookup } \\ & \mathrm{i}, 1 \\ & 0 \text { otherwise }\end{aligned}$

$\mathrm{dhf}_{-} \mathrm{dT} \mathrm{T}_{\mathrm{i}}:=\mid \begin{aligned} & \text { Water_Sat_lookup } \\ & 0 \text { otherwise }\end{aligned}$

Psat_WV_1 $:=\operatorname{linterp}\left(T\right.$, Water_Sat_lookup $\left.\langle 2\rangle, \frac{T \text { _air_1 }}{R}-459.67\right) \mathrm{psi}$ 
hg_WV_1 $:=\operatorname{linterp}\left(T\right.$, Water_Sat_lookup $\left.\langle 1\rangle, \frac{T_{-} \text {air_1 }}{R}-459.67\right) \frac{\text { BTU }}{\mathrm{lbm}}$
hf_WV_1 $=$ linterp $\left(T\right.$, Water_Sat_lookup $\left.\langle 0\rangle \frac{T_{-} \text {air_1 }}{\mathrm{R}}-459.67\right) \frac{\text { BTU }}{\mathrm{lbm}}$

d_P_dT_WV_1 $=\operatorname{linterp}\left(T, \mathrm{dP}_{-} \mathrm{dT}, \frac{\mathrm{T}_{-} \mathrm{air} \_1}{\mathrm{R}}-459.67\right) \frac{\mathrm{psi}}{\mathrm{R}}$

d_hg_dT_WV_1 $:=\operatorname{linterp}\left(\mathrm{T}, \mathrm{dhg}\right.$ _dT,$\left.\frac{\mathrm{T}_{-} \text {air_1 }}{\mathrm{R}}-459.67\right) \frac{\mathrm{BTU}}{\mathrm{lbm} \cdot \mathrm{R}}$

d_hf_dT_WV_1 $=\operatorname{linterp}\left(T\right.$, dhf_dT, $\left.\frac{\text { T_air_1 }}{\text { R }}-459.67\right) \frac{\text { BTU }}{\mathrm{lbm} \cdot \mathrm{R}}$

$\omega 1:=\frac{.622 \cdot \text { RH1 } \cdot .01 \cdot \text { Psat_WV_1 }}{\text { P_atm }- \text { RH1 } \cdot .01 \cdot \text { Psat_WV_1 }}$

$\omega 1=0.015$

u_hf_WV_1 := d_hf_dT_WV_1 u_T_air $_{-}$

u_hg_WV_1 $:=$ d_hg_dT_WV_1 - u_T_air

u_Psat_WV_1 $:=$ d_P_dT_WV_1 - u_T_air

Psat_WV_2 $:=\operatorname{linterp}\left(\mathrm{T}\right.$, Water_Sat_lookup $\left\langle\frac{\mathrm{T}_{-} \text {air_2 }}{\mathrm{R}}-459.67\right) \mathrm{psi}$

hg_WV_2 $:=\operatorname{linterp}\left(T\right.$, Water_Sat_lookup $\left\langle\frac{T_{-} \text {air_2 }}{\mathrm{R}}-459.67\right) \frac{\text { BTU }}{\mathrm{lbm}}$

hf_WV_2 $:=\operatorname{linterp}\left(T\right.$, Water_Sat_lookup $\left.\langle 0\rangle, \frac{T_{-} \text {air_2 }}{R}-459.67\right) \frac{\text { BTU }}{\mathrm{lbm}}$

d_P_dT_WV_2 $:=\operatorname{linterp}\left(T, \mathrm{dP}_{-} \mathrm{dT}, \frac{\mathrm{T}_{-} \mathrm{air} \_2}{\mathrm{R}}-459.67\right) \frac{\mathrm{psi}}{\mathrm{R}}$

d_hg_dT_WV_2 $:=\operatorname{linterp}\left(T\right.$, dhg_dT, $\left.\frac{T_{-} \text {air_2 }}{\mathrm{R}}-459.67\right) \frac{\mathrm{BTU}}{\mathrm{lbm} \cdot \mathrm{R}}$

d_hf_dT_WV_2 $:=\operatorname{linterp}\left(T\right.$, dhf_dT, $\left.\frac{T_{-} \text {air_2 }}{\mathrm{R}}-459.67\right) \frac{\text { BTU }}{\mathrm{lbm} \cdot \mathrm{R}}$ 


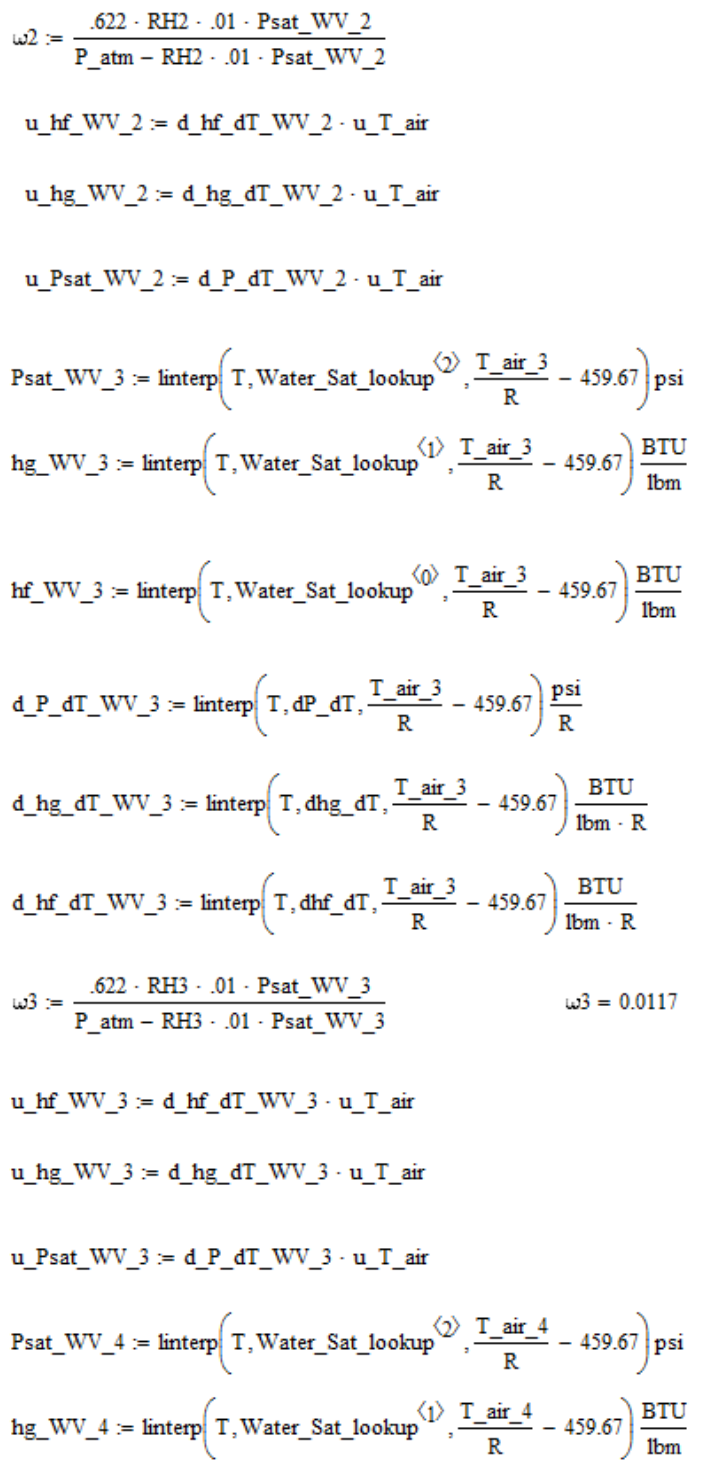


hf_WV_4 $:=\operatorname{linterp}\left(\mathrm{T}\right.$, Water_Sat_lookup $\left.\langle 0\rangle \frac{\mathrm{T}_{-} \mathrm{air} \_4}{\mathrm{R}}-459.67\right) \frac{\mathrm{BTU}}{\mathrm{lbm}}$

d_P_dT_WV_4 $:=\operatorname{linterp}\left(T, \mathrm{dP}_{-} \mathrm{dT}, \frac{\mathrm{T}_{-} \mathrm{air} \_4}{\mathrm{R}}-459.67\right) \frac{\mathrm{psi}}{\mathrm{R}}$

d_hg_dT_WV_4 $:=\operatorname{linterp}\left(\mathrm{T}, \mathrm{dhg} \_\mathrm{dT}, \frac{\mathrm{T} \_\mathrm{air} \_4}{\mathrm{R}}-459.67\right) \frac{\mathrm{BTU}}{\mathrm{lbm} \cdot \mathrm{R}}$

d_hf_dT_WV_4 $:=\operatorname{linterp}\left(T\right.$, dhf_dT, $\left.\frac{T_{-} \text {air_4 }}{\text { R }}-459.67\right) \frac{\text { BTU }}{\mathrm{lbm} \cdot \mathrm{R}}$

$\omega 4:=\frac{.622 \cdot \mathrm{RH} 4 \cdot .01 \cdot \text { Psat_WV_4 }}{\text { P_atm }- \text { RH4 } 4.01 \cdot \text { Psat_WV } 4}$

$\omega 4=9.4793 \times 10^{-3}$

u_hf_WV_4 $:=$ d_hf_dT_WV_4 $\cdot u_{-}$I_air $_{-}$

u_hg_Wv_4 := d_hg_dT_Wv_4 $\cdot$ u_T_air

u_Psat_WV_4 $:=$ d_P_AT_WV_$_{-} \cdot \mathrm{u}_{-} \mathrm{T}_{-}$air

Uncertainty of state 3 quality calculation

X3 $:=\frac{\text { h_ref_2 }- \text { hf_ref_3 }}{\text { hg_ref_3 } 3-\text { hf_ref_3 }^{-3}}$

From the assumed nominal Temps and pressures for states 2 and 3

dX3_dh2 $:=\frac{\text { d }}{\text { dh_ref_2 }} \frac{\text { h_ref_2 }- \text { hf_ref_3 } 3}{\text { hg_ref_3 }- \text { hf_ref_3 }}$

$\mathrm{dX} 3$ _dh $3 \mathrm{~g}:=\frac{\mathrm{d}}{\mathrm{dhg} \text { ref_3 }} \frac{\mathrm{h} \text {-ref_2 }-\mathrm{hf} \text { href_3 } 3}{\mathrm{hgef} 3-\mathrm{hf} \text { _ref_3 }}$

dX3_dh $3 f:=\frac{\text { d }}{\text { dhf_ref_3 } 3} \frac{\text { h_ref_2 } 2-\text { hf_ref_3 } 3}{\text { hg_ref_3 }- \text { hf_ref_3 }}$ 
From this, the uncertainty in the state 3 quality calc is given by

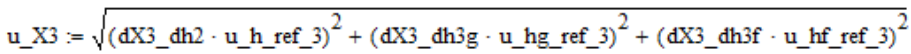

Uncertainty of condenser subcool

Subcool :=(T_cond $-T_{-}$ref_2 $)$

u_sub $:=\sqrt{\left(\text { d_Tf_dP_ref_ } 2 \cdot \text { u_P_ref }^{2}+\text { u_T_ref }^{2}\right.}$

Uncertainty of Evaporator superheat

Superheat := (T_ref_4 $-T_{-}$evap)

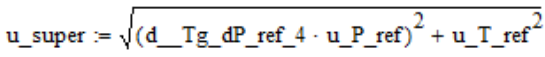

Uncertainty of evaporator heat transfer calculation

q_evap $=$ mdot $\cdot($ h_ref_3 - h_ref_4 $)$

dq_evap_dh3 := mdot

dq_evap_dh $4:=-$ mdot

dq_evap_dmdot $:=($ h_ref_3 - h_ref_4 $)$

u_q_evap $:=\sqrt{\left(\text { dq_evap_dh } 3 \cdot u_{-} \_ \text {ref_3 }\right)^{2}+\left(\text { dq_evap_dh } 4 \cdot u_{-} \text {_ref_4 }\right)^{2}+\left(\text { dq_evap_dmdot } \cdot u_{-} \text {mdot }\right)^{2}}$

u_q_evap $=57.158 \cdot \frac{\mathrm{BTU}}{\mathrm{hr}}$ 
Uncertainty of condenser heat transfer calculation

q_cond $=$ mdot $\cdot$ (h_ref_1 $-\mathrm{h} \_$ref_2)

dq_cond_dh $2:=-$ mdot

dq_cond_dh $1:=$ mdot

dq_cond_dmdot $:=\left(h \_r e f \_1-h \_r e f \_2\right)$

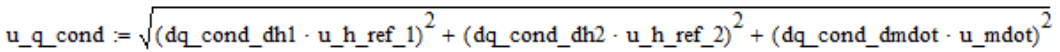

u_q_cond $=62.432 \cdot \frac{\mathrm{BTU}}{\mathrm{hr}}$

COP $:=\frac{\text { q_evap }}{\text { P_fan }_{-} \text {P_comp }_{-}} \quad$ EER $:=3.412 \cdot$ COP

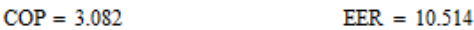

dCOP_dq_evap $:=\frac{d}{d q \_ \text {evap }} \frac{\text { q_evap }}{P_{-} \text {fan }+P_{-} \text {comp }}$

dCOP_dP_fan $_{=}=\frac{\mathrm{d}}{\mathrm{dP}_{-} \text {fan }} \frac{\text { q_evap }}{\mathrm{P}_{-} \text {fan }+\mathrm{P}_{-} \text {comp }}$

$\mathrm{dCOP} \_\mathrm{dP} \_$comp $:=\frac{\mathrm{d}}{\mathrm{dP} \_ \text {comp }} \frac{\text { q_evap }}{\mathrm{P}_{-} \text {fan }+\mathrm{P}_{-} \text {comp }}$

$u_{-} C O P:=\sqrt{\left(d C O P \_d q \_e v a p \cdot u_{-} q_{e} e v a p\right)^{2}+\left(d_{C O P} d P_{-} f a n \cdot u_{-} f a n\right)^{2}+\left(d C O P \_d P \_c o m p \cdot u_{-} \text {comp }\right)^{2}}$

u_EER $:=3.412 \cdot u_{-}$COP 
Uncertainty in condenser humidity ratios

$$
\omega 1=\frac{.622 \cdot .01 \cdot \text { RH1 } \cdot \text { Psat_WV_1 }}{\text { P_atm }-.01 \cdot \text { RH1 } \cdot \text { Psat_WV_1 }}
$$

The derivatives are

$\mathrm{d} \omega 1 \_\mathrm{dRH}:=\frac{\mathrm{d}}{\mathrm{dRH} 1} \frac{.622 \cdot .01 \cdot \mathrm{RH} 1 \cdot \text { Psat_WV_1 }}{\text { P_atm }-.01 \cdot \mathrm{RH1} \cdot \text { Psat_WV_1 }}$

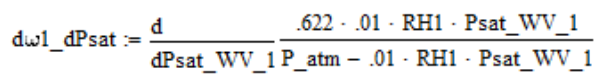

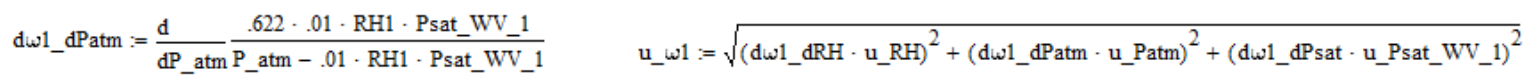

Again for air state 2

$\mathrm{d} \omega 2 \_\mathrm{dRH}:=\frac{\mathrm{d}}{\mathrm{dRH} 2} \frac{.622 \cdot .01 \cdot \mathrm{RH} 2 \cdot \mathrm{P}_{-} \text {atm }-.01 \cdot \mathrm{RH} 2 \cdot \mathrm{Ps}_{-} \mathrm{Wt}_{-} \mathrm{WV}_{-} 2}{}$

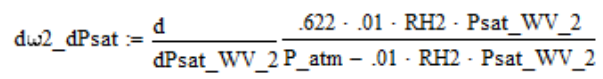

$\mathrm{d} \omega 2 \_\mathrm{dPatm}:=\frac{\mathrm{d}}{\mathrm{dP} \text { atm }} \frac{.622 \cdot .01 \cdot \mathrm{RH} 2 \cdot \text { Psat_WV_2 }}{\text { P_atm }-.01 \cdot \mathrm{RH} 2 \cdot \text { Psat_WV_2 }}$

$u_{-} \omega 2:=\sqrt{\left(\mathrm{d} \omega 2 \_\mathrm{dRH} \cdot \mathrm{u}_{-} \mathrm{RH}\right)^{2}+\left(\mathrm{d} \omega 2 \_\mathrm{dPatm} \cdot \mathrm{u}_{-} \mathrm{Patm}\right)^{2}+\left(\mathrm{d} \omega 2 \_\mathrm{dPsat} \cdot \mathrm{u}_{-} \text {Psat_WV_2 }\right)^{2}}$

67 
Uncertainty in evaporator humidity ratios

The derivatives are

$\mathrm{d} \omega 3 \_\mathrm{dRH}:=\frac{\mathrm{d}}{\mathrm{dRH} 3} \frac{.622 \cdot .01 \cdot \mathrm{RH} 3 \cdot \text { Psat_WV_3 }}{\text { P_atm }-.01 \cdot \mathrm{RH} 3 \cdot \text { Psat_WV_3 }}$

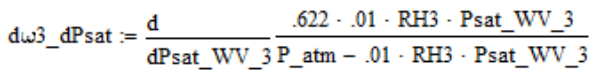

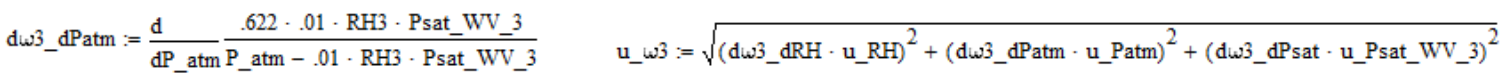

Again for air state 4

$\mathrm{d} \omega 4$ _dRH $:=\frac{\mathrm{d}}{\mathrm{dRH} 4} \frac{.622 \cdot .01 \cdot \mathrm{RH} 4 \cdot \text { Psat_WV_4 }}{\text { P_tm }-.01 \cdot \mathrm{RH} 4 \cdot \text { Psat_WV_4 }}$

$\mathrm{d} \omega 4$ dPsat $:=\frac{\mathrm{d}}{\mathrm{dPsat}+W V \_4} \frac{.622 \cdot .01 \cdot \mathrm{RH} 4 \cdot \text { Psat_WV_4 }}{\text { Patm }-.01 \cdot \mathrm{RH} 4 \cdot \text { Psat_WV_4 }}$

d $\omega 4$ dPatm $:=\frac{\mathrm{d}}{\mathrm{dP} \_ \text {atm }} \frac{.622 \cdot .01 \cdot \mathrm{RH} 4 \cdot \text { Psat_WV_4 }}{\text { Patm }-.01 \cdot \mathrm{RH} 4 \cdot \text { Psat_WV_4 }}$

$u_{-} \omega 4:=\sqrt{\left(\mathrm{d} \omega 4 \text { _dRH } \cdot \mathrm{u}_{-} \mathrm{RH}\right)^{2}+\left(\mathrm{d} \omega 4 \text { _dPatm } \cdot \mathrm{u}_{-} \text {Patm }\right)^{2}+\left(\mathrm{d} \omega 4 \text { _dPsat } \cdot \mathrm{u}_{-} \text {Psat_WV_4 }\right)^{2}}$

68 
Uncertainty in condenser inlet air density

P_air_1 $:=\frac{\text { P_atm }-.01 \cdot R H 1 \cdot \text { Psat_WV_1 }}{\text { R_air } \cdot \text { T_air_1 }}$

The derivatives are

d p1_dPatm $:=\frac{1}{\text { R_air } \cdot \text { T_air_1 }} \quad$ d 1 1_dRH $:=-\frac{0.01 \cdot \text { Psat_WV_1 }}{\text { R_air } \cdot \text { T_air_1 }}$

d $\rho 1 \_d P s a t:=-\frac{0.01 \cdot R H 1}{R_{-} \text {air } \cdot T_{-} \text {air_1 }} \quad d \rho 1 \_d T:=\frac{\text { P_atm }+-0.01 \cdot \text { Psat_WV_1 } \cdot \text { RH1 }}{\text { R_air } \cdot T_{-} \text {air_1 }{ }^{2}}$

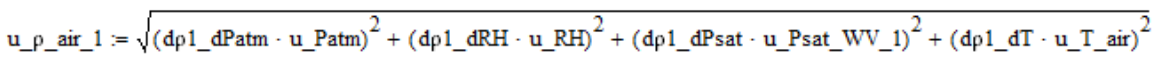

u_P_air_1 $=7.048 \times 10^{-5} \cdot \frac{\mathrm{lbm}}{3} \quad \begin{aligned} & \text { This is in Ibm of dry air per cubic } \\ & \text { foot of mix into the } \mathrm{HX}\end{aligned}$

Likewise at the evaporator inlet

\section{Likewise at the evaporator inlet}

The derivatives are

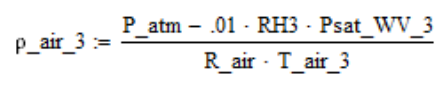

$\mathrm{d} \rho 3$ _dPatm $:=\frac{1}{\text { R_air } \cdot \text { T_air_3 }}$

d $\rho 3$ dRH $:=-\frac{0.01 \cdot \text { Psat_WV_3 }}{\text { R_air } \cdot \text { T_air_3 }}$

d 3 _dPsat $:=-\frac{0.01 \cdot \mathrm{RH} 3}{\text { R_air } \cdot T_{\text {_air_3 }}}$

$\mathrm{d} \rho 3 \_\mathrm{dT}:=-\frac{\text { P_atm }+-0.01 \cdot \mathrm{Psat}_{-} \mathrm{WV}_{-} 3 \cdot \mathrm{RH} 3}{\mathrm{R}_{-} \text {air } \cdot \mathrm{T}_{\text {_air_3 }}{ }^{2}}$

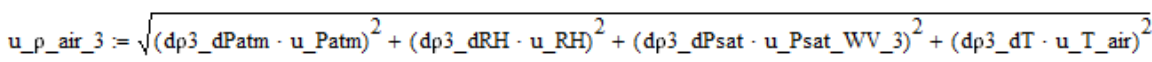




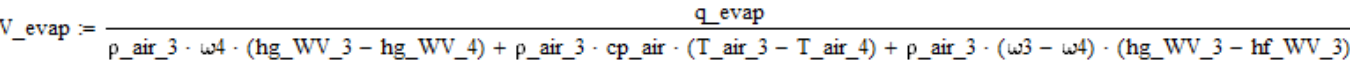

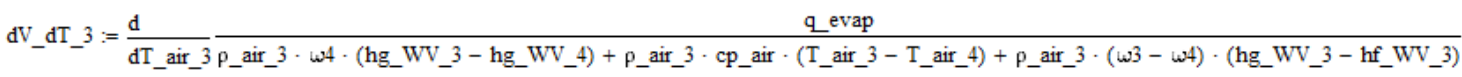

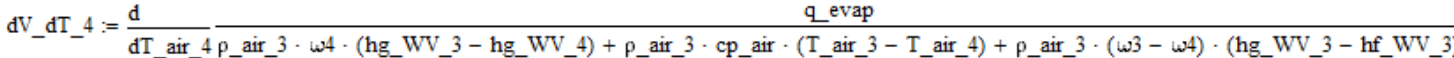

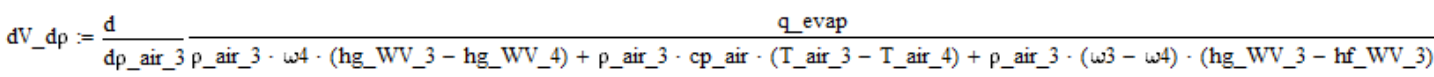

$\mathrm{dV} \mathrm{d} \omega 3:=\frac{\mathrm{d}}{\mathrm{d} \omega} \mathrm{P}$

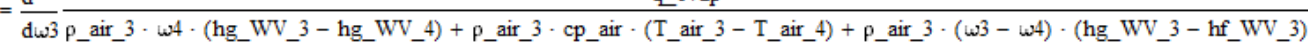

$\mathrm{dV} \_\mathrm{d} \omega 4:=\frac{\mathrm{d}}{\mathrm{d} \omega}$

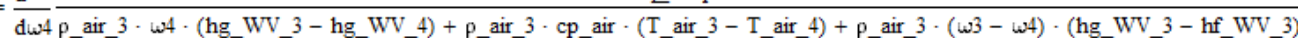

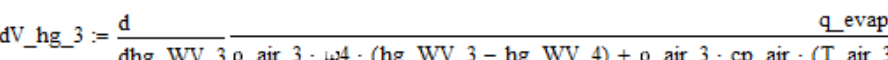

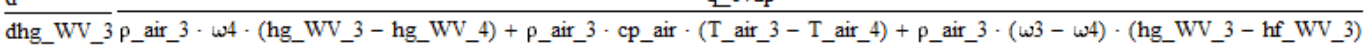

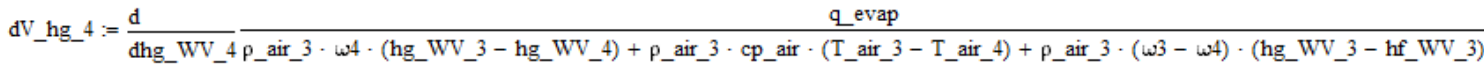

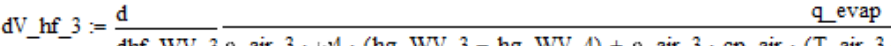

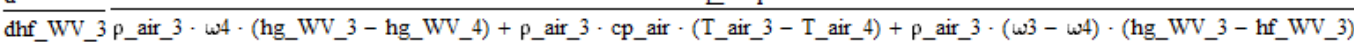

dV dq evap $:=\frac{d}{d}$ q evap

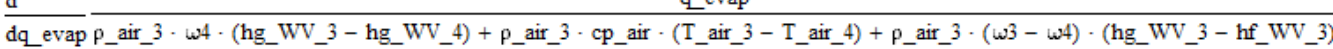

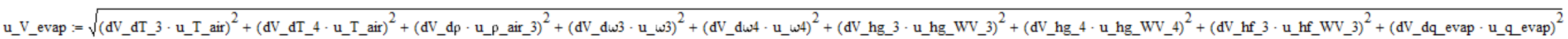




\section{Uncertainty in condenser airflow rate}

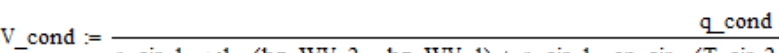

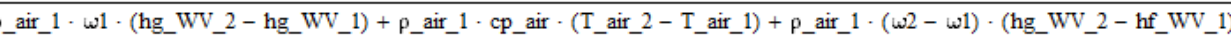

$\mathrm{dV}_{-} \mathrm{dT} \mathrm{T}_{-} 1:=\frac{\mathrm{d}}{\mathrm{d}} \mathrm{q}$ cond

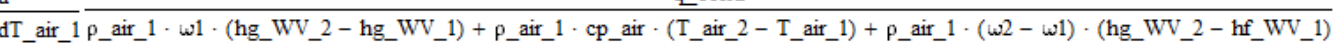

$\mathrm{dV}$ dT $2:=\frac{\mathrm{d}}{\mathrm{d}}$ q cond

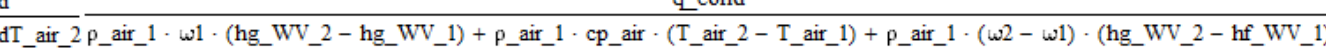

$\mathrm{dV}$ d $\mathrm{p}_{\mathrm{N}}=\frac{\mathrm{d}}{\mathrm{d}} \mathrm{q}$ cond

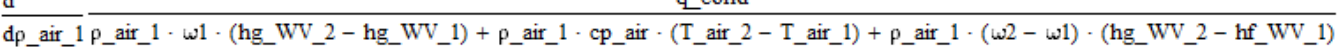

$\mathrm{dV} d \omega 1:=\frac{\mathrm{d}}{\mathrm{d} \omega \text { cond }}$

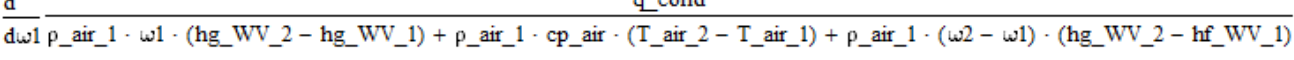

$\mathrm{dV} d \omega 2:=\frac{\mathrm{d}}{\mathrm{d} 2} \mathrm{Q}$ cond

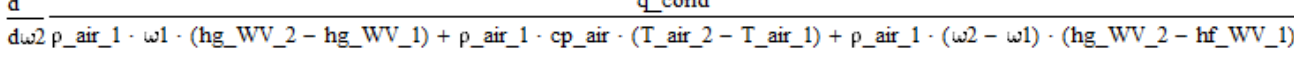

dV_hg_ $1:=\frac{\mathrm{d}}{\mathrm{q}} \mathrm{q}$ cond

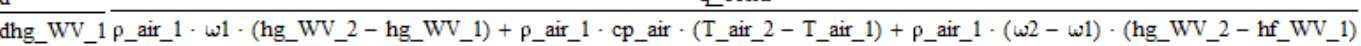

dV_hg_ $2:=\frac{d}{d{ }_{-}}$cond

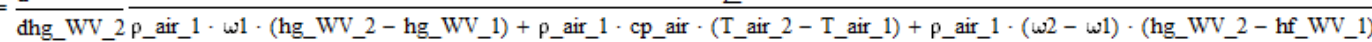

dV_hf_ $1:=\frac{\mathrm{d}}{\mathrm{d}}$ cond

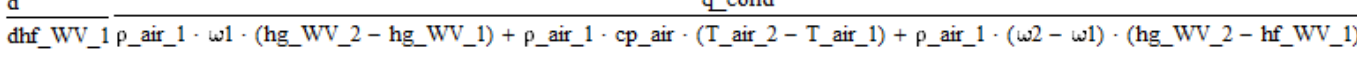

dV_dq cond $:=\frac{\mathrm{d}}{\mathrm{d}} \mathrm{q} \mathrm{q}_{\mathrm{C}}$ cond

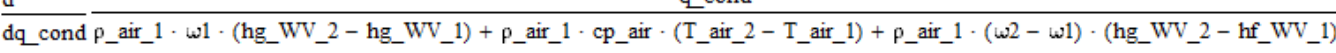

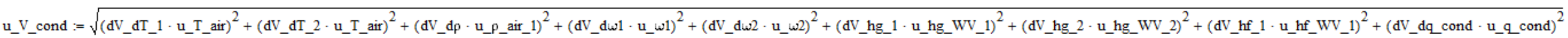


Uncertainty in SHR calculation

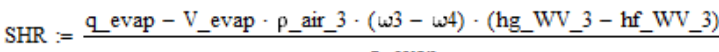

q evap

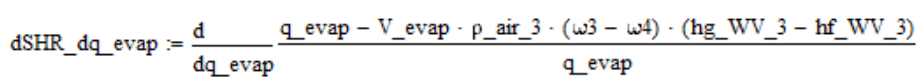

$\mathrm{dSHR} \_\mathrm{d} \omega 3:=\frac{\mathrm{d}}{\mathrm{d} \omega 3} \frac{\mathrm{q} \text { evap }-\mathrm{V}_{-} \text {evap } \cdot p_{-} \mathrm{air} \_3 \cdot(\omega 3-\omega 4) \cdot\left(\mathrm{hg}_{-} \mathrm{WV} \_3-\mathrm{hf} \mathrm{WV}_{-} 3\right)}{\mathrm{q} \text { evap }}$

$\mathrm{dSHR} \_\mathrm{d} \omega 4:=\frac{\mathrm{d}}{\mathrm{d} \omega 4} \frac{\mathrm{q} \text { evap }-V_{-} \text {evap } \cdot p_{-} \mathrm{air} \_3 \cdot(\omega 3-\omega 4) \cdot\left(\mathrm{hg}_{-} \mathrm{WV} \_3-\mathrm{hf} \mathrm{WV}_{-} 3\right)}{\mathrm{q} \text { evap }}$

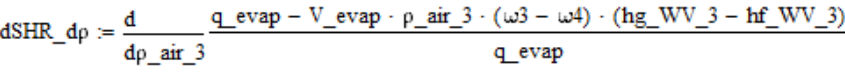

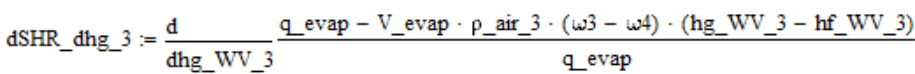

dSHR_dhf_3 $:=\frac{\mathrm{d}}{\mathrm{dhf} \mathrm{WV}_{-} 3} \frac{\text { q_evap }-V_{-} \text {evap } \cdot P_{-} \text {air_3 } 3 \cdot(\omega 3-\omega 4) \cdot\left(\mathrm{hg}_{-} \mathrm{WV} \mathrm{C}_{-} 3-\mathrm{hf} \mathrm{WV}_{-} 3\right)}{\mathrm{q} \text { evap }}$

$\mathrm{dSHR}_{-} \mathrm{dV} \_$evap $:=\frac{\mathrm{d}}{\mathrm{dV} \_ \text {evap }} \frac{\text { qevap }-V_{-} \text {evap } \cdot p_{-} \text {air_3 } \cdot(\omega 3-\omega 4) \cdot\left(\mathrm{hg}_{-} \mathrm{WV} \_3-\mathrm{hf} \_\mathrm{WV} \_3\right)}{\text { q evap }}$

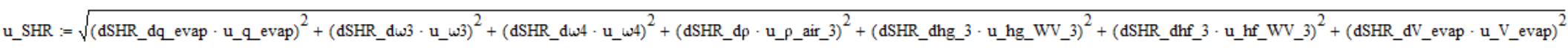




$$
\text { pint }:=\frac{1}{8} \text { gal }
$$

$\mathrm{DH}_{-}$rate $:=\frac{(\omega 3-\omega 4) \cdot \text { V_evap }_{0} \text { P_air_3 }}{\left(\frac{1000 \mathrm{~kg}}{3}\right)}$

$\mathrm{dDh} \_\mathrm{D} \omega 3:=\frac{\mathrm{d}}{\mathrm{d} \omega 3} \frac{(\omega 3-\omega 4) \cdot \mathrm{V} \_ \text {evap } \cdot \text { __air_3 }}{\left(\frac{1000 \mathrm{~kg}}{\mathrm{~m}^{3}}\right)}$

$\mathrm{dDh} \_\mathrm{D} \omega 4:=\frac{\mathrm{d}}{\mathrm{d} \omega 4} \frac{(\omega 3-\omega 4) \cdot V_{-} \text {evap } \cdot \text { P_air_3 } 3}{\left(\frac{1000 \mathrm{~kg}}{\mathrm{~m}^{3}}\right)}$

dDh_DV_evap $:=\frac{d}{d V \_ \text {evap }} \frac{(\omega 3-\omega 4) \cdot V_{-} \text {evap } \cdot \text { p_air_3 }}{\left(\frac{1000 \mathrm{~kg}}{\mathrm{~m}^{3}}\right)}$

$\mathrm{dDh} \mathrm{D}_{\rho}:=\frac{\mathrm{d}}{\mathrm{d} \rho_{-} \text {air___ }} \frac{(\omega 3-\omega 4) \cdot \mathrm{V}_{-} \text {evap } \cdot \rho_{-} \text {air_3 } 3}{\left(\frac{100 \mathrm{~kg}}{\mathrm{~m}^{3}}\right)}$

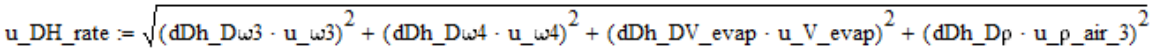

Sling_rate $:=\frac{(\omega 2-\omega 1) \cdot V_{-} \text {cond } \cdot P_{-} \text {air_ } 1}{(\text { _o }}$

$$
\left(\frac{1000 \mathrm{~kg}}{\mathrm{~m}^{3}}\right)
$$


Calculated Refrigerant Pressures

P_ref_1 $=427.464 \cdot \mathrm{psi}$

P_ref_2 $=427.464 \cdot \mathrm{psi}$

P_ref_3 $=159.16 \cdot \mathrm{psi}$

P_ref_4 $=159.16 \cdot \mathrm{psi}$

Calculated Airflow rates

$$
\begin{array}{ccc}
\text { V_cond }=479.209 \cdot \frac{\mathrm{ft}^{3}}{\min } \quad \text { u_V_cond }_{-}=98.104 \cdot \frac{\mathrm{ft}^{3}}{\min } \quad \frac{\text { u_V}_{-} \text {cond }}{\text { V_cond }}=0.205 \\
\text { V_evap }=313.196 \cdot \frac{\mathrm{ft}^{3}}{\min } \quad \text { u_V_evap }^{3}=15.209 \cdot \frac{\mathrm{ft}^{3}}{\min } \quad \frac{\text { u_V_evap }}{\text { V_evap }}=0.049
\end{array}
$$

Calculated quality, superheat and sub cool

$\begin{array}{ll}\text { Subcool }=28.8 \cdot R & \text { u_sub }_{-}=0.273 \cdot R \\ \text { Superheat }=12.3 \cdot R & \text { u_super }_{-}=0.34 \cdot R \\ \mathrm{X} 3=0.171 & \text { u_X3 }_{-}=2.472 \times 10^{-3}\end{array}$

Calculated dehumidification and sling rates

DH_rate $=2.8301581 \cdot \frac{\text { pint }}{\text { hr }}$

u_DH_rate $=0.472 \cdot \frac{\text { pint }}{\mathrm{hr}}$

$\begin{array}{ll}\text { Calculated humidity ratios } \\ \omega 1=0.01509 & \text { u } \omega 1=5.066 \times 10^{-4} \\ \omega 2=0.01511 & u_{-} \omega 2=9.997 \times 10^{-4} \\ \omega 3=0.01172 & u_{-} \omega 3=3.233 \times 10^{-4} \\ \omega 4=9.47927 \times 10^{-3} & u_{-} \omega 4=1.524 \times 10^{-4}\end{array}$

Calculated COP, EER and SHR

$$
\begin{aligned}
& \mathrm{COP}=3.082 \quad \mathrm{u}_{-} \mathrm{COP}=0.036 \\
& \text { EER }=10.514 \quad u_{-} \text {EER }=0.124 \\
& \text { SHR }=0.6987 \text { u_SHR }=0.0503
\end{aligned}
$$




\section{APPENDIX B}

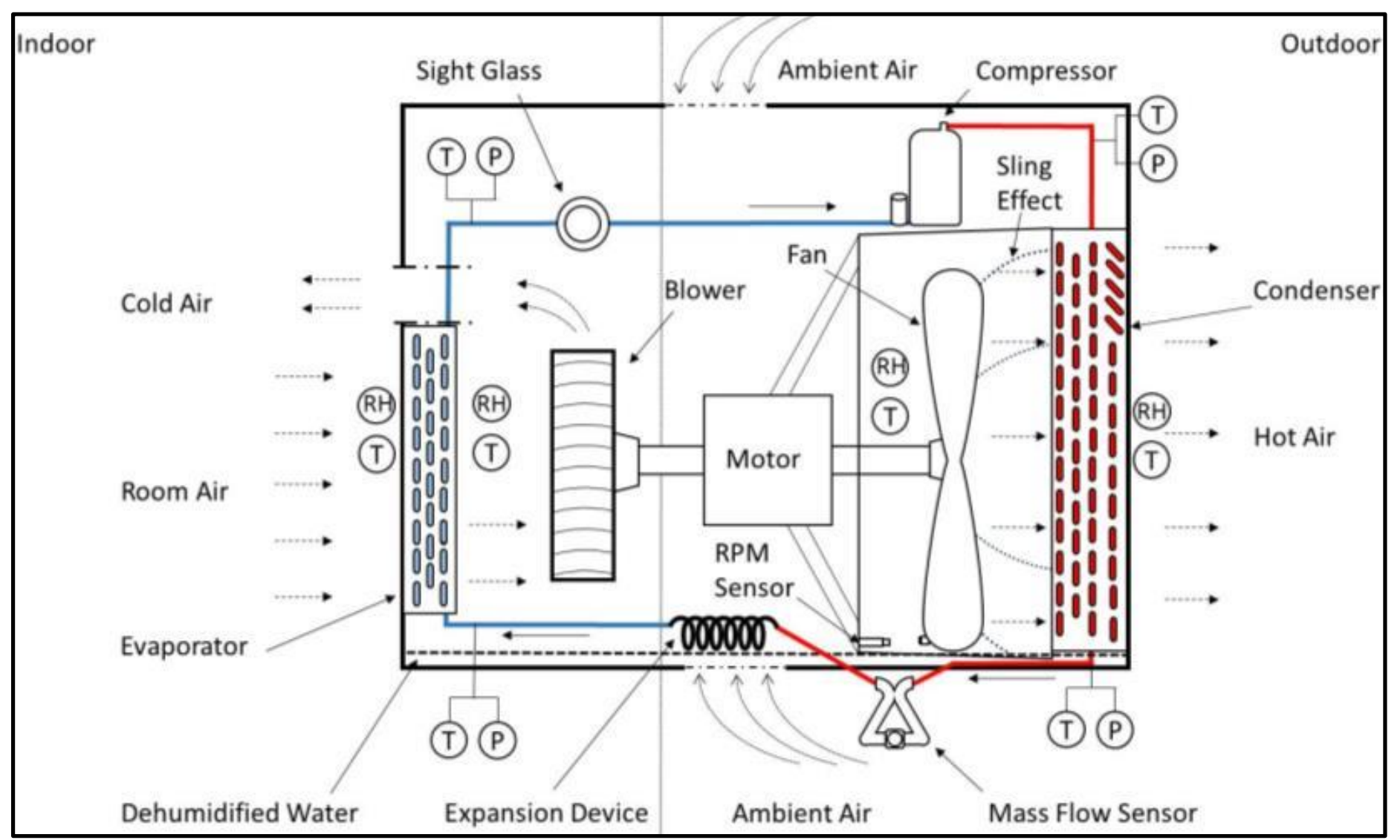

Figure B1: Schematic diagram of the instrumented window air conditioning unit. 
Table B1: Details of Design Production Ready Window Air-Conditioner Prototype

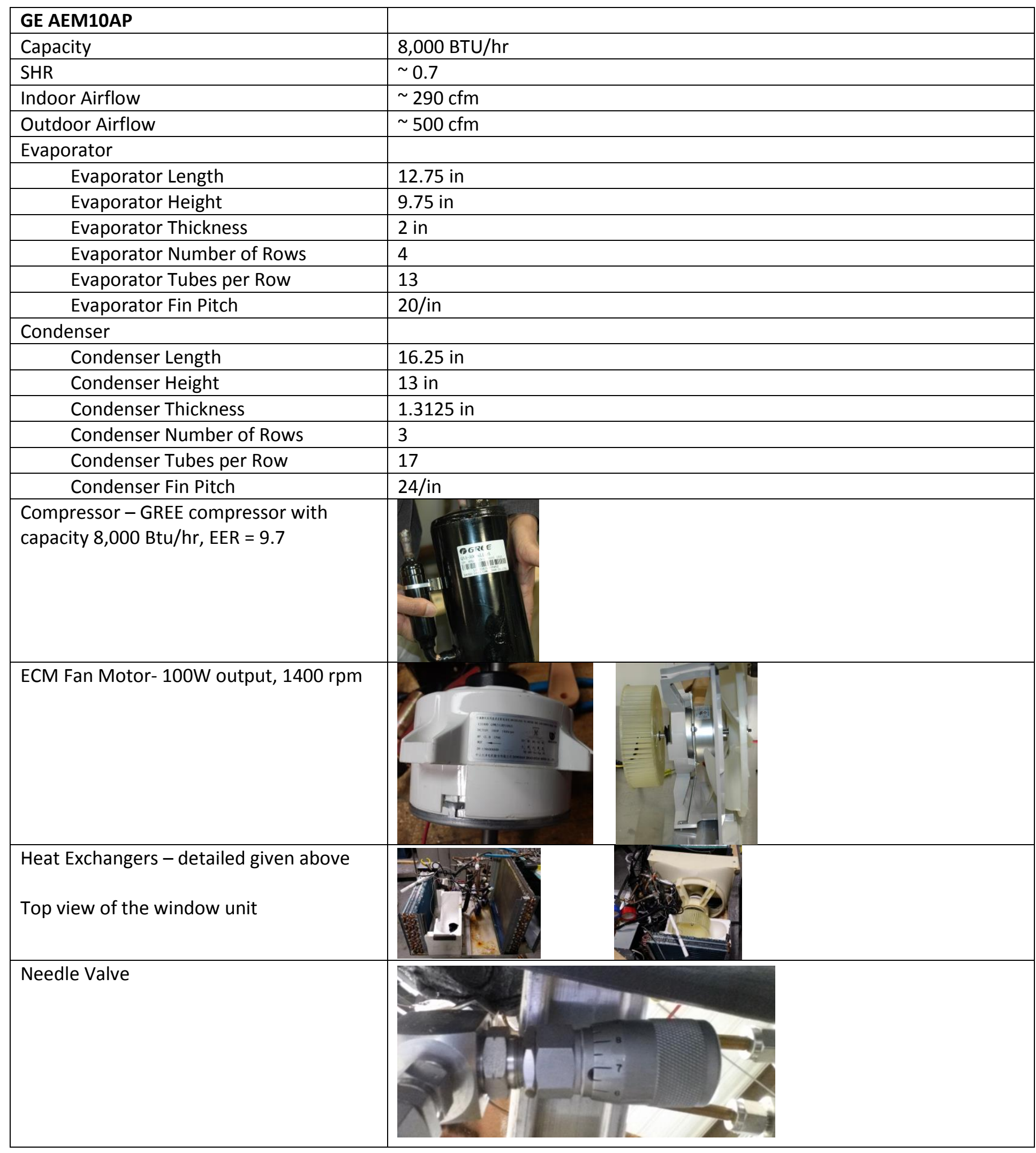

